Florida International University

FIU Digital Commons

FIU Electronic Theses and Dissertations

University Graduate School

6-22-2018

\title{
The Effect of Microbial Growth on the Spectral Induced Polarization Response in Hanford Vadose Zone Sediment in the Presence of Autunite
}

Alejandro Garcia

Florida International University, agarc277@fiu.edu

DOI: $10.25148 /$ etd.FIDC006908

Follow this and additional works at: https:// digitalcommons.fiu.edu/etd

Part of the Environmental Health and Protection Commons, Geophysics and Seismology

Commons, and the Microbiology Commons

\section{Recommended Citation}

Garcia, Alejandro, "The Effect of Microbial Growth on the Spectral Induced Polarization Response in Hanford Vadose Zone Sediment in the Presence of Autunite" (2018). FIU Electronic Theses and Dissertations. 3728.

https://digitalcommons.fiu.edu/etd/3728

This work is brought to you for free and open access by the University Graduate School at FIU Digital Commons. It has been accepted for inclusion in FIU Electronic Theses and Dissertations by an authorized administrator of FIU Digital Commons. For more information, please contact dcc@fiu.edu. 


\section{FLORIDA INTERNATIONAL UNIVERSITY}

Miami, Florida

THE EFFECT OF MICROBIAL GROWTH ON THE SPECTRAL INDUCED

POLARIZATION RESPONSE IN HANFORD VADOSE ZONE SEDIMENT IN THE

PRESENCE OF AUTUNITE MINERAL

A thesis submitted in partial fulfillment of the

Requirements for the degree of

MASTERS OF SCIENCE

in

GEOSCIENCE

by

Alejandro Garcia

2018 
To: Dean Michael R. Heithaus

College of Arts, Sciences and Education

This thesis, written by Alejandro Garcia, and entitled The Effect of Microbial Growth on the Spectral Induced Polarization Response in Hanford Vadose Zone Sediment in the presence of Autunite Mineral, having been approved in respect to style and intellectual content, is referred to you for judgment.

We have read this thesis and recommend that it be approved.

Michael Sukop

Yelena Katsenovich

Dean Whitman, Major Professor

Date of Defense: June 22, 2018

The thesis of Alejandro Garcia is approved.

Dean Michael R. Heithaus

College of Arts, Sciences and Education

Andrés G. Gil

Vice President for Research and Economic Development and Dean of the University Graduate School

Florida International University, 2018 


\section{ACKNOWLEDGMENTS}

Funding for this research was provided by the U.S. Department of Energy, Office of Environmental Management, under Cooperative Agreement DE-EM0000598. I would like to thank the members of my committee, Dr. Dean Whitman, Dr. Yelena Katsenovich, and Dr. Mike Sukop for their support in writing this thesis. I would also like to thank Dr. Brady Lee for directly contributing to the project as well as Jon Thomle. I would also like to acknowledge DOE Fellows program and PI Dr. L. Lagos and colleagues from PNNL- Dr. Tim Johnson, Dr. Vicky Freedman, and Dr. Edmundo Placencia Gomez for their support of this project. I would like to thank Sarah Solomon for providing assistance in conducting the experiments presented in this thesis. 


\section{ABSTRACT OF THE THESIS \\ THE EFFECT OF MICROBIAL GROWTH ON THE SPECTRAL INDUCED \\ POLARIZATION RESPONSE IN HANFORD VADOSE ZONE SEDIMENT IN THE \\ PRESENCE OF AUTUNITE MINERAL}

by

Alejandro Garcia

Florida International University, 2018

Miami, Florida

Professor Dean Whitman, Major Professor

Uranium contamination of the subsurface remains a significant problem at the Department of Energy Hanford site. A series of column experiments were conducted on Hanford sediment saturated with simulated groundwater to study the effects of aqueous bicarbonate and microbial growth on the mobility of Uranium. Spectral induced polarization (SIP) measurements in the columns were conducted concurrently with pore water sampling in order to monitor changes occurring inside the sediment after the initiation of microbial growth induced by glucose injection. The microbial growth caused significant increases in the real component of the complex conductivity and is the result of ion release into the pore fluid. In addition, an increase in the imaginary conductivity was observed at low frequencies $(<10 \mathrm{~Hz})$, which may be due to biotic processes. Due to the use of natural sediment, the SIP response is complex and difficult to understand. However, results across all columns with microbial growth are consistent. Pore water testing showed that microbial growth leads to sudden increases in uranium 
concentrations; however, microbes also eventually create reducing conditions in the sediment which transforms soluble $\mathrm{U}^{6+}$ to insoluble $\mathrm{U}^{4+}$. Bicarbonate leads to significant increases in uranium concentrations likely due to the formation of mobile uranyl carbonate complexes. For the purposes of field scale remediation, microbial growth in an oxic environment should be avoided. However, within reducing conditions present in the deep vadose zone and phreatic zone, microbial growth seems unlikely to significantly increase uranium mobility. 


\section{TABLE OF CONTENTS}

CHAPTER

PAGE

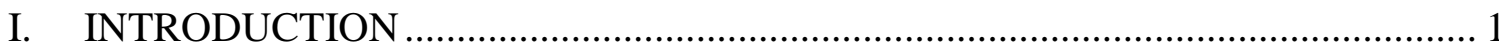

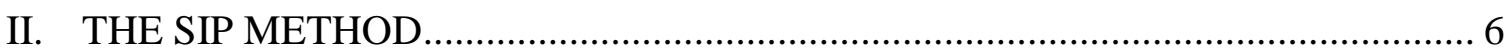

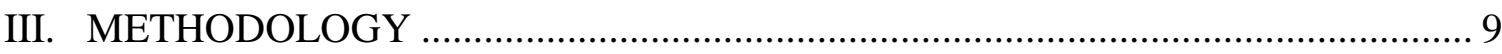

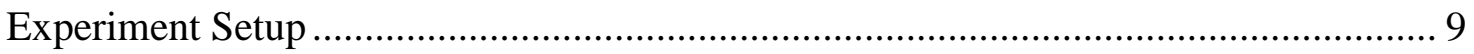

Spectral Induced Polarization and Data Analysis .................................................. 16

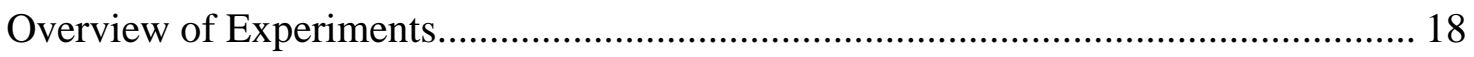

Techniques for Analysis of Porewater ................................................................. 22

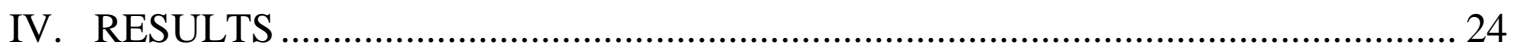

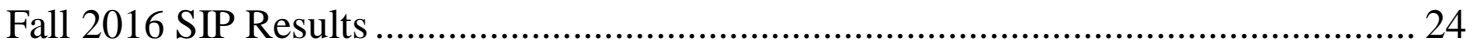

Fall 2016 Porewater Composition Results ......................................................... 43

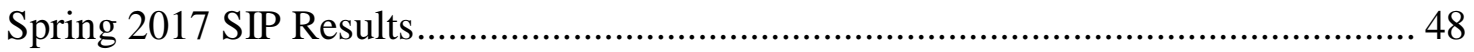

Spring 2017 Porewater Composition Results ........................................................... 54

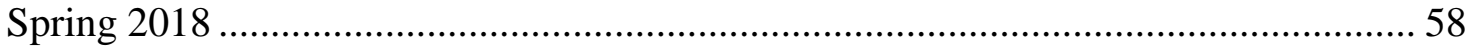

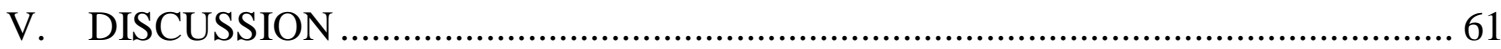

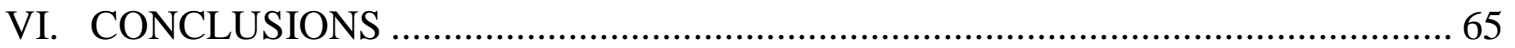

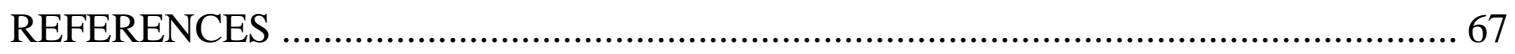

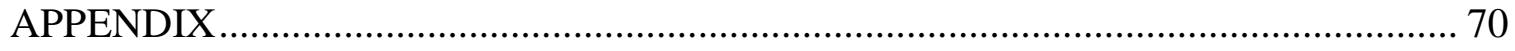




\section{LIST OF TABLES}

TABLE

PAGE

Table 1 Amount of sediment in each column as well as quantity of autunite. ................ 14

Table 2 Simulated Groundwater stock solutions. .......................................................... 14

Table 3 Compound concentrations in final SGW solution......................................... 14

Table 4 Differentiation between columns for Fall 2016 experiment............................. 20

Table 5 Differentiation between columns for Spring 2017 experiment. ........................ 21

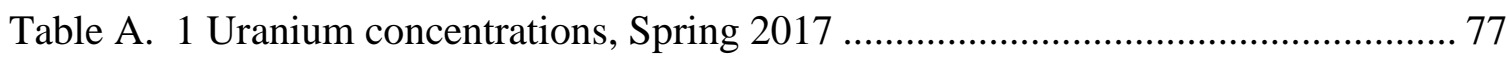

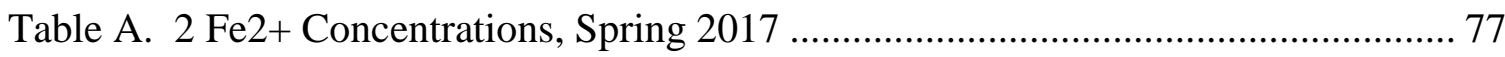

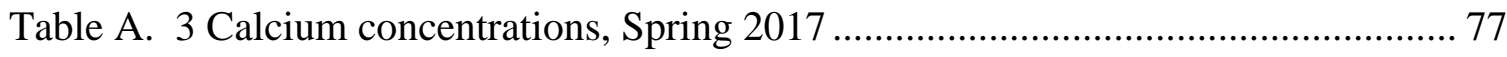

Table A. 4 Magnesium concentrations, Spring 2017 ............................................. 78

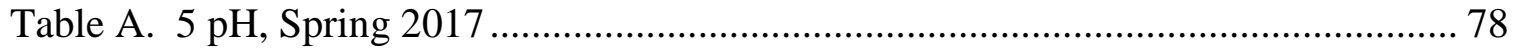

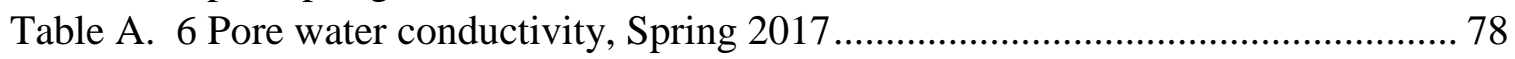

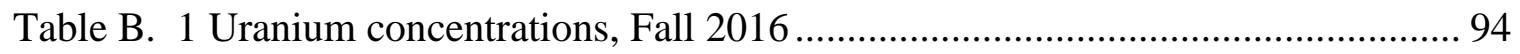

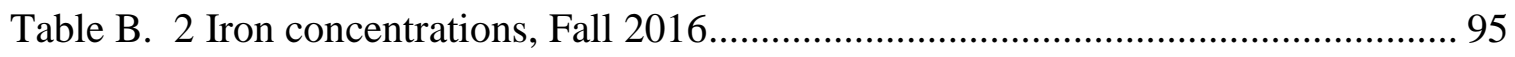

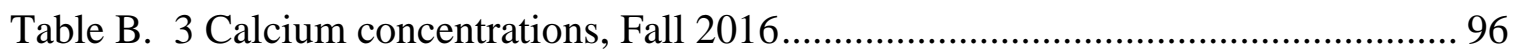

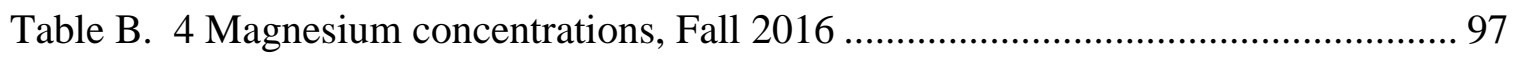

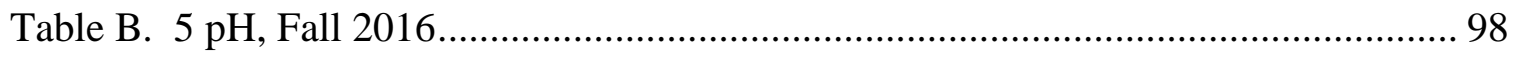

Table B. 6 Pore water conductivity, Fall 2016 ........................................................... 99 


\section{LIST OF FIGURES}

\section{FIGURE}

PAGE

Figure 1 Map of the Hanford site (Vermeul et al., 2009) ................................................ 2

Figure 2 Effects of changing Cole-Cole Parameters on Synthetic Phase ........................... 9

Figure 3 Image of Hanford Fine Sand prior to packing in column.................................. 10

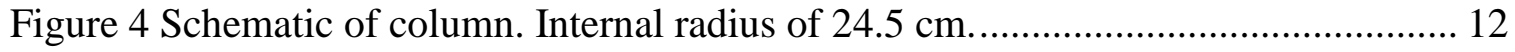

Figure 5 Image of column showing settling of sediment at the top................................. 13

Figure 6 Experimental setup during Fall 2016 and Spring 2017.................................... 16

Figure 7 Comparison between reference phase circuit and measurement........................ 18

Figure 8 Vials used to culture microbes at PNNL...................................................... 19

Figure 9 Phase spectra for Column 1, Fall 2016, Port 3 ………………......................... 26

Figure 10 Phase Spectra for Column 2, Fall 2016, Port 3............................................ 27

Figure 11 Real Conductivity for Column 1, Fall 2016, Port 3 ……………………......... 28

Figure 12 Real Conductivity for Column 2, Fall 2016, Port 3 ……………………....... 29

Figure 13 Imaginary Conductivity for Column 1, Fall 2016, Port 3. ............................... 30

Figure 14 Imaginary Conductivity for Column 2, Fall 2016, Port 3.............................. 31

Figure 15 Phase spectra for Column 3, Fall 2016, Port 3 ………………..................... 32

Figure 16 Phase Spectra for Column 5, Fall 2016, Port 3............................................. 33

Figure 17 Real Conductivity for Columns 3, Fall 2016, Port 3....................................... 34

Figure 18 Real Conductivity for Column 5, Fall 2016, Port 3....................................... 35

Figure 19 Imaginary Conductivity for Columns 3, Fall 2016, Port 3 ............................... 36

Figure 20 Imaginary Conductivity for Column 5, Fall 2016, Port 3 .............................. 37

Figure 21 Phase spectra for Column 4, Fall 2016, Port 3 ................................................ 38

Figure 22 Phase Spectra for Column 6, Fall 2016, Port 3............................................. 39

Figure 23 Real Conductivity for Column 4, Fall 2016, Port 3....................................... 40

Figure 24 Real Conductivity for Column 6, Fall 2016, Port 3. .......................................... 41

Figure 25 Imaginary Conductivity for Column 4, Fall 2016, Port 3. .............................. 42

Figure 26 Imaginary Conductivity for Column 6, Fall 2016, Port 3. ............................. 43

Figure 27 Dissolved Iron and Uranium for Columns 1 and 2, Fall 2016, Port 3............. 44

Figure 28 Dissolved Iron and Uranium for Columns 3,4,5, and 6, Fall 2016, Port 3....... 45

Figure $29 \mathrm{pH}$ for Columns 3,4,5, and 6, Fall 2016, Port 3.......................................... 46

Figure 30 Calcium Concentrations for Columns 3,4,5, and 6, Fall 2016, Port 3............. 47

Figure 31 Magnesium Concentrations for Columns 3,4,5, and 6, Fall 2016, Port 3....... 47

Figure 32 Porewater Conductivity for Columns 3,4,5, and 6, Fall 2016, Port 3............. 48

Figure 33 Phase spectra for Column 1, Spring 2017, Port 3........................................... 49

Figure 34 Phase Spectra for Column 2, Spring 2017, Port 3.......................................... 50

Figure 35 Real Conductivity for Column 1, Spring 2017, Port 3.................................. 51

Figure 36 Real Conductivity for Column 2, Spring 2017, Port 3.................................. 52

Figure 37 Imaginary Conductivity for Column 1, Spring 2017, Port 3........................... 53

Figure 38 Imaginary Conductivity for Column 2, Spring 2017, Port 3.......................... 54

Figure 39 Dissolved Iron and Uranium for Columns 1 and 2, Spring 2017, Port 3......... 55 


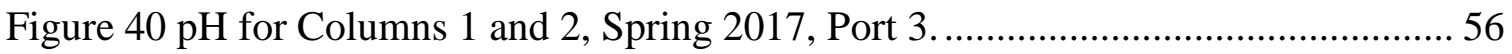

Figure 41 Calcium Concentrations for Columns 1 and 2, Spring 2017, Port 3.............. 57

Figure 42 Magnesium Concentrations for Columns 1 and 2, Spring 2017, Port 3.......... 57

Figure 43 Porewater Conductivity for Columns 1 and 2, Spring 2017, Port 3............... 58

Figure 44 Phase spectra for Spring 2018 Column ..................................................... 59

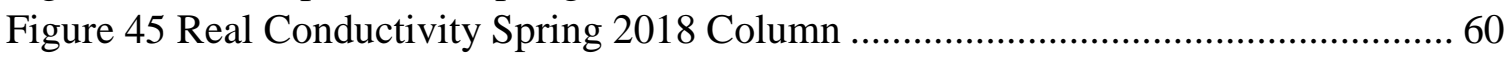

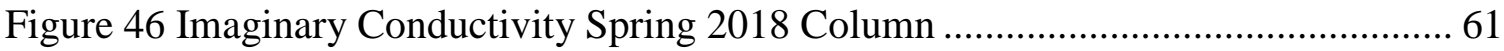

Figure A. 1 Phase Spectra for Columns 1 and 2, Spring 2017. ................................... 70

Figure A. 2 Real Conductivity Spectra for Columns 1 and 2, Spring 2017 ................... 71

Figure A. 3 Imaginary Conductivity Spectra for Columns 1 and 2, Spring 2017 ........... 72

Figure A. 4 Plot of Bulk Conductivity vs. Pore Fluid Conductivity for Columns 1 and 2,

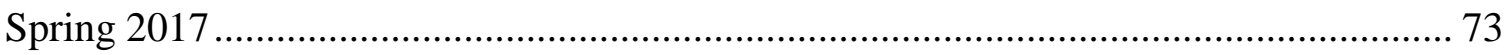

Figure A. 5 Uranium Concentrations for Columns 1 and 2, Spring 2017 ...................... 74

Figure A. 6 Iron Concentrations for Columns 1 and 2, Spring 2017 ............................ 74

Figure A. 7 Calcium Concentrations for Columns 1 and 2, Spring 2017 ...................... 75

Figure A. 8 Magnesium Concentrations for Columns 1 and 2, Spring 2017 ................. 75

Figure A. 9 Porewater $\mathrm{pH}$ for Columns 1 and 2, Spring 2017..................................... 76

Figure A. 10 Porewater Conductivity for Columns 1 and 2, Spring 2017...................... 76

Figure B. 1 Phase spectra for columns 1 and 2, Fall 2016........................................... 79

Figure B. 2 Phase spectra for columns 3 and 5, Fall 2016............................................ 80

Figure B. 3 Phase spectra for columns 4 and 6, Fall 2016........................................... 81

Figure B. 4 Real conductivity for columns 1 and 2, Fall 2016 ..................................... 82

Figure B. 5 Real conductivity for columns 3 and 5, Fall 2016 ..................................... 83

Figure B. 6 Real conductivity for columns 4 and 6, Fall 2016 ..................................... 84

Figure B. 7 Imaginary conducitivty for columns 1 and 2, Fall 2016............................. 85

Figure B. 8 Imaginary conducitivty for columns 3 and 5, Fall 2016 ............................. 86

Figure B. 9 Imaginary conductivity for columns 4 and 6, Fall 2016........................... 87

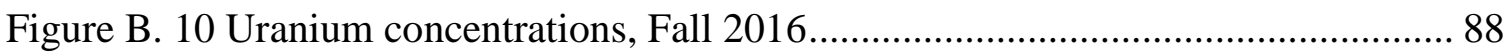

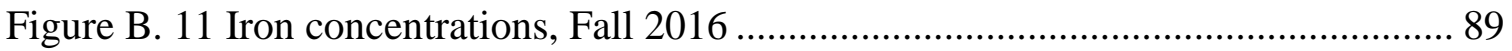

Figure B. 12 Calcium concentrations, Fall 2016 .......................................................... 90

Figure B. 13 Magnesium concentrations, Fall 2016 .................................................. 91

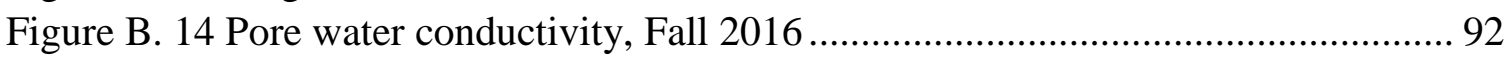

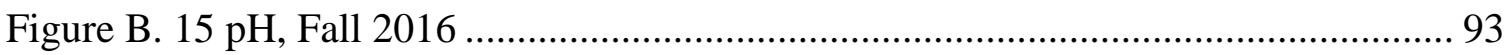




\section{INTRODUCTION}

The production of Plutonium at the U.S. Department of Energy (DOE) Hanford Site (Washington State) during the Second World War and Cold War has led to significant radionuclide contamination of the environment. High level liquid waste was stored in 177 single and double shelled tanks which were located in the 200 West Area and 200 East Area tank farms (Figure 1). While most of the tanks remain intact, 68 of the single shell tanks have begun leaking into the vadose zone (VZ) (Um et al., 2010). These tanks hold 56 million gallons of high level waste (HLW) and low-activity waste (LAW) which is composed of a mix of hazardous radioactive and chemical waste. This waste will eventually be vitrified in the form of borosilicate glass for final disposal in a geologic repository. HLW is in the form of low solubility sludge at the bottoms of the tanks while the LAW is in the form of supernatant and saltcake solids. $\mathrm{Cs}^{137}$ is present in the supernatant and saltcake and will be removed prior to vitrification.(Peterson et al., 2018)

One component of this contamination is Uranium, which exists in the form of low-mobility uranyl silicates (Na-Boltwoodite, Uranophane) as well as high mobility uranyl carbonates (Liebigite, Rutherfordine). The mobile carbonate phases are a threat as they can leach into the underlying phreatic zone (PZ) and serve as a source for a contaminant plume (Szecsody et al., 2012). 


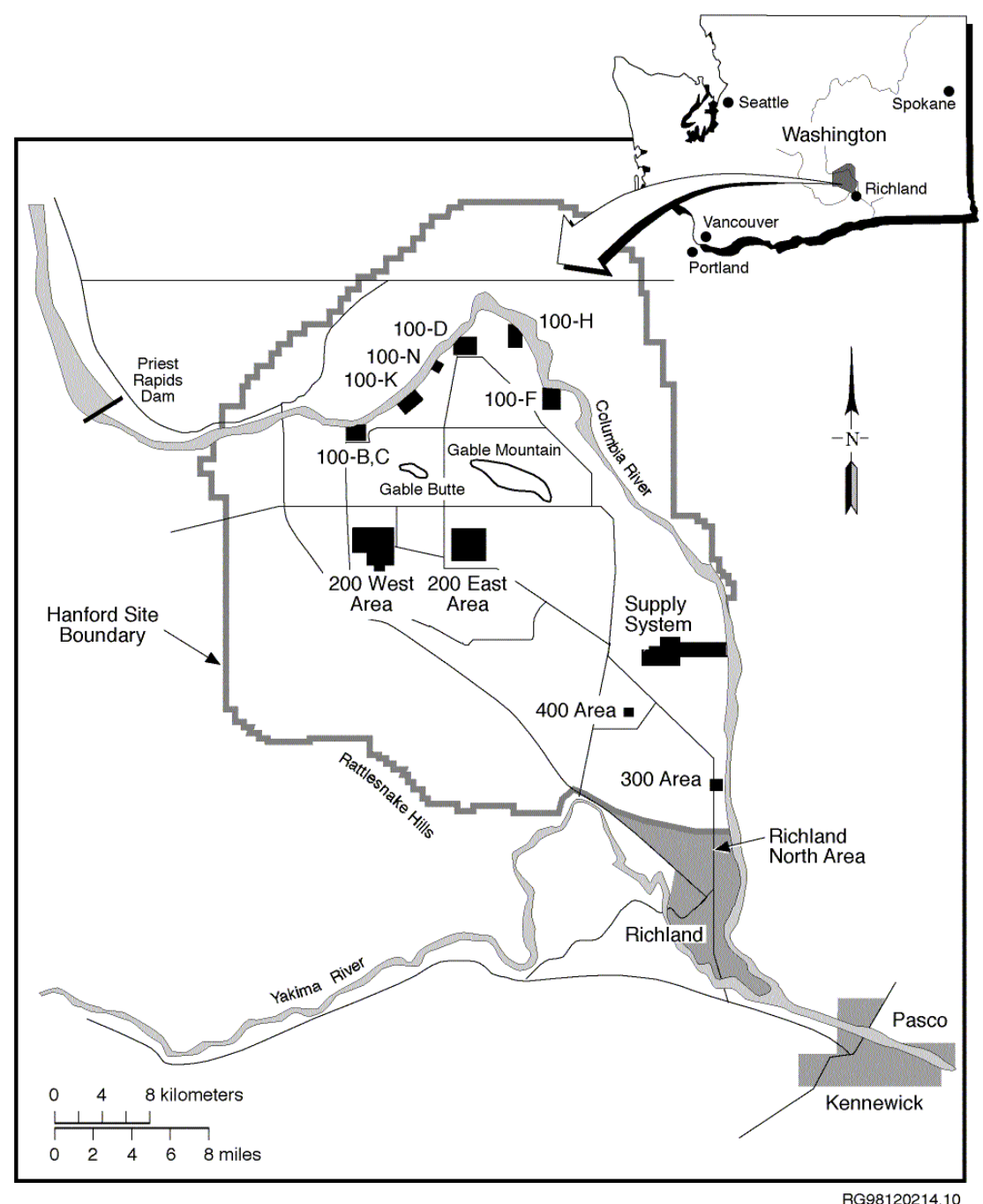

Figure 1 Map of the Hanford site (Vermeul et al., 2009)

One possible solution to reduce the mobility of Uranium in the subsurface could be an injection of a liquid Sodium Tripolyphosphate amendment. This phosphate compound would undergo hydrolysis and release orthophosphate $\left(\mathrm{PO}_{4}{ }^{3-}\right)$, which would then lead to the formation of the insoluble uranyl phosphate mineral sodium autunite $\left(\mathrm{Na}_{2}\left(\mathrm{UO}_{2}\right)_{2}\left(\mathrm{PO}_{4}\right)_{2} \cdot 8 \mathrm{H}_{2} \mathrm{O}\right)$. This remediation strategy has the added advantage of sequestering uranium by precipitation in the $6+$ state, which is the natural state of $\mathrm{U}$ in the vadose zone. (Vermeul et al., 2009) Even small quantities of phosphate present in the 
groundwater can promote the formation of autunite minerals that are persistent over geologic time (De Vivo et al., 1984).

A field scale test in the 300 Area examined the ability of a three part injection in sequestering Uranium within the phreatic zone. This test involved three sequential injections:

(1) An initial sodium tripolyphosphate injection.

(2) A Calcium Chloride $(\mathrm{CaCl})$ injection.

(3) A second and final sodium tripolyphosphate injection.

The test had limited success in treating the groundwater directly, Uranium concentrations in the groundwater dropped to below drinking water standards initially but then returned to previous values within two months. Consequently, the researchers proposed treating the source of contamination in the vadose zone directly. (Vermeul et al., 2009)

The presence of soil bacteria can affect uranium mobility significantly. Bacteria may dissolve uranyl-phosphate minerals in an effort to obtain phosphorus, thus liberating uranium back to the liquid phase. This process can be much more intensive in the presence of bicarbonate ions that enhance uranium release into the aqueous phase (Gudavalli, et al, 2013). Under oxidizing conditions microbes have been shown to interact with meta-autunite including biomineral precipitation. (Neu et al., 2011) As such there is a need for a better detection of microbes for implementation of any remediation 
actions. This might be possible via geophysical methods such as spectral induced polarization (SIP).

Geophysical techniques allow researchers to understand subsurface processes using surface measurements. Electrical techniques such as DC resistivity and Induced Polarization are sensitive to changes in the conductive and capacitive properties of the subsurface (Binley, 2015). These techniques have great potential for furthering our understanding of the spatial distribution of contamination in the subsurface as well as for monitoring vadose zone remediation techniques.

The emerging field of biogeophysics seeks to study how geophysical techniques can be used to understand microbiological processes in the subsurface. Mircobial action can affect geophysical measurements through various pathways. These include the formation of biofilm, increases in cell counts, and chemical alterations to the surroundings. Of particular focus are electrical geophysical techniques which study charge storage including induced polarization and spectral induced polarization. These methods are effective due to the fact that most bacterial cell walls have a net negative surface charge. This net charge forms the basis for the formation of an electrical double layer at bacterial surfaces which can polarize in the presence of an electric field.(Atekwana and Slater, 2009)

Near surface geophysical techniques have been used extensively at the Hanford site for the purpose of detecting contamination in the subsurface. Often contaminated sediment will have a contrasting bulk conductivity to the surrounding sediment and as such will be detectable using resistivity techniques which are sensitive to this difference. 
These applications have included the tracking of riverwater intrusion at the 300 area using 4D (time domain) electrical resistivity tomography (ERT) at the shore, the visualization of nitrate contaminant plumes under the B-Complex using cross-borehole ERT, and the monitoring of nitrogen-driven desiccation for the purpose of in-situ remediation at the 200 Area. (Johnson et al., 2015a)

Changes in bulk conductivity were exploited in order to monitor subsurface changes during biostimulation (injection of amendment in order to promote microbial breakdown of contaminants) at the Department of Defense (DoD) Brandywine site. Time-lapse ERT monitoring proved a robust and effective method to track subsurface changes in conductivity driven by microbial activity. (Johnson et al., 2015b)

Spectral Induced Polarization (SIP) uses a time varying alternating sinusoidal current and measured potential in order to calculate an impedance, $Z(\omega)$, composed of a magnitude (i.e. resistance), $|Z(\omega)|$ and phase, $\varphi(\omega)$ (controlled mainly by capacitive and inductive effects), as a function of the current frequency, $\omega$. The sensitivity of SIP to microbial processes has been demonstrated in various studies. These have included the study of microbe induced sulfide mineral precipitation (Ntarlagiannis et al., 2005a), the effect of artificial biofilms (Ntarlagiannis and Ferguson, 2008), and the release of biogenic gases in peat soils (Slater et al., 2007). Even deactivated microbial cells can affect the phase when injected into sand columns (Ntarlagiannis et al., 2005b), and this was attributed to clogging of pores and enhancement of pore throat polarization effects.

In particular these studies show the significant effect that microbes can have on the imaginary component $\left(\sigma^{\prime \prime}\right)$ of the complex conductivity $\left(\sigma^{*}\right)$. 
Recently (Mellage et al., 2018) conducted column experiments involving alternating layers of ferrihydrite-coated sand and pure quartz sand and found strong correlations between biomass growth and $\sigma^{\prime \prime}$.

Although many experiments have been conducted exploring microbial effects on SIP, most have used idealized media. This study focuses on site-specific needs and conditions at the Department of Energy Hanford site. This was accomplished by using Hanford Fine Sand (HFS) and a Simulated Groundwater Solution (SGW) designed to be similar to groundwater at the site. Hanford Fine Sand was taken from a pit on the site.

Saturated column experiments were conducted in Fall 2016, Spring 2017, and Spring 2018. These experiments monitored changes in the SIP response as well as chemical changes in the pore fluid of saturated Hanford Fine Sand with the purpose of studying the effects of microbes on autunite as well as to determine the ability of SIP to remotely detect microbial growth under these conditions.

\section{THE SIP METHOD}

Spectral Induced Polarization (SIP) uses a time-varying alternating sinusoidal current (AC) and measured potential in order to calculate an impedance, $Z(\omega)$, composed of a magnitude (i.e. resistance), $|Z(\omega)|$ and phase, $\varphi(\omega)$ (controlled mainly by capacitive and inductive effects), as a function of the current frequency, $\omega$

$$
Z(\omega)=|Z(\omega)| e^{-i \varphi(\omega)}
$$

Similar to traditional DC resistivity methods, SIP often uses a four-electrode configuration (two current electrodes, two potential electrodes). Generally a reference 
resistor is used in order to calibrate the impedance. The measured impedance and phase can be used to calculate a complex resistivity which is made up of real and imaginary components (Slater et al., 2005):

$$
\begin{gathered}
\left|\rho^{*}(\omega)\right|=\frac{|Z(\omega)|}{K} . \\
K=\frac{L}{A}=\frac{L}{\pi r^{2}}
\end{gathered}
$$

The geometric factor $(K)$ is a constant that translates the measured impedance to a complex resistivity and is a function of the system dimensions. For this experiment a cylindrical column was used, as such: $L$ is the distance between the measurement electrodes while $r$ is the inner radius of the PVC pipe being used.

The complex conductivity is then simply the inverse of the complex resistivity:

$$
\begin{gathered}
\sigma^{*}(\omega)=\frac{1}{\rho^{*}(\omega)} \\
\sigma^{*}(\omega)=\sigma^{\prime}+i \sigma^{\prime \prime}=|\sigma(\omega)| e^{i \varphi(\omega)} \\
\sigma^{\prime}=|\sigma| \cos (\varphi) \\
\sigma^{\prime \prime}=|\sigma| \sin (\varphi)
\end{gathered}
$$


Furthermore the real component of the conductivity can be divided into an electrolytic component and a surface component (Aal et al., 2004):

$$
\sigma^{\prime}=\sigma_{e l}+\sigma_{\text {surf }}^{\prime}=\frac{\sigma_{w}}{F}+\sigma_{\text {surf }}^{\prime}
$$

By plotting the real conductivity against the pore fluid conductivity it is possible to obtain both the formation factor $F$ and the surface conductivity.

SIP measurements can be related to physical properties of the sediment by fitting the data to a Cole-Cole model (Cole and Cole, 1941; Pelton et al., 1978; Slater et al., 2006):

$$
\sigma^{*}(\omega)=\sigma_{0}\left[1+m\left(\frac{(i \omega \tau)^{c}}{1+(i \omega \tau)^{c}(1-m)}\right)\right]
$$

Where $m$ is the chargeability, $\omega$ is the angular frequency, $\tau$ is the relaxation time, and $c$ is a constant based on the shape of the measured phase spectra. Figure 2 shows a series of synthetic Cole-Cole phase spectra while also demonstrating the effect of changing the Cole-Cole parameters in the equation. 

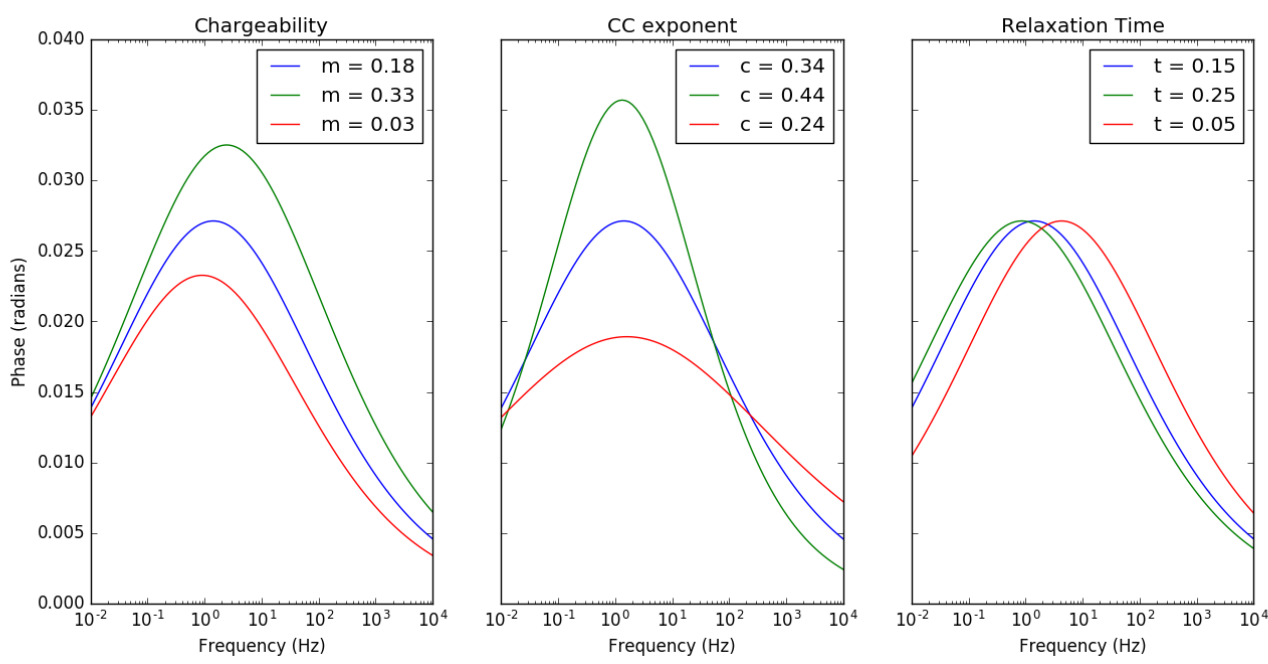

Figure 2 Effects of changing Cole-Cole Parameters on Synthetic Phase

Polarization below $1 \mathrm{MHz}$ is controlled mainly by Maxwell-Wagner polarization (dominant at $>1 \mathrm{KHz}$ ), Stern Layer Polarization, Diffuse Layer Polarization, Membrane Polarization, and Electrode Polarization. (Kemna, 2014)

\section{METHODOLOGY}

\section{Experiment Setup}

Originally six sediment filled columns were constructed in order to monitor the effects of microbial growth on Autunite and the SIP response. The sediment used in this study is Hanford Fine Sand (HFS) (Figure 3). The following characterization of HFS is found in Serne et al. (2008). HFS is characteristic of the sediment under the SX Tank Farm. The sample was obtained from the 218-E-12B site and characterized as a silty sand. The sediment is made up of $72.61 \%$ sand, $20.57 \%$ silt, $6.59 \%$ clay, and $0.23 \%$ 
gravel sized particles. $\mathrm{CaCO}_{3}$ made up $1.75 \%$ by weight of the total sediment. Mineralogy of the samples is dominated by quartz (80\%), K-Feldspar(10\%), and NaFeldspar(20\%). The mineralogy of the clay fraction is Smectite (30\%), Illite(15\%), Chlorite(15\%), Kaolinite(10\%), Quartz(5\%), and a small amount of Feldspar.

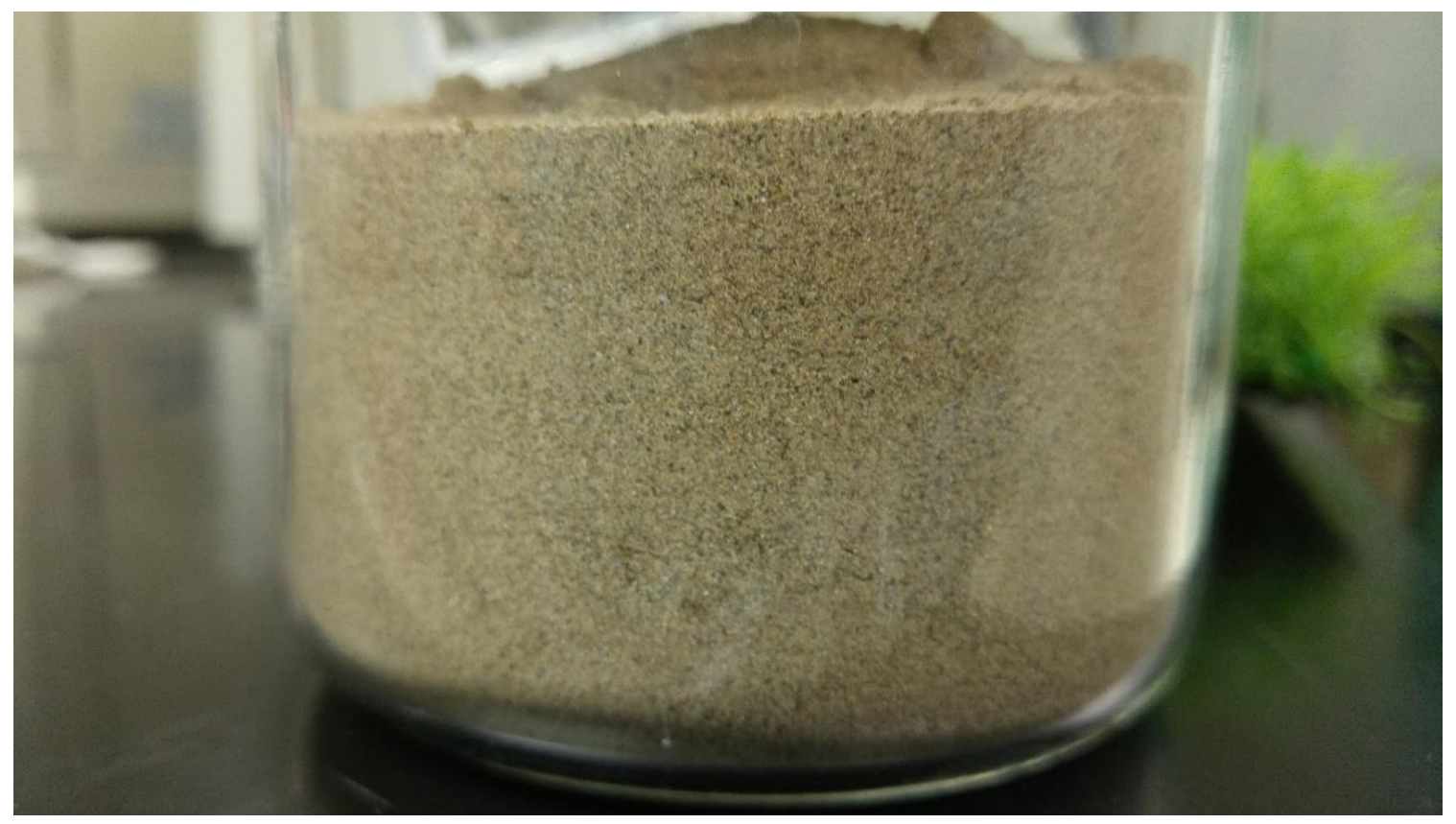

Figure 3 Image of Hanford Fine Sand prior to packing in column.

These columns were constructed of clear PVC. Each column had two coiled Ag$\mathrm{AgCl}$ current electrodes at either end, these were chosen due to the non-polarizing property of $\mathrm{Ag}-\mathrm{AgCl}$. These electrodes were constructed by dipping a coiled silver wire (.9999 fine, $1.29 \mathrm{~mm}$ ) into conventional Chlorox ${ }^{\circledR}$ bleach (Sodium Hypochlorite, $\mathrm{NaClO}$ ). This reacts with the silver wire to form an $\mathrm{AgCl}$ coating (dark gray color) over the silver.

Along the sides of the column were positioned four potential electrodes. These were constructed from a short silver wire encased in agar gel. The agar gel was prepared 
by mixing agar with the simulated groundwater solution used during the experiment. The purpose of this was to improve electrical contact with the sediment.

Each column had a 3D-printed porous plastic stopper as well as a circular cutout of filter at either end which were added in order to prevent sediment from entering the tubing. A schematic of the column design is included (Figure 4). 


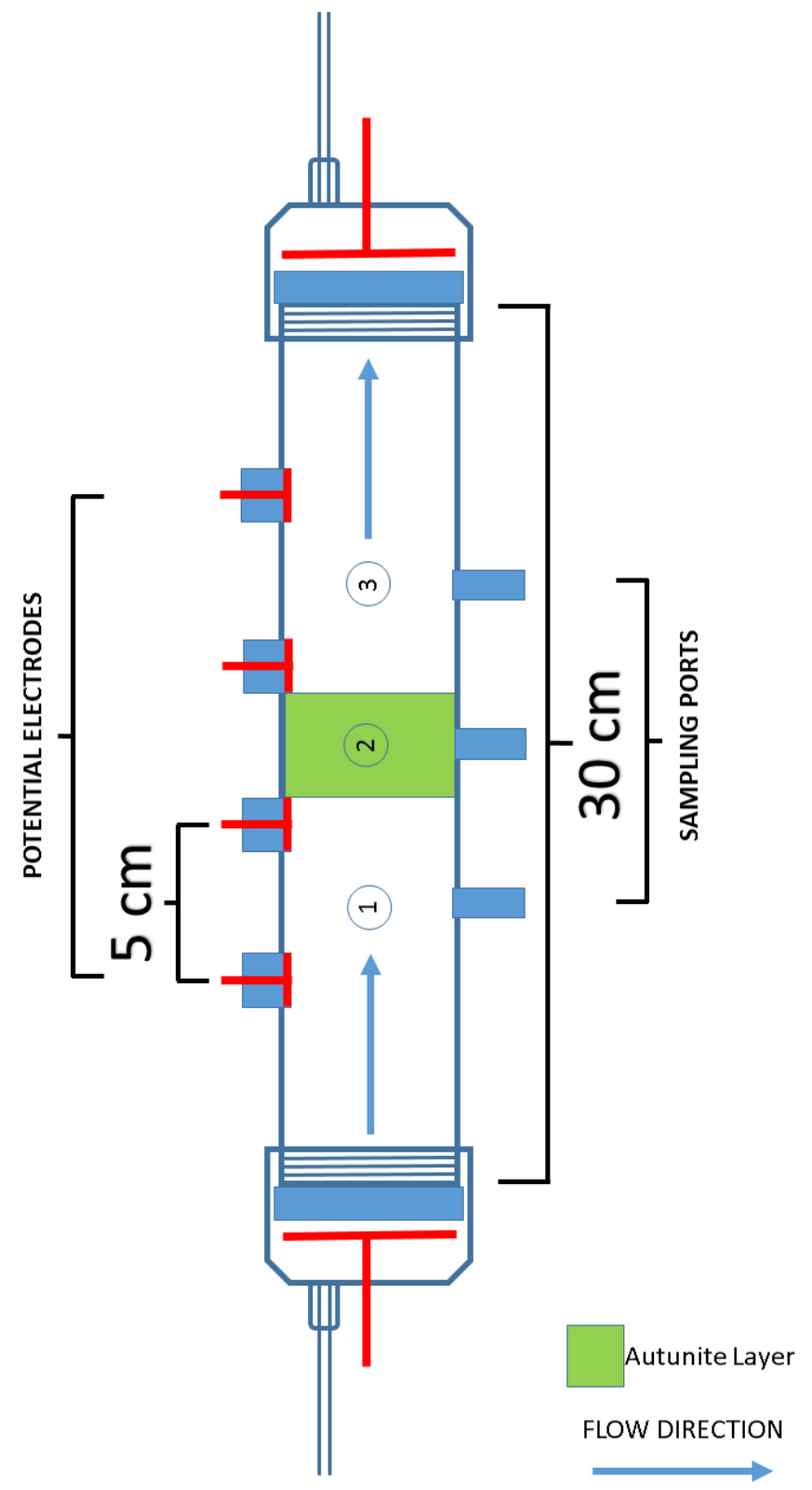

Figure 4 Schematic of column. Internal radius of $24.5 \mathrm{~cm}$.

Each column was packed using the following method:

(1) Pouring 50 g of sediment into column and packing of layer using a rubber stopper attached to a metal rod. 
(2) Disturbing top sediment in column. This is to prevent to formation of distinct strata throughout the column.

(3) New sediment poured in, repeat step 1.

The middle layer was a mix of sediment and $100 \mathrm{mg}$ of Autunite (Table 1). Each column was packed tightly to the top, after saturation settling occurred (Figure 5).

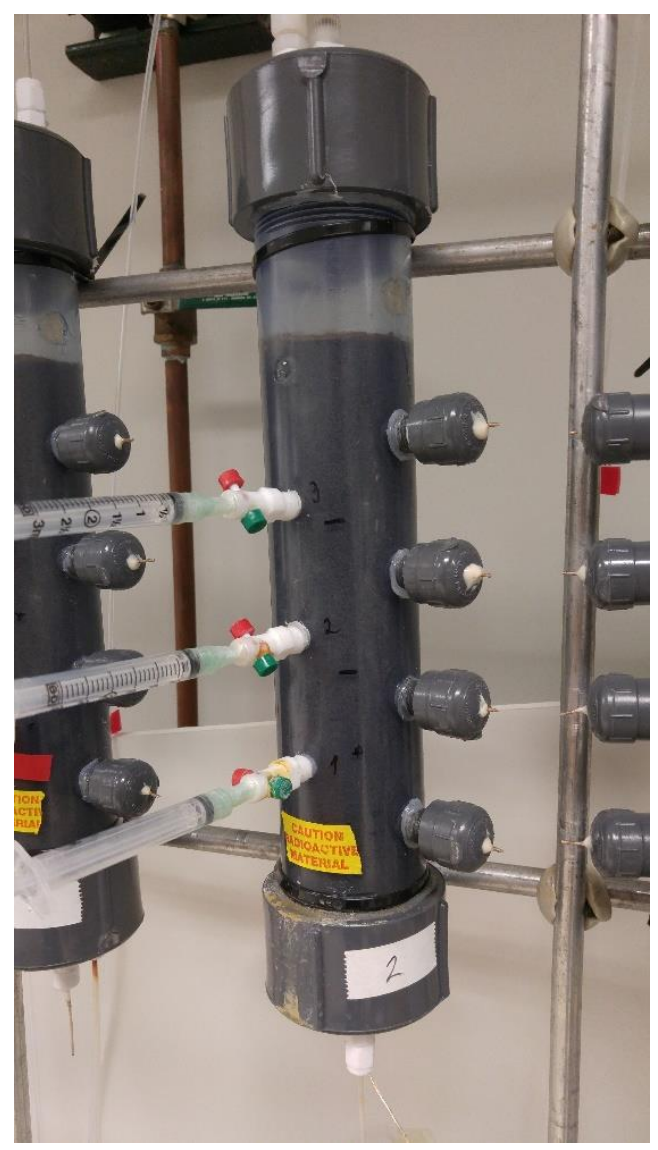

Figure 5 Image of column showing settling of sediment at the top. 
Table 1 Amount of sediment in each column as well as quantity of autunite.

\begin{tabular}{|c|c|c|}
\hline Column Number & Sediment $(\mathbf{g})$ & Autunite $(\mathbf{m g})$ \\
\hline $\mathbf{1}$ & 762.2 & 100 \\
\hline $\mathbf{2}$ & 652.2 & 100 \\
\hline $\mathbf{3}$ & 725.0 & 100 \\
\hline $\mathbf{4}$ & 704.1 & 100 \\
\hline $\mathbf{5}$ & 746.5 & 100 \\
\hline $\mathbf{6}$ & 780.9 & 100 \\
\hline
\end{tabular}

The simulated groundwater solution used in the experiment was made by diluting previously prepared stock solutions. These stock solutions are listed in (Table 2)

Table 2 Simulated Groundwater stock solutions.

\begin{tabular}{|c|c|}
\hline SGW Stock Solutions & Concentration $(\mathrm{g} / \mathrm{L})$ \\
\hline \multicolumn{2}{|l|}{ B } \\
\hline $\mathrm{MgSO}_{4}$ & 3.06 \\
\hline $\mathrm{CaSO}_{4}$ & 0.82 \\
\hline \multicolumn{2}{|l|}{$\mathbf{C}$} \\
\hline $\mathrm{Ca}\left(\mathrm{NO}_{3}\right)_{2} \times 4 \mathrm{H}_{2} \mathrm{O}$ & 5.43 \\
\hline $\mathrm{CaCl}_{2} \times 2 \mathrm{H}_{2} \mathrm{O}$ & 9.56 \\
\hline
\end{tabular}

In order to produce $1 \mathrm{~L}$ of SGW, $10 \mathrm{~mL}$ of $\mathrm{C}$ and $20 \mathrm{~mL}$ of B are diluted into $970 \mathrm{~mL}$ of deionized water. The final concentrations are listed in Table 3:

Table 3 Compound concentrations in final SGW solution.

\begin{tabular}{|c|c|c|}
\hline SGW Final Concentration & Concentration $(\mathrm{g} / \mathrm{L})$ & Concentration $(\mathbf{p p m})$ \\
\hline $\mathbf{M g S O}_{4}$ & .0612 & 61.2 \\
\hline $\mathbf{C a S O}_{4}$ & .0164 & 16.4 \\
\hline $\mathbf{C a}\left(\mathbf{N O}_{3}\right)_{2} \times \mathbf{4 H}_{2} \mathbf{O}$ & .0543 & 54.3 \\
\hline $\mathbf{C a C l}_{2} \times \mathbf{2 H}_{\mathbf{2}} \mathbf{O}$ & .0956 & 95.6 \\
\hline
\end{tabular}

Stock solutions were used for both bicarbonate and glucose. In this case bicarbonate stock was $0.3 \mathrm{M}$ while glucose stock was $100 \mathrm{~g} / \mathrm{L}$. Both were diluted 100x in the final solution resulting in concentrations of $3 \mathrm{mM}$ and $1 \mathrm{~g} / \mathrm{L}$ respectively. Glucose stock was autoclaved on a regular basis and great care was taken to ensure that it 
remained sterile including weekly inspection for possible microbial growth in the bottle. Using a microelectrode, the conductivity of the SGW solution was $328.1 \mu \mathrm{Scm}^{-1}$, added bicarbonate increases the conductivity to $352.1 \mu \mathrm{Scm}^{-1}$. Glucose is not ionic and does not directly contribute to the conductivity of the solution.

Flow into the columns was powered by an Ismatec $®$ peristaltic pump at a rate of $50 \mathrm{~mL}$ per day. This flow entered through the bottom of the column and exited from the top before eventually being drained into a waste container. Originally the waste container was located under the columns; however, it was later placed above. This placement leads to the formation of positive pressure within the column which may have helped prevent a siphon effect that could potentially suck air into the column through microscopic gaps. Tubing was mainly hard Teflon tubing however flexible tubing was also used. Four reservoirs were used to hold the SGW solutions I prepared; each reservoir was connected to an inflatable bag full of Nitrogen which prevented Oxygen from entering into the solution (Figure 6). 


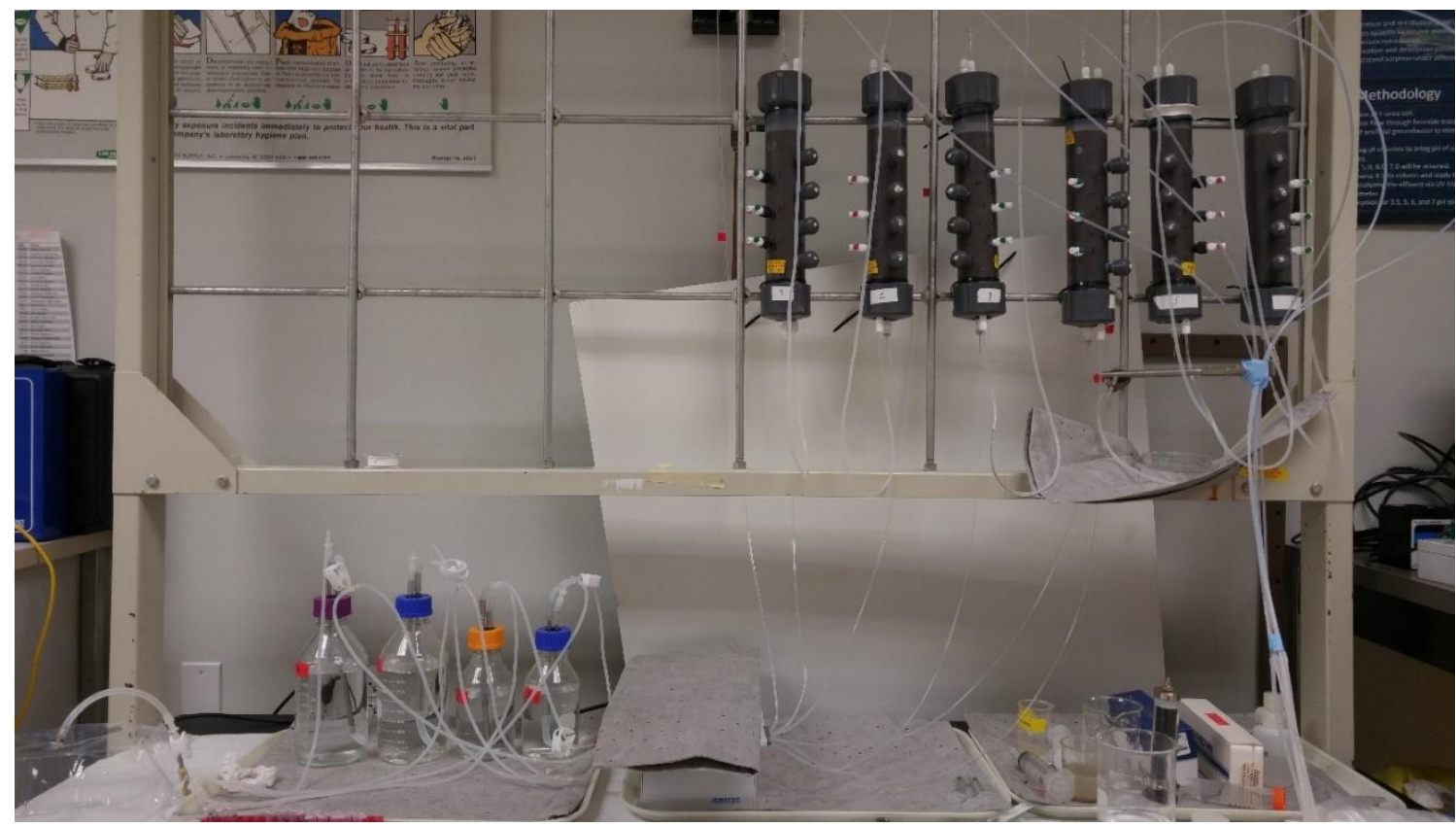

Figure 6 Experimental setup during Fall 2016 and Spring 2017.

Spectral Induced Polarization and Data Analysis

Spectral Induced Polarization measurements were taken using a National Instruments ${ }^{\mathrm{TM}}$ Data Acquisition Card (DAQ , PCI-4461) connected inside of a standard Microsoft Windows personal computer (PC) through a PCI interface. A $12 \mathrm{~V}$ battery was connected in the circuit. Measurements were taken at 21 frequencies ranging from $.1 \mathrm{~Hz}$ to $10,000 \mathrm{~Hz}$ spaced logarithmically. Each measurement was repeated three times and averaged. A reference resistor was placed in series with the column being measured, this allowed computation of the impedance by comparing the measured voltage of the column to the measured voltage of the resistor.

Measurement of the phase inherent to the circuit was done and subtracted from phase measurements of columns. This circuit phase was obtained by measuring the phase of a 120k Ohm reference resistor which should act as an ideal resistor and have a phase of 0 . Sporadically, measurements would be off by $2 \pi$ (eg. the measurement would be off 
by 4 quadrants), this was corrected by either subtracting or adding $2 \pi$ to the measured value based on whether it was negative or positive. This most often seemed to occur during the $0.1 \mathrm{~Hz}$ measurement. All measurements were repeated three times and averaged after the previous corrections. The test circuit was repeated ten times in order to ensure a reliable spectrum to subtract since it would be applied throughout all measurements in the experiment.

Measurements that were higher or lower than certain limits were also discarded as they represented measurements negatively affected by bubbles or other conditions in the columns.

Comparison to an Ontash and Ermac phase reference (Figure 7) shows that while our measurements are accurate between 0.1 and $100 \mathrm{~Hz}$, the accuracy quickly drops past that point. For this reason I only show measurements taken between 0.1 and $100 \mathrm{~Hz}$. This error is associated with the DAQ and the circuit along which measurement is taken. Ido not know a way to correct for it, although a procedure described in Huisman et al. (2016) for correcting error between $100 \mathrm{~Hz}$ and $1 \mathrm{kHz}$ may be promising. 


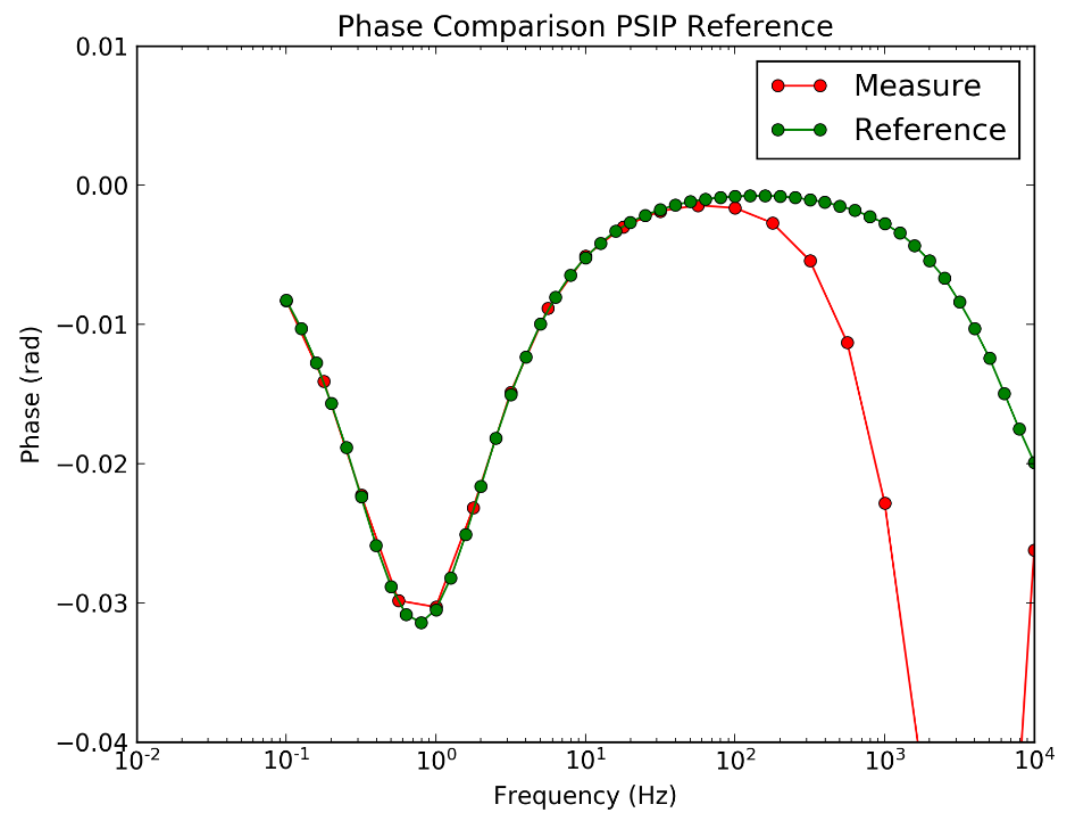

Figure 7 Comparison between reference phase circuit and measurement.

\section{Overview of Experiments}

Three sets of experiments were conducted starting in Fall of 2016 and ending in Spring of 2018; these will be referred to as Fall 2016, Spring 2017, and Spring 2018 experiments.

For the spring 2017 experiments, a microbial consortia was injected into the columns. This consortia was cultured at PNNL by mixing HFS with $10 \mathrm{mg}$ autunite and SGW1 solution (Figure 8). Samples of these solutions were taken and transferred to fresh containers multiple times. Final consortia were frozen and shipped to FIU. 


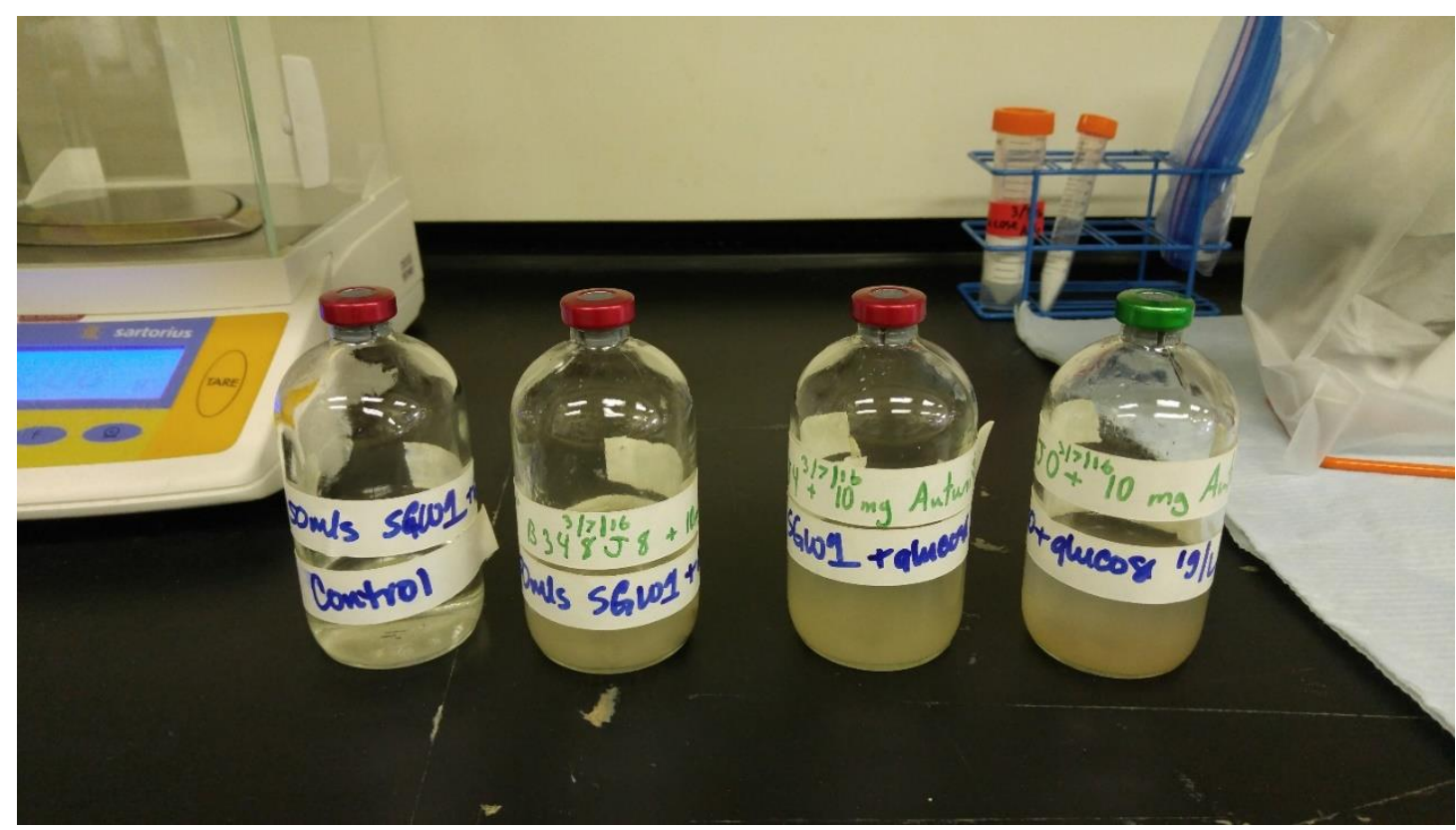

Figure 8 Vials used to culture microbes at PNNL.

The original Fall 2016 experiment involved the continual monitoring of six columns over a period of 149 days. In this case the purpose was to study the effect of microbial growth on Autunite solubility as well as whether SIP could be used to detect microbial growth. We were also interested in seeing the effects that bicarbonate could have on the system. As such, aside from the SGW solution that served as the base, columns 2,4, and 6 also had bicarbonate at a concentration of $3 \mathrm{mM}$. Columns 3,4,5,6 had glucose which served as a carbon source in order to nurture microbial growth in the sediment. Columns 5 and 6 also were inoculated directly with microbes. Columns 1 and 2 served as controls (Table 4). 
Table 4 Differentiation between columns for Fall 2016 experiment.

\begin{tabular}{|lc|}
\hline \multicolumn{1}{|c|}{ Column Contents Fall 2016 } \\
\hline Column 1 & $0 \mathrm{mM} \mathrm{HCO}$ \\
\hline Column 2 & $3 \mathrm{mM} \mathrm{HCO}_{3}$ \\
\hline Column 3 & $0 \mathrm{mM} \mathrm{HCO}_{3}+1 \mathrm{~g} / \mathrm{L}$ glucose \\
\hline Column 4 & $3 \mathrm{mM} \mathrm{HCO}_{3}+1 \mathrm{~g} / \mathrm{L}$ glucose \\
\hline Column 5 & $0 \mathrm{mM} \mathrm{HCO}_{3}+1 \mathrm{~g} / \mathrm{L}$ glucose+ Inoculum \\
\hline Column 6 & $3 \mathrm{mM} \mathrm{HCO}_{3}+1 \mathrm{~g} / \mathrm{L}$ glucose+ Inoculum \\
\hline
\end{tabular}

Geophysical measurements were taken once a week (Wednesdays) followed by pore water sampling (Fridays). Initially $1.5 \mathrm{~mL}$ of porewater was taken each week; however, this was increased to $3.0 \mathrm{~mL}$ in order to facilitate a greater number of chemical tests.

Initially there was difficulty extracting porewater samples from the columns. The primary culprit behind this was the clogging of needles used to extract water. This means that early in the experiment it was not uncommon to have porewater data missing. Similarly the production of $\mathrm{CO}_{2}$ by microbes was a hurdle in taking SIP measurements. Often bubbles would form on potential electrodes or bubbles would migrate upwards and pool on the upper current electrode. Apart from physical vibration of the columns there was little recourse in removing gas.

Although initially it was planned that microbial growth in these columns would be driven by an inoculation, the pumping of glucose prior to any such injection promoted the growth of the naturally occurring microbes in the sediment. When an inoculation did occur, changes were not apparent due to existing microbial growth. This experiment ran for 149 days. Initially the SGW pumped through the columns was prepared incorrectly; on Day 33 of the experiment this was corrected and glucose and bicarbonate solutions 
began being pumped through the columns which resulted in a small increase in the measured conductivity.

During Spring 2017, columns 1 and 2 (control columns) were converted to microbial columns and monitored over a period of 34 days (Table 5). The main purpose of this experiment was to obtain measurements more frequently and cleanly in order to better capture initial changes due to microbial growth. SIP measurements were taken five times a week (Mon, Tue, Wed, Thu, Fri) while porewater samples were taken thrice weekly (Mon, Wed, Fri).

Table 5 Differentiation between columns for Spring 2017 experiment.

\begin{tabular}{|lc|} 
& Column Contents Spring 2017 \\
\hline Column 1 & $1 \mathrm{~g} / \mathrm{L}$ glucose + Inoculum + $0 \mathrm{mM} \mathrm{HCO}_{3}$ \\
\hline Column 2 & $1 \mathrm{~g} / \mathrm{L}$ glucose + Inoculum $+3 \mathrm{mM} \mathrm{HCO}_{3}$ \\
\hline
\end{tabular}

During this experiment we were able to successfully collect all porewater samples; however, the production of gas caused much of the SIP data from column 1 to be nearly unusable. Column 2 fortunately was not as affected.

We inoculated these columns on Day 9 of the experiment which was concurrent with initiation of pumping of glucose solution. This seems to have led to rapid microbial growth compared to that observed during Fall 2016 experiments.

Because SIP measurements were taken on the same days as porewater measurements we were also able to calculate the formation factor of the sediment.

A third experiment was conducted in late Spring of 2018 with the purpose of improving understanding of existing results by doing basic measurements on less 
complex systems. For this experiment a new, smaller column was used. Similar to previous columns it had two coiled $\mathrm{Ag}-\mathrm{AgCl}$ current electrodes at either end; however, only one pair of potential electrodes along the side. The potential electrodes were Ag$\mathrm{AgCl}$ and submerged directly in the column solution.

This experiment is still underway with expected completion sometime in Summer 2018. As such, only initial results are presented in this thesis. These results are for pure solutions without sediment as well as aerated and anaerobic SGW-saturated Hanford Fine Sand.

\section{Techniques for Analysis of Porewater}

At the time of collection the conductivity and $\mathrm{pH}$ of the porewater were measured using calibrated microelectrodes. Later on, during the Fall 2016 experiment, some measurements of ORP (Oxidation Reduction Potential) were taken as well. All Spring 2017 porewater samples had ORP measured. ORP is indicative of oxidative or reducing conditions.

The ferrozine method (Stookey, 1970) and the 1,10-phenanthroline method (Fadrus and Malý, 1975) were used in order to measure the concentrations of $\mathrm{Fe}^{2+}$ and the sum of $\mathrm{Fe}^{2+}$ and $\mathrm{Fe}^{3+}$. The ferrozine method is a dye-based method in which the intensity of the resultant purple color is dependent on the concentration of $\mathrm{Fe}^{2+}$ in solution; this intensity is measured using an ultraviolet visible spectroscopy (UV-Vis) instrument. The UV-Vis measures the absorbance at $562 \mathrm{~nm}$.

The procedure for ferrozine analysis is as follows. $200 \mu \mathrm{L}$ of sample (at original concentration or diluted if suspected concentration was higher than $30 \mathrm{mg} / \mathrm{L}$, the upper 
concentration limit for the UV-Vis) was mixed with $0.3 \mathrm{~mL}$ of $0.15 \mathrm{M} \mathrm{HCl}$ and $1.5 \mathrm{~mL}$ of ferrozine solution in a clear cuvette (a very clear plastic vial with 6 flat sides designed for analysis by the UV-Vis). After mixing the new solution was let to rest for 10 minutes in order to ensure equilibrium of the reaction between the ferrozine and $\mathrm{Fe}^{2+}$.

The use of an ICP-OES (Inductively Coupled Plasma-Optical Emission Spectroscopy) was used in order to measure concentrations of $\mathrm{Fe}, \mathrm{Ca}, \mathrm{Mg}$, and $\mathrm{P}$. These systems use an inert argon plasma in order to excite atoms to release electromagnetic radiation at a characteristic wavelength. The intensity of the measured peak is calibrated using solutions of known concentration and a calibration curve is formed which allows us to calculate the concentration in each sample. While an ICP-OES has the ability to measure a variety of elements, it is unable to distinguish individual oxidation states. It is also not suitable for the measurement of Uranium.

Samples were diluted 100x for ICP-OES analysis, in this case $60 \mu \mathrm{L}$ of sample was diluted into $5940 \mu \mathrm{L}$ of $1 \%$ nitric acid. A sample of the nitric acid was used as a background to account for any existing dissolved elements. Each measurement done by the ICP-OES consumed approximately $2 \mathrm{~mL}$ of solution. By having $6 \mathrm{~mL}$ of prepared solution we were able to repeat measurements that produced incorrect results.

A Chemchek ${ }^{\mathrm{TM}}$ KPA (Kinetic Phosphorescence Analyzer) was employed to measure concentrations of Uranium. Phosphorescence is induced in an aqueous sample by an exciting laser. Similar to the method used for the ICP-OES, a calibration curve was constructed using samples of know concentrations which correlated the measured intensity with sample concentrations. 
Special procedures needed to be followed in order to use the KPA with our samples. This is due to the presence of glucose and organic matter in the solution which can interfere with the device. In order to remove any organic matter all samples were wet ashed while samples from Spring 2017 and some Fall 2016 samples were both wet ashed and dry ashed. Ashing is a process that removes organic matter by adding hydrogen peroxide and nitric acid to samples, these samples are then evaporated leaving a solid precipitate behind minus any organic components. Samples are then re-dissolved in a $1 \%$ nitric acid solution to original volumes. No noticeable difference was observed between samples which were wet ashed versus samples that were both wet and dry ashed.

\section{RESULTS}

\section{Fall 2016 SIP Results}

Originally for this experiment, microbial growth was planned to be initiated through an inoculation directly into the center of the column; however, due to the lack of sterility and the tardiness in applying the inoculation, microbial growth began in the column soon after we began pumping glucose on Day 33. An inoculation was conducted on Day 124. However, by this point microbial growth was so rampant in the columns that it had no perceivable effect. This was corrected for the Spring 2017 experiments during which the pumping of glucose and the inoculation of the columns occurred concurrently.

In the following discussion of results for Fall 2016, I group the experiments as follows: 1) Columns 1 and 2, comparing the effect of bicarbonate on the control columns; 2) Columns 3 and 5, comparing the effect of microbial growth on columns with no 
bicarbonate; and 3) Columns 4 and 6, comparing the effect of microbial growth on columns with bicarbonate.

As a reminder: the phase is the delay between voltage and current and is controlled mainly by capacitive and inductive effects in the sediment while the real and imaginary conductivities are respectively the real and imaginary components of the complex conductivity calculated from the measured impedance, phase, and a geometric factor. All figures are based on data from port 3. Data from ports 1 and 2 are included in the appendix. In general data from all three ports seem to show similar changes; as such it would be redundant to include them all in the main body of the text. Whenever data from the other ports are beneficial to the discussion they will be referenced.

Column 1 (Figure 9) shows little significant change in phase over the period of 149 days that the experiment ran. There is a natural slightly asymmetrical parabolic shape to the curve which shows a peak of 0.020 radians around $3 \mathrm{~Hz}$ with 0.015 radians observed at 0.1 and $100 \mathrm{~Hz}$. Column 2 (Figure 10) on the other hand shows a significant increase in phase from starting values similar to Column 1 to 0.025 radians at $0.1 \mathrm{~Hz}$ and a peak of 0.028 radians at $1 \mathrm{~Hz}$. Changes in the phase are first seen on Day 37 and are likely the result of the pumping of new solution during Day 33. The shift in the peak from $\sim 3 \mathrm{~Hz}$ to $1 \mathrm{~Hz}$ is first seen on Day 44 . On Day 37 phase is seen to decrease then quickly begin increasing as seen in Day 44 onwards. The decrease on Day 37 is observed in Port 2 but not in Port 1 (Figure B. 1) where it is an increase in line with the trend observed throughout the remainder of the experiment. 
This increase in phase is consistent across the range of frequencies shown $(0.1-$ $100 \mathrm{~Hz}$ ); however, it is greater at the low frequencies and lower at the high-end. The rate of change observed in Column 2 seems to slow down after Day 100 and reaches equilibrium by the end of the experiment.

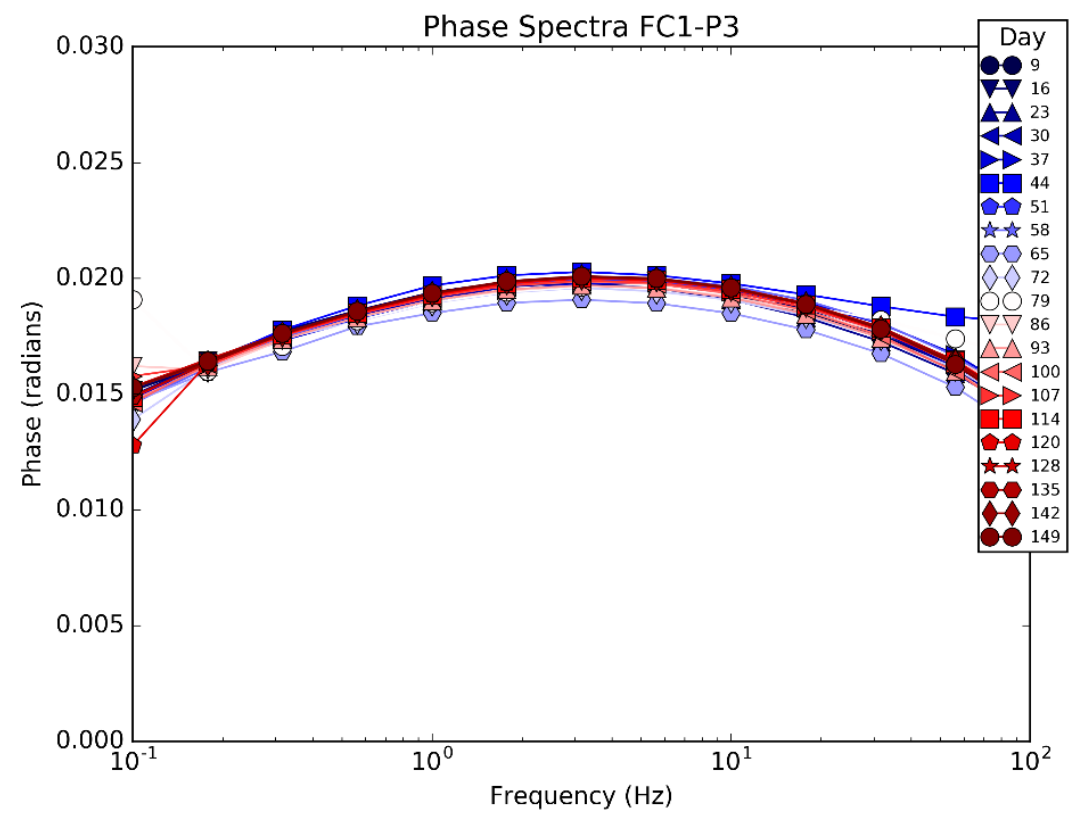

Figure 9 Phase spectra for Column 1, Fall 2016, Port 3. 


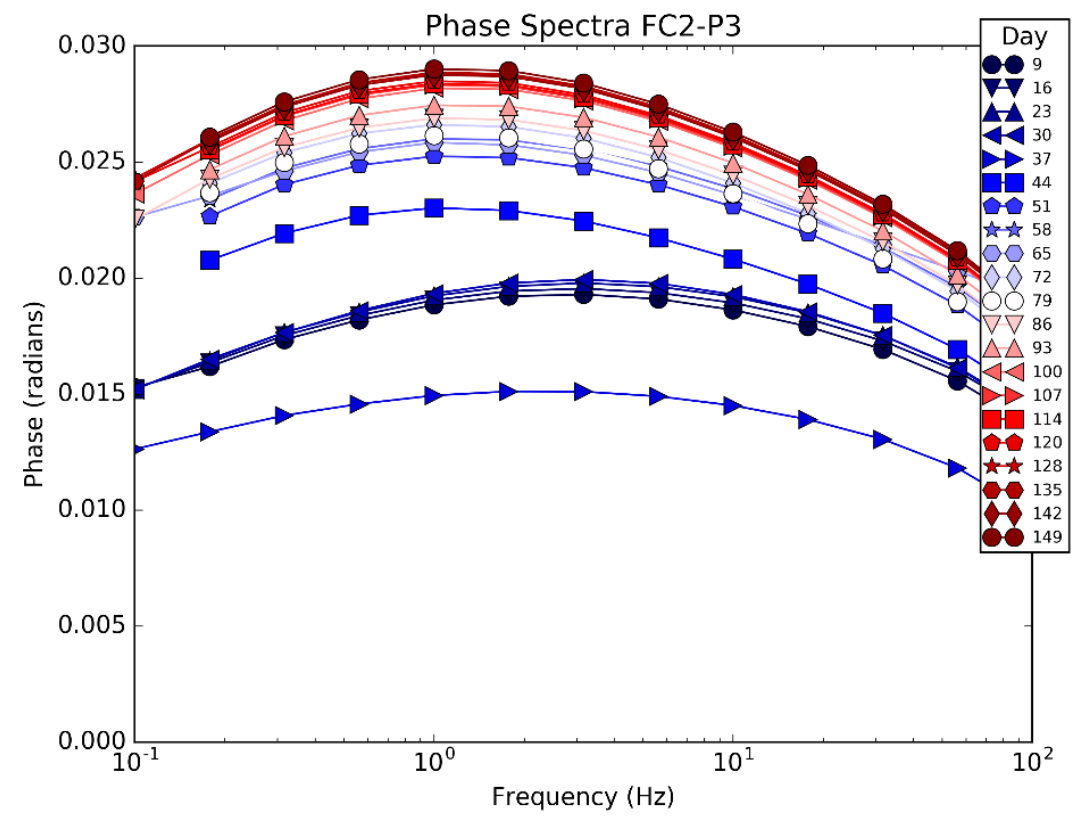

Figure 10 Phase Spectra for Column 2, Fall 2016, Port 3.

The real component of the conductivity remained mostly constant for Column 1

(Figure 11) however a minor increase in the conductivity can be seen starting on Day 37. This is due to the injection of new solutions on Day 33 which were slightly more conductive than the previous solution. Conductivity increases slightly with frequency in a linear manner. For example on Day 9 conductivity was $0.0132 \mathrm{~S} / \mathrm{m}$ at $0.1 \mathrm{~Hz}$ and 0.0144 $\mathrm{S} / \mathrm{m}$ at $100 \mathrm{~Hz}$, while on Day 149 conductivity was $0.0144 \mathrm{~S} / \mathrm{m}$ at $0.1 \mathrm{~Hz}$ and $0.0155 \mathrm{~S} / \mathrm{m}$ at $100 \mathrm{~Hz}$. A maximum in conductivity was observed on Day 65.

Column 2 (Figure 12) shows an increase in the conductivity starting Day 37 due to the addition of $3 \mathrm{mM}$ bicarbonate which is an ionic species in solution. This solution was more conductive than the one used in Column 1; thus the increase in the conductivity is significantly greater. Similar to Column 1 , the conductivity is positively correlated to frequency. Conductivity starts at $0.0143 \mathrm{~S} / \mathrm{m}$ at $0.1 \mathrm{~Hz}$ and $0.0155 \mathrm{~S} / \mathrm{m}$ at $100 \mathrm{~Hz}$ on Day 
9, at the end of the experiment (Day 149) the conductivity rose to $0.0170 \mathrm{~S} / \mathrm{m}$ at $0.1 \mathrm{~Hz}$ and $0.0189 \mathrm{~S} / \mathrm{m}$ at $100 \mathrm{~Hz}$. A maximum was observed on Day 44.

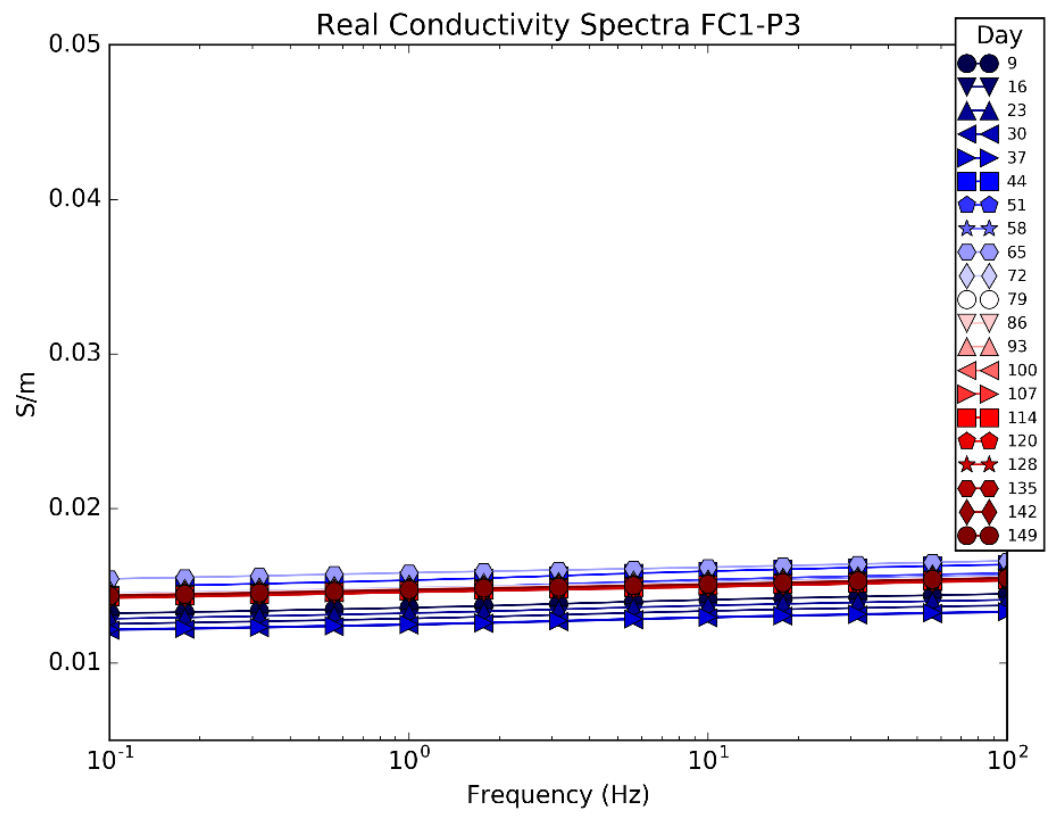

Figure 11 Real Conductivity for Column 1, Fall 2016, Port 3 


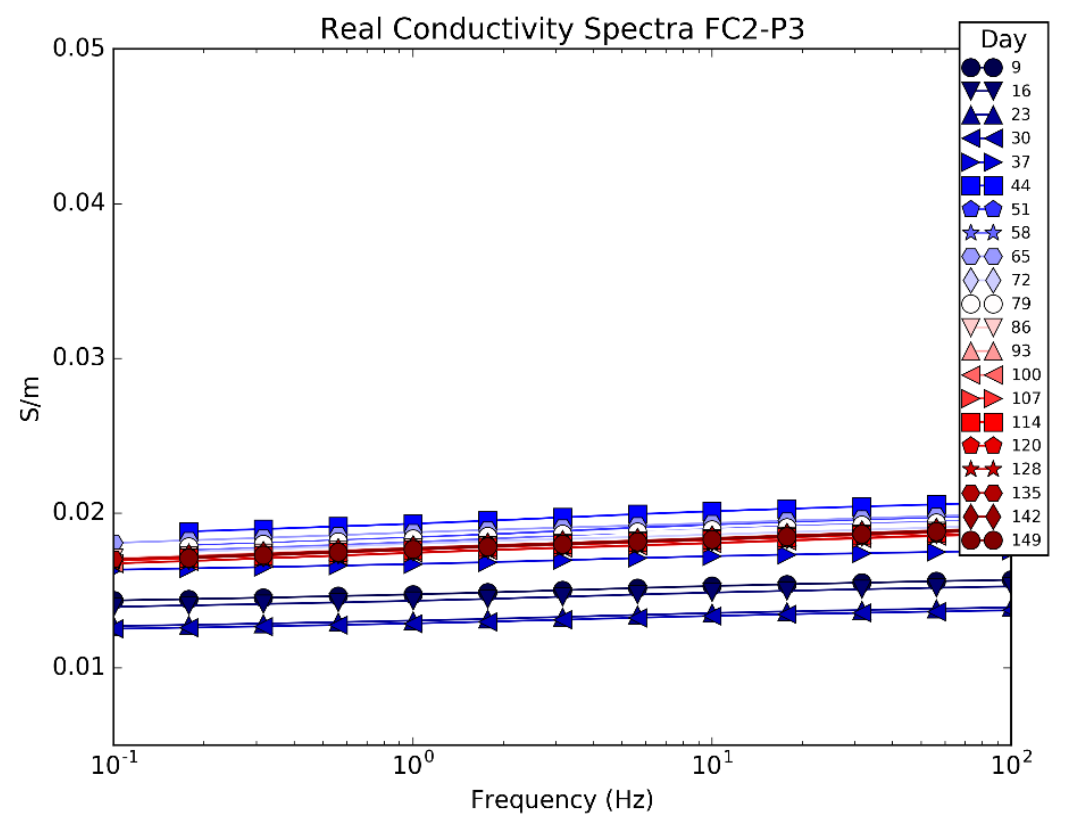

Figure 12 Real Conductivity for Column 2, Fall 2016, Port 3

The imaginary conductivity of Column 1 (Figure 13) initially decreases.

However, after Day 37 there is a sudden increase. Equilibrium seems to occur starting Day 51 with only minor variation observed afterwards.

Similar to Column 1, in Column 2 (Figure 14) there is an initial decrease of the imaginary conductivity which reverses on Day 37 (as noted by the change in the shape of the spectra) and significantly increases starting on Day 44. Changes in the shape of the spectra match those seen in the phase spectra (figure 10). 


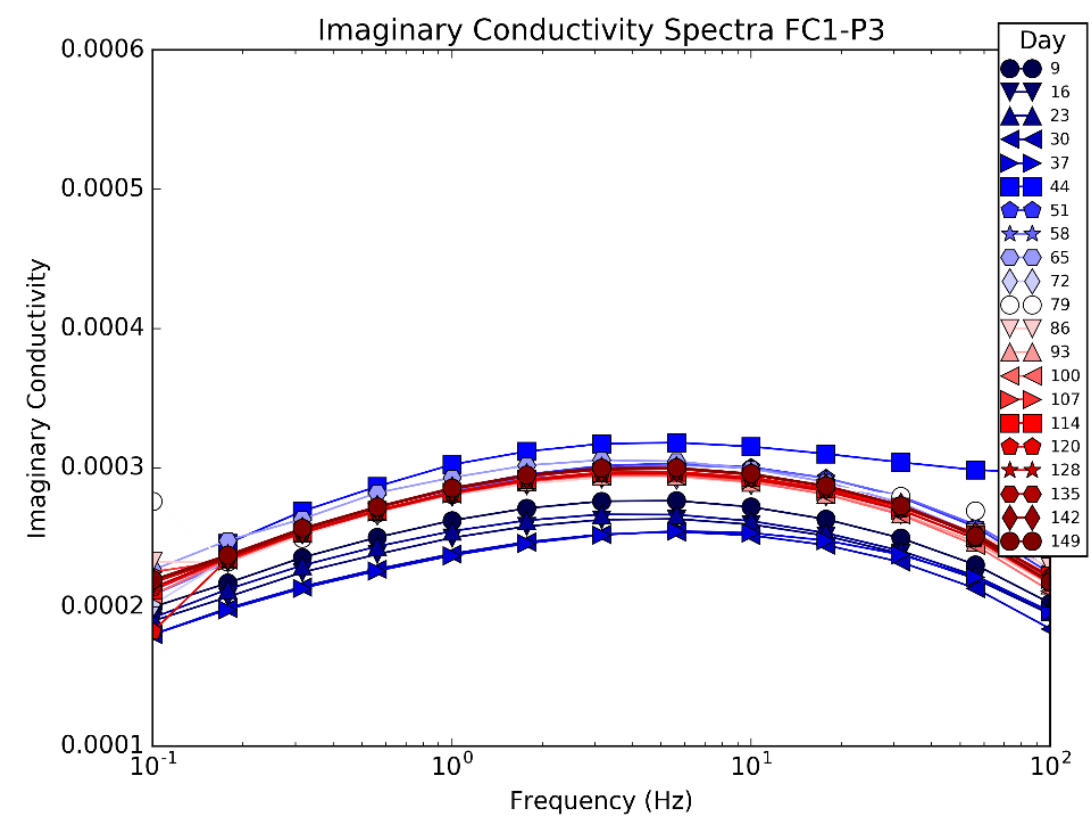

Figure 13 Imaginary Conductivity for Column 1, Fall 2016, Port 3. 


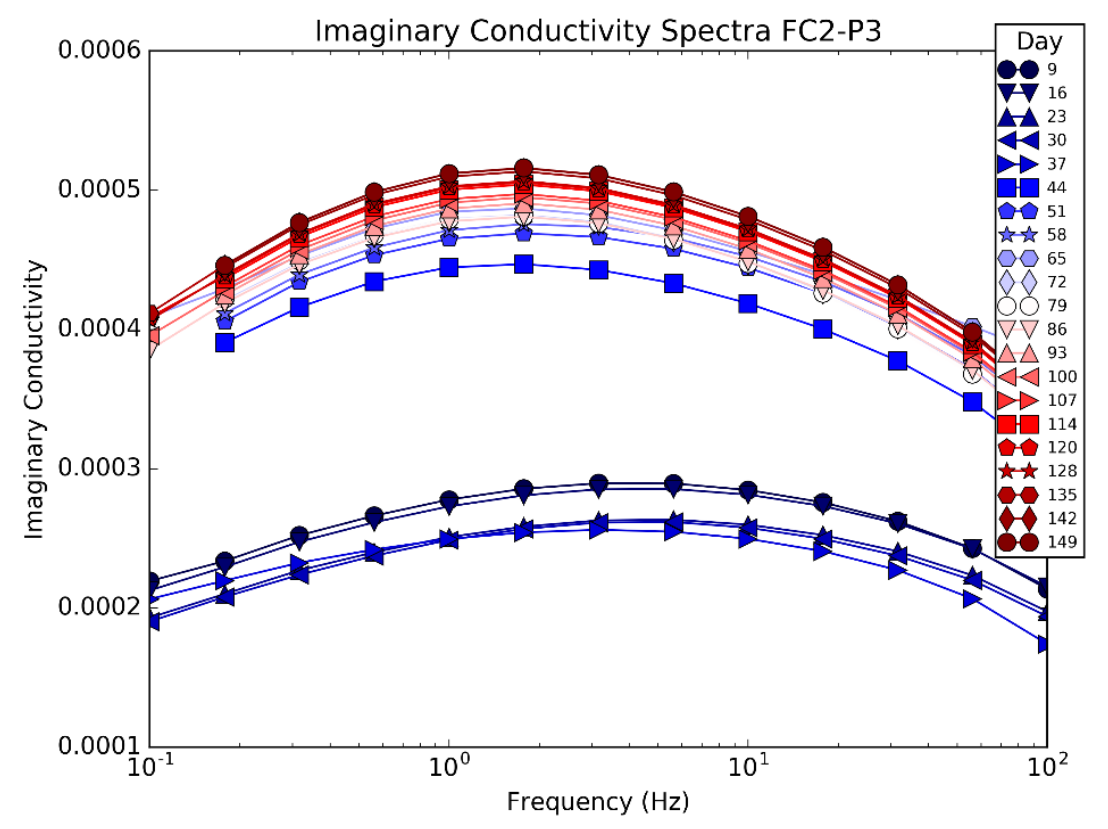

Figure 14 Imaginary Conductivity for Column 2, Fall 2016, Port 3.

Both columns 3 and 5 had glucose but no bicarbonate. Column 3 (Figure 15)

shows initial phase values similar to Column 1. A sudden decrease is observed on Day 37 which also involves the loss of the parabolic shape that the phase spectra previously had. The new spectrum is flat until the higher frequencies starting with $56 \mathrm{~Hz}$ where it begins to drop. On Day 149 the phase was recorded as 0.0076 radians at $0.1 \mathrm{~Hz}, 0.0058$ radians at $31 \mathrm{~Hz}$, and 0.0031 radians at $100 \mathrm{~Hz}$. Data for Day 30 are erroneous and can be overlooked.

Column 5 (Figure 16) shows a similar response to Column 3. In this case the data for Day 37 are erroneous; however, Day 44 shows a similar decrease and loss of the shape of the phase spectrum. On Day 149 the phase was recorded as 0.0065 radians at 0.1 $\mathrm{Hz}, 0.0054$ radians at $31 \mathrm{~Hz}$, and 0.0031 radians at $100 \mathrm{~Hz}$. The spectrum remains flat between $0.1 \mathrm{~Hz}$ and $31 \mathrm{~Hz}$. 


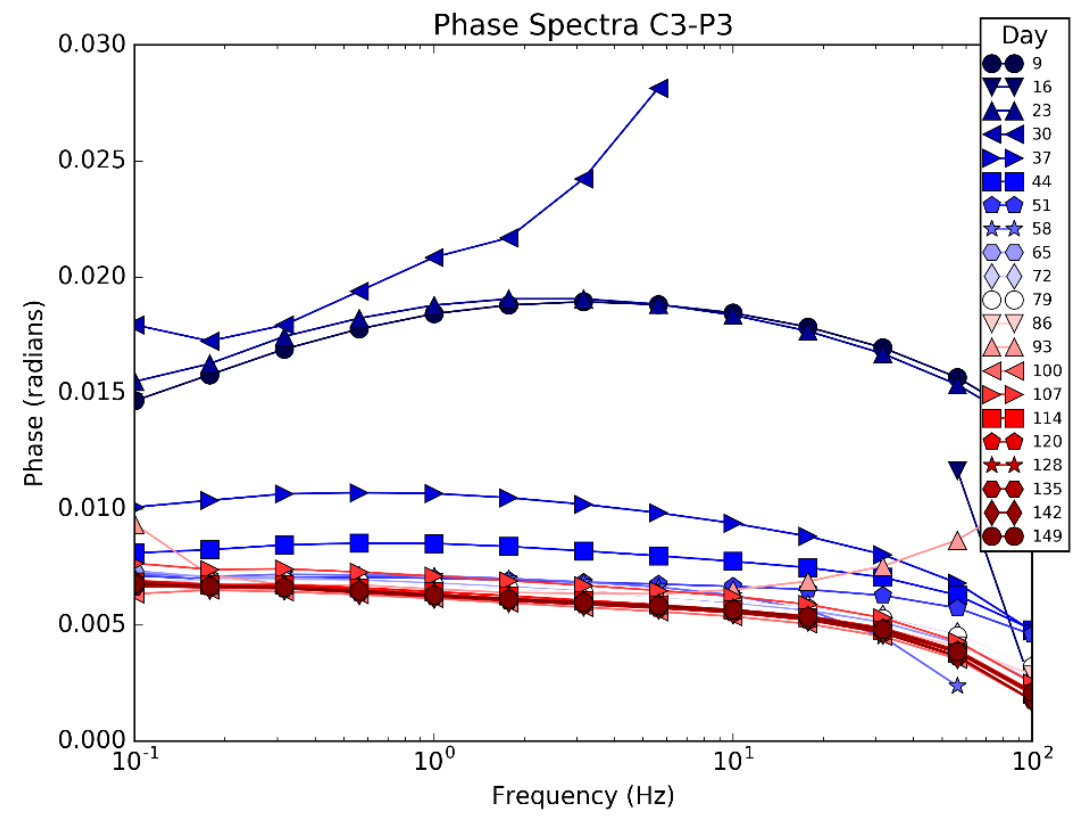

Figure 15 Phase spectra for Column 3, Fall 2016, Port 3. 


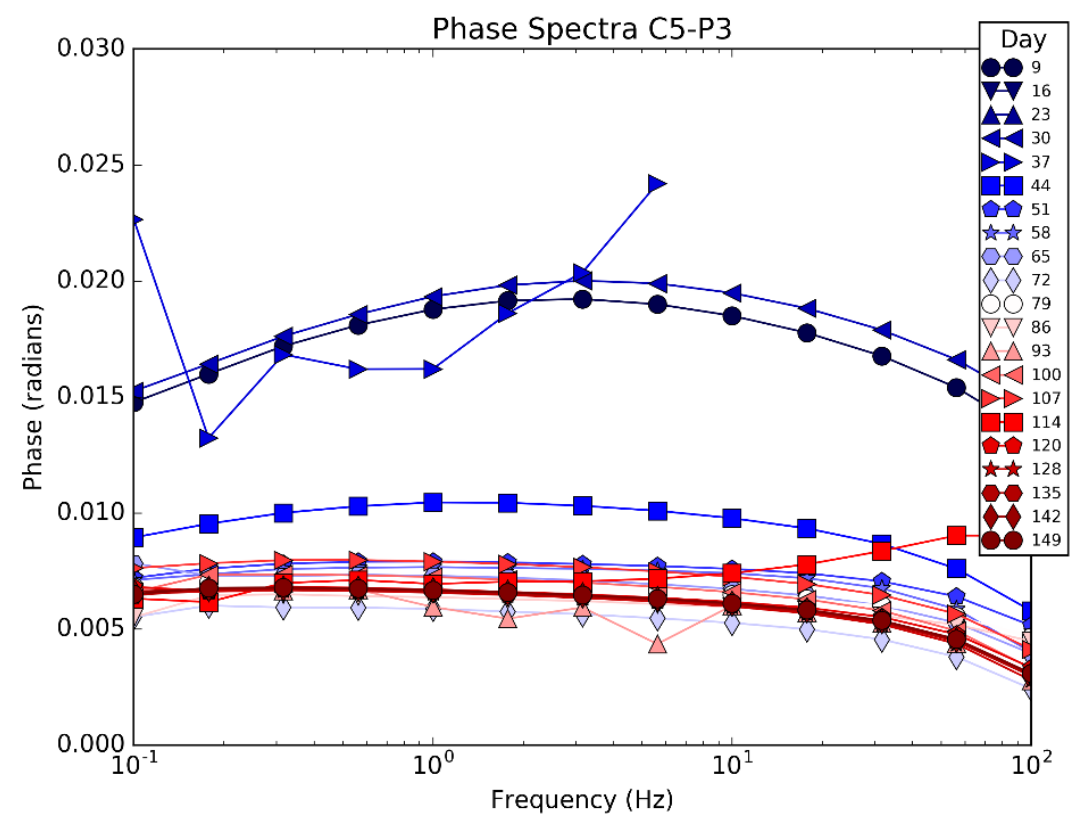

Figure 16 Phase Spectra for Column 5, Fall 2016, Port 3.

The real conductivity of Column 3 (Figure 17) shows an increase first observed on Day 37 of the experiment. The spectrum maintains a shape similar to that of columns 1 and 2 with conductivity correlating positively to frequency. A maximum is observed on Day 86 while it seems to equilibrate by Day 149. On Day 149 the conductivity was 0.038 $\mathrm{S} / \mathrm{m}$ at $0.1 \mathrm{~Hz}$ and $0.039 \mathrm{~S} / \mathrm{m}$ at $100 \mathrm{~Hz}$.

Column 5 (Figure 18) seems to show 2 events of conductivity increasing. The first is observed starting on Day 37 while the second seems to occur between Day 58 and Day 79 (the max observed conductivity). Days 65 and 72 are not shown due to erroneous data. There also seems to be variation among the different ports in this case (Figure B. 5) with ports 1 and 2 not showing the two jumps or the maximum at Day 79. 


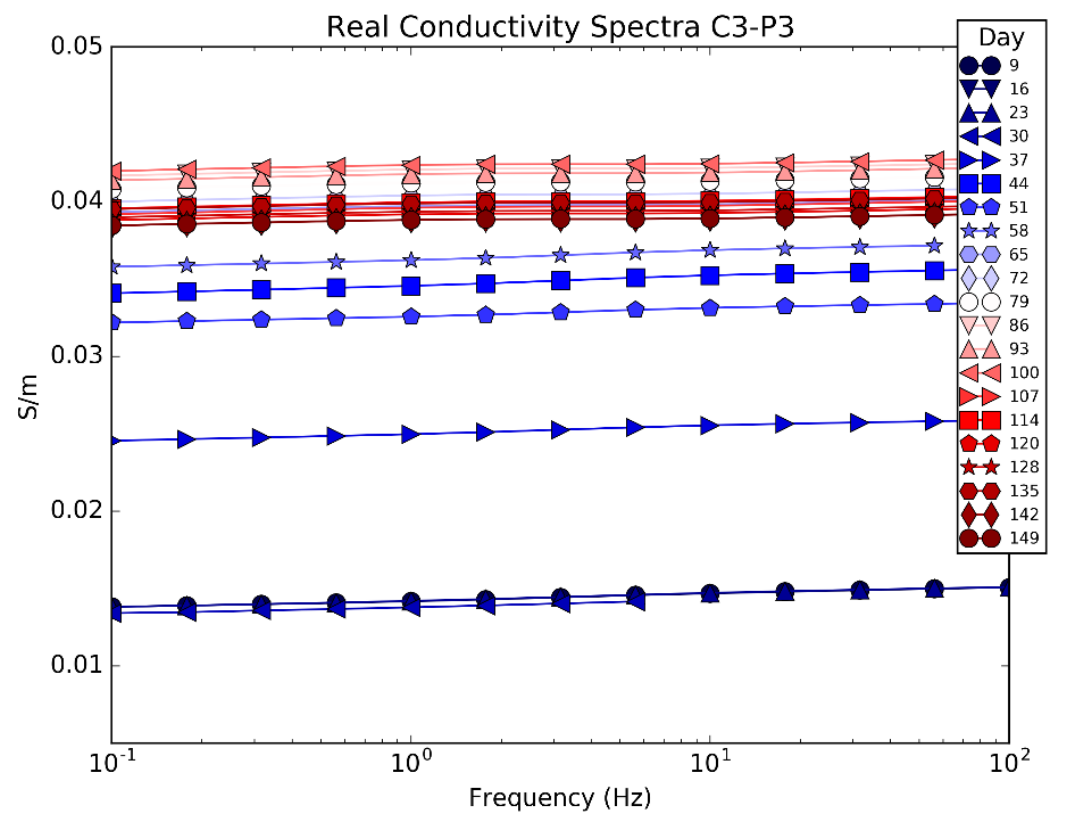

Figure 17 Real Conductivity for Columns 3, Fall 2016, Port 3. 


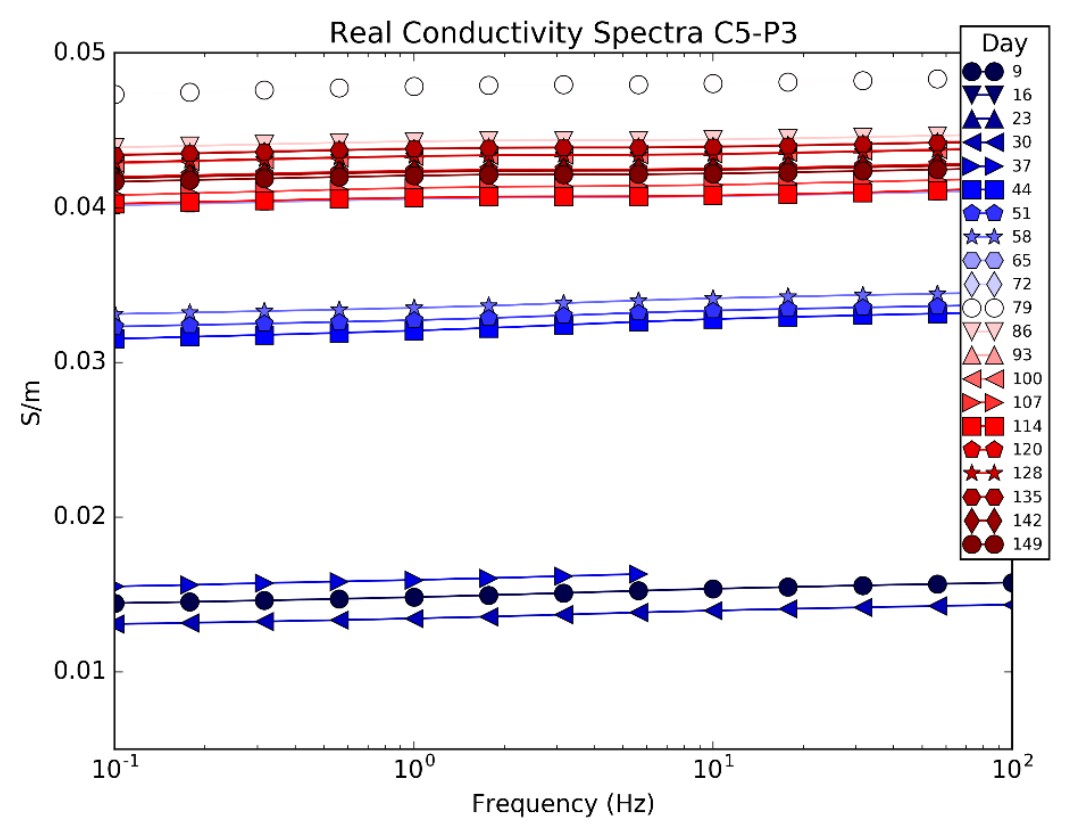

Figure 18 Real Conductivity for Column 5, Fall 2016, Port 3.

Column 3 ports 1 and 2 (Figure B. 8) show significant increases in the imaginary conductivity between $0.1 \mathrm{~Hz}$ and $1.77 \mathrm{~Hz}$. Especially at $0.1 \mathrm{~Hz}$ in Port 1, we see an increase from 1.86E-4 S/m (Day 9) to a maximum of 2.94E-4 S/m (Day 100) then to apparent equilibrium at 2.63E-4 S/m (Day 149). A similar change is seen in Port 2. In Port 3 the changes are more subdued (Figure 19). For all ports we see a change in the shape of the phase spectra with the apparent peak shifting towards $0.1 \mathrm{~Hz}$.

Column 5 shows changes similar to Column 3 with the magnitude of the change being greatest in ports 1 and 2 (Figure B. 8). Port 3 (Figure 20) shows less change than 1 and 2 in regards to the magnitude of the difference. The change in the peak is also effectively identical to Column 3. 


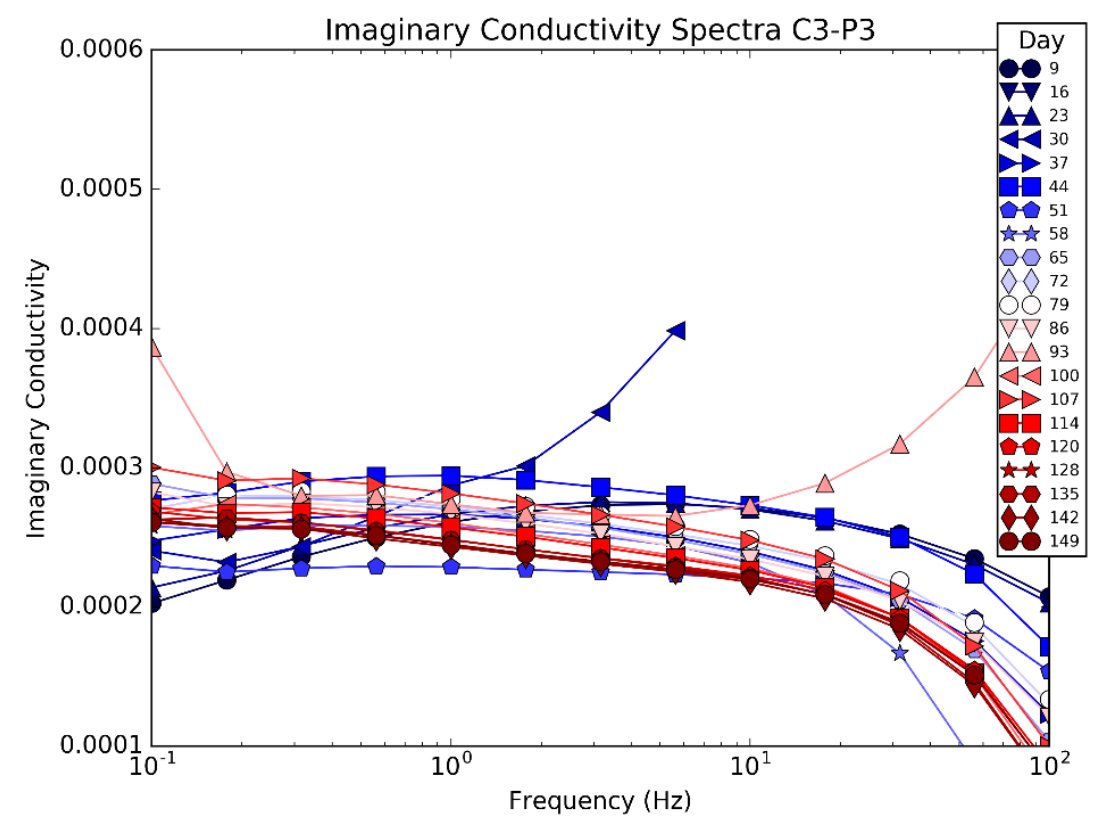

Figure 19 Imaginary Conductivity for Columns 3, Fall 2016, Port 3 


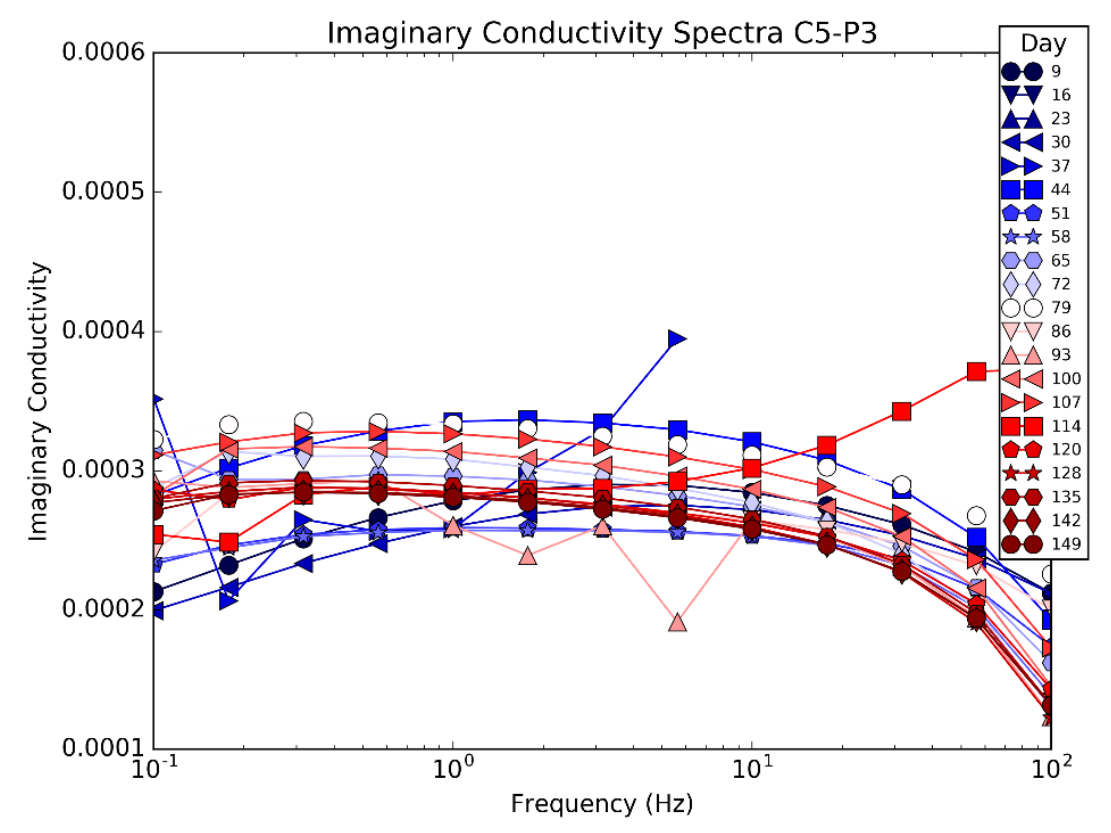

Figure 20 Imaginary Conductivity for Column 5, Fall 2016, Port 3.

Column 4 (Figure 21) shows a sudden decrease in the phase starting on Day 37 however on Day 44 the phase shows an increase which is followed by a steady decline until equilibrium first observed on Day 120. On Day 44 we also see a shift in the shape of the spectrum. As with columns 3 and 5, the spectra for Column 4 slowly becomes flatter over time until equilibrium.

The phase measured for Column 6 (Figure 22) displays the same sudden decrease on Day 37. However, it lacks the reversal seen in Column 4 with the phase values dropping until Day 107 where a minimum is observed. After this point, phase increases until it reaches equilibrium. 


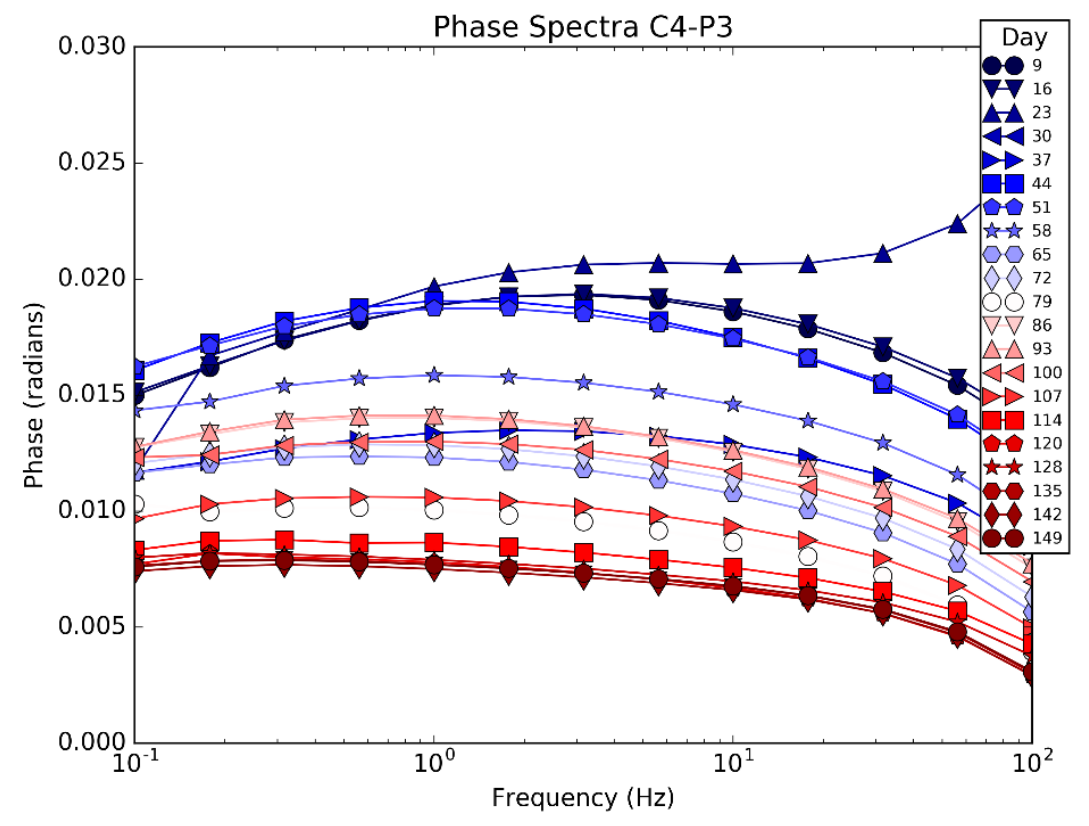

Figure 21 Phase spectra for Column 4, Fall 2016, Port 3 


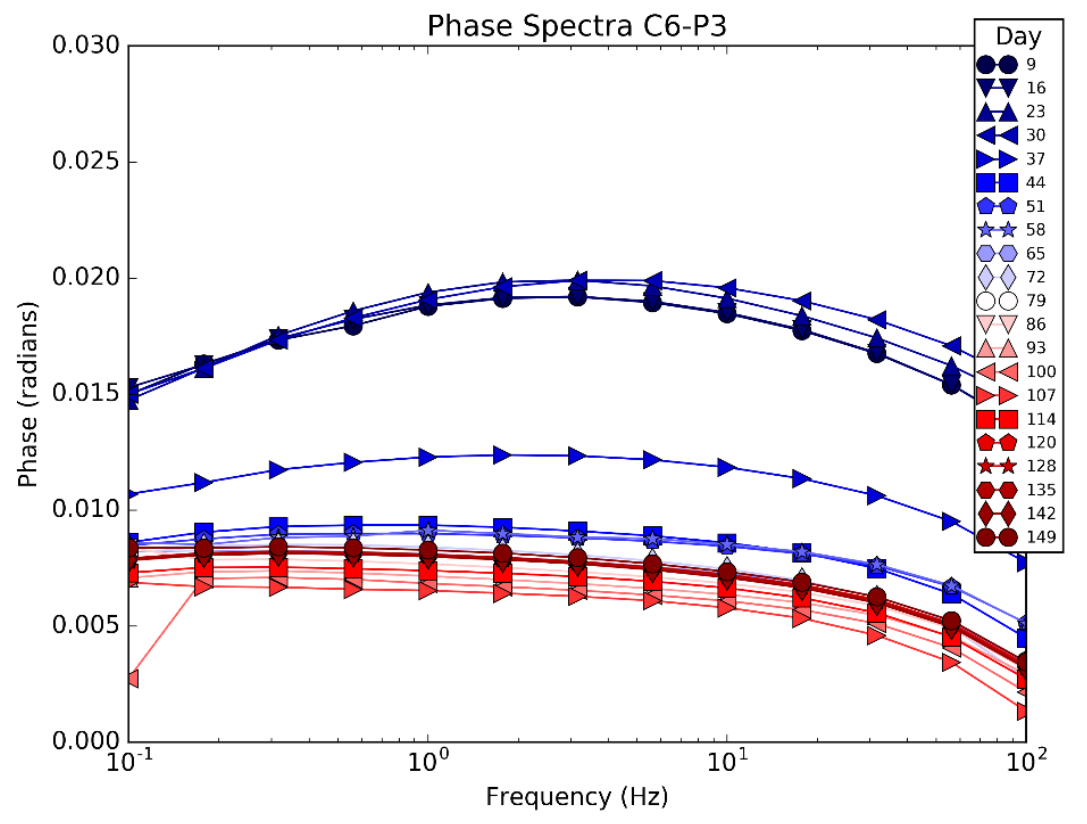

Figure 22 Phase Spectra for Column 6, Fall 2016, Port 3.

Both columns 4 (Figure 23) and 6 (Figure 24) see increases in the real component of the conductivity starting on Day 37. Column 6 shows a peak conductivity on Day 93 (0.045 S/m), afterwards conductivity lowers until equilibrium.

Column 4 shows an early peak on Day 65 followed by a short period of reducing conductivity (ending on Day 100) which is then followed by a sudden increase ending on Day $135(\sim 0.045 \mathrm{~S} / \mathrm{m})$. It may be possible that this column did not reach an equilibrium state as evidenced by the continual decrease following Day 135. 


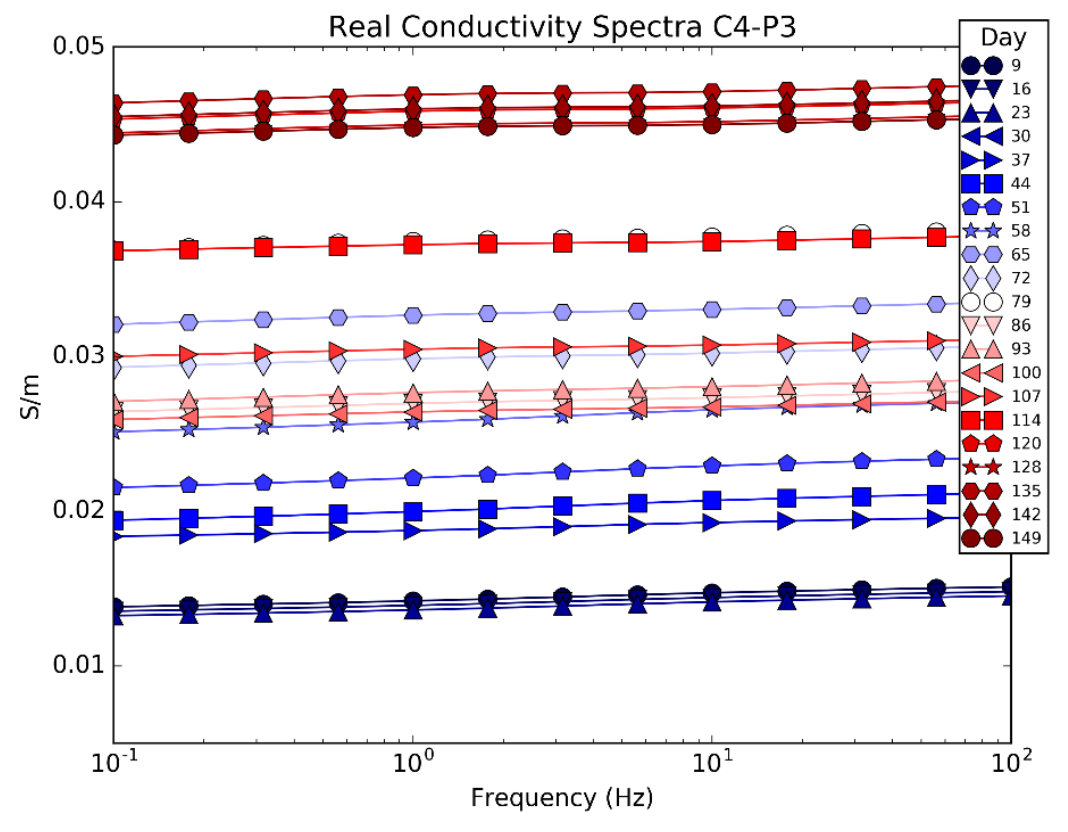

Figure 23 Real Conductivity for Column 4, Fall 2016, Port 3. 


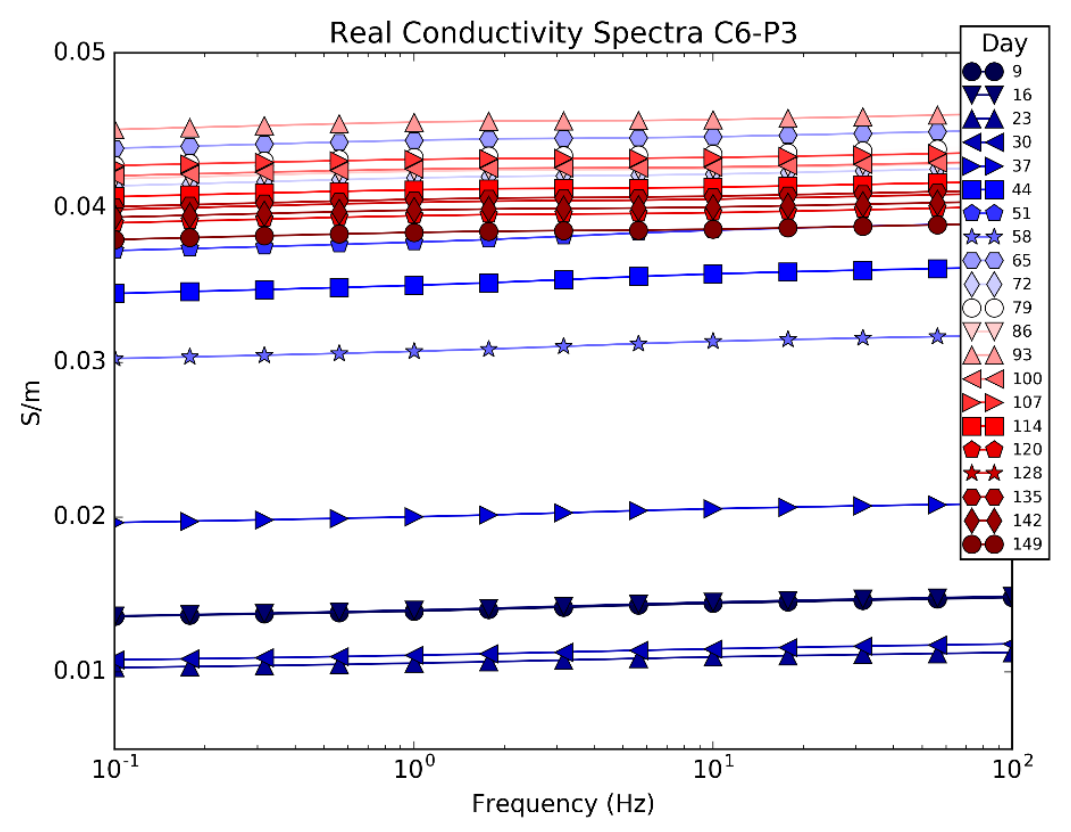

Figure 24 Real Conductivity for Column 6, Fall 2016, Port 3.

Column 4 (Figure 25) initially shows an increase in the imaginary conductivity similar to that seen in column 2 . The imaginary conductivity shows a maximum on Day $51(0.0004 \mathrm{~S} / \mathrm{m})$ after which we see an overall drop as well as a change in the shape of the observed spectra. The change in the spectra is similar to that seen in columns 3,5 , and 6.

While Column 6 (Figure 26) does show a decrease in the imaginary conductivity after Day 9, tied to a decrease in the conductivity magnitude, after Day 37 the imaginary conductivity quickly increases resulting in a peak on Day 65. There is then a minimum observed on Day 107 which is followed by a small increase which ends by reaching equilibrium (Day 149). The change in the shape of the phase spectra is similar to that seen in columns 3,4 , and 5 . 


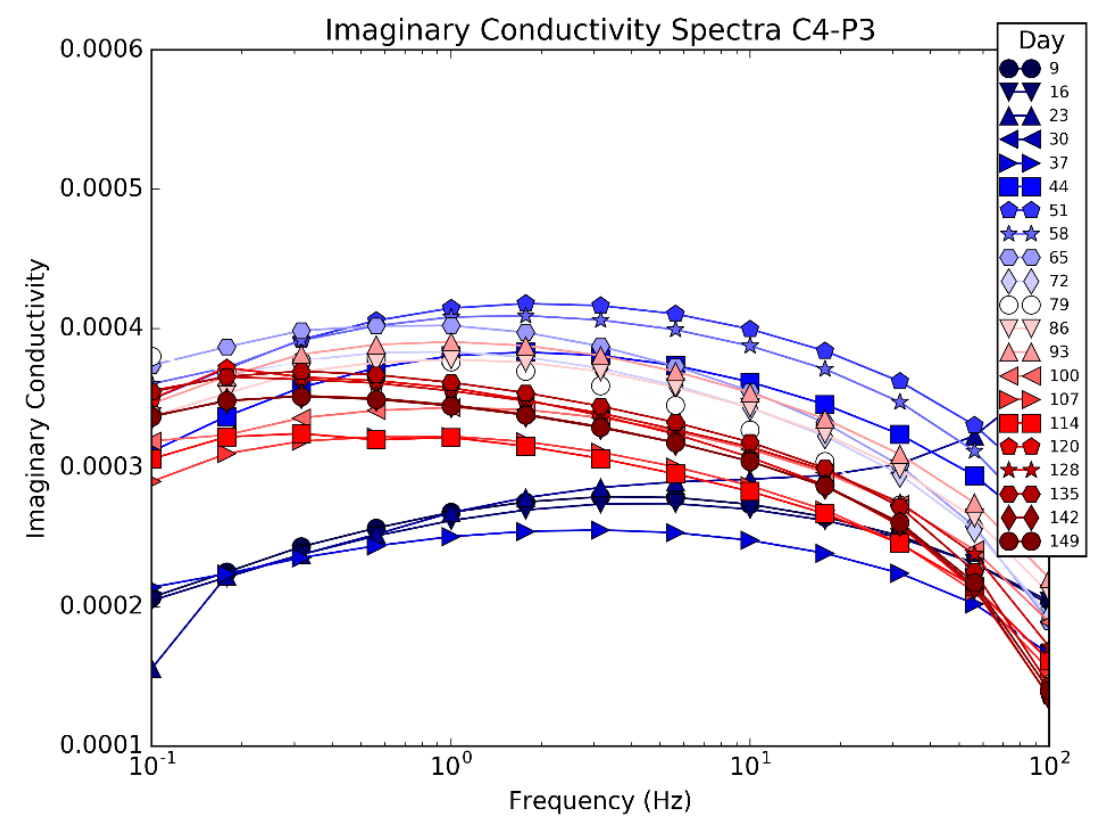

Figure 25 Imaginary Conductivity for Column 4, Fall 2016, Port 3. 


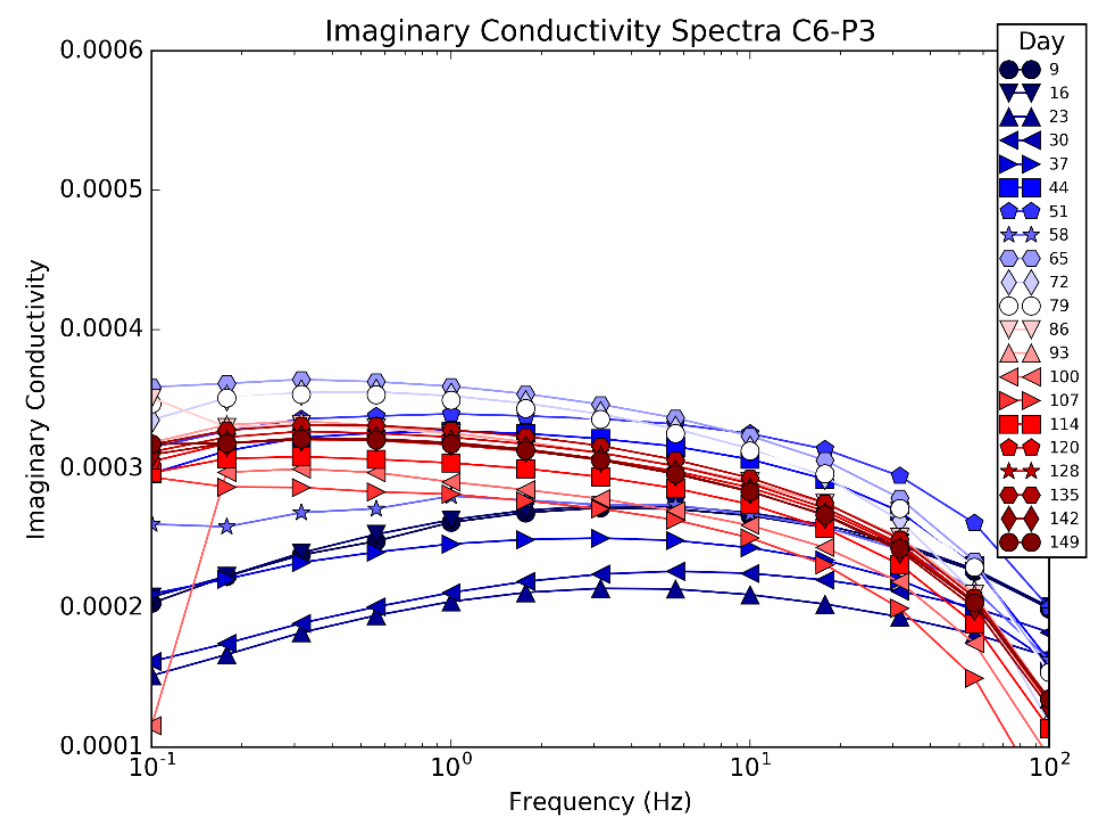

Figure 26 Imaginary Conductivity for Column 6, Fall 2016, Port 3.

\section{Fall 2016 Porewater Composition Results}

Uranium concentrations for control columns (Figure 27) show that column 1 (no bicarbonate) displays some variation in Uranium concentrations; however, concentrations in this column generally stay below $1 \mathrm{mg} / \mathrm{L}$.

Column 2 on the other hand shows a sudden increase following Day 33, due to a combination of measurement error and missing samples Port 3 does not properly capture the peak in $\mathrm{U}$ concentrations, Port 2 data on the other hand is more complete and shows a peak starting after Day 33 where U concentrations rise as high as $8.69 \mathrm{mg} / \mathrm{L}$. (Figure B. 10). Afterwards $\mathrm{U}$ concentrations stabilize at around $3.8 \mathrm{mg} / \mathrm{L}$ for both ports 2 and 3 .

Both columns show low amounts of dissolved iron, generally below $2 \mathrm{mg} / \mathrm{L}$ (Figure 27). 


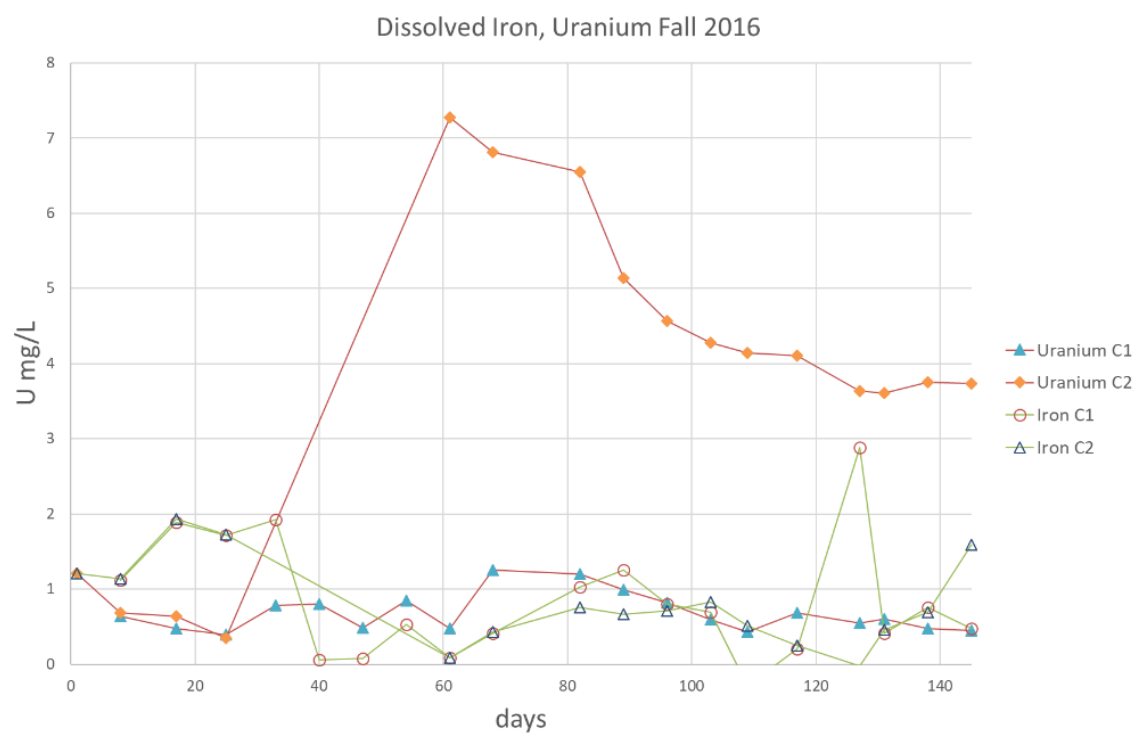

Figure 27 Dissolved Iron and Uranium for Columns 1 and 2, Fall 2016, Port 3.

Microbial columns all show sudden increases in Uranium concentrations (Figure 28) a few days after the pumping of glucose began (Day 33). Columns 3, 4, and 5 show two peaks in Uranium concentrations. The first peak is at the start due to the pumping of glucose while the second peak seems to occur when iron concentrations begin to increase, after this event $U$ concentrations trend towards zero. Column 6 does not display the second peak and instead reaches close to zero U concentration starting Day 96.

All microbial columns apart from Column 4 begin to show significant increases in Iron concentrations (Figure 28) starting on Day 60. Column 4 begins to see this occur on Day 131. We can see that columns 3 and 5 peak at $92 \mathrm{mg} / \mathrm{L}$ and $91 \mathrm{mg} / \mathrm{L}$ respectively. Column 5 peaks at $55 \mathrm{mg} / \mathrm{L}$ and Column 4 peaks at $18 \mathrm{mg} / \mathrm{L}$. It is clear however that these concentrations likely could have gone higher if the experiment continued. 


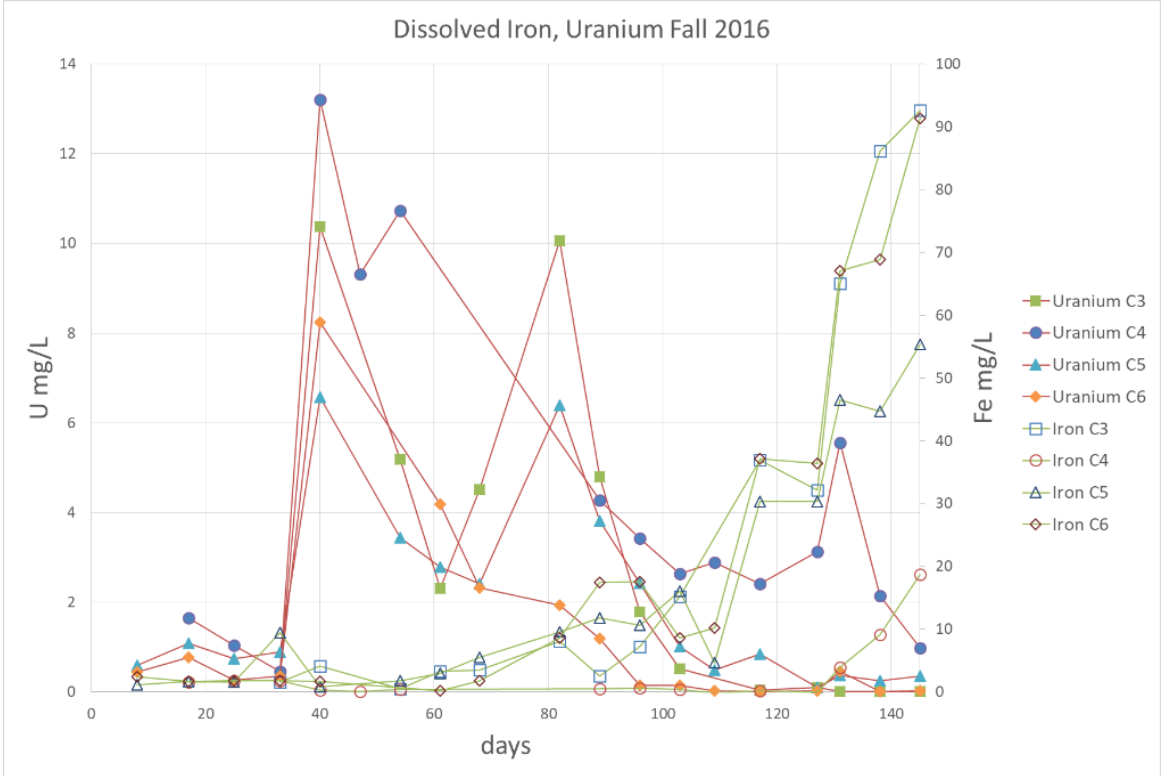

Figure 28 Dissolved Iron and Uranium for Columns 3,4,5, and 6, Fall 2016, Port 3. $\mathrm{pH}$ for columns 3,4,5, and 6 (Figure 29) tends to remain between 7.5 and 8 although towards the end of the experiment a downward trend is observed; this may however be instrumentation error. Columns 3 and 5 show a drop in $\mathrm{pH}$ between Day 40 and 60 . 


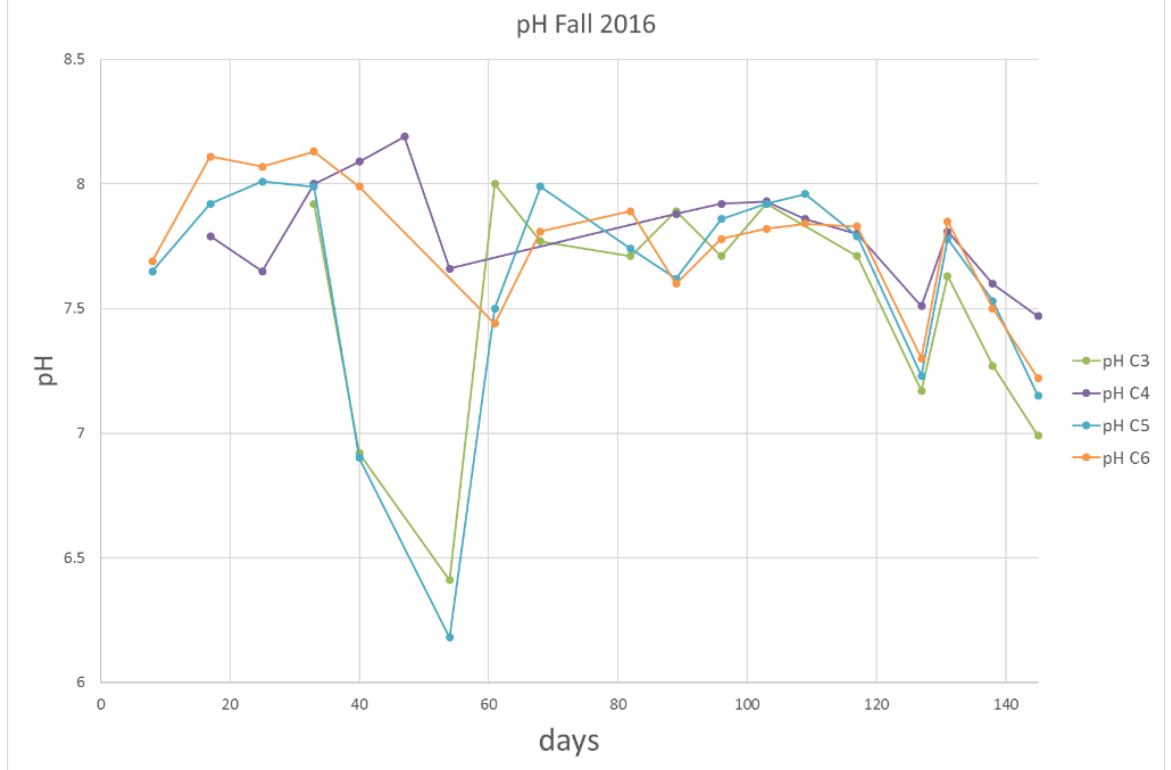

Figure 29 pH for Columns 3,4,5, and 6, Fall 2016, Port 3.

Calcium (Figure 30) concentrations show significant increases after glucose pumping going from slightly below $50 \mathrm{mg} / \mathrm{L}$ to between 200 and $250 \mathrm{mg} / \mathrm{L}$ after Day 33 . A drop is seen in all microbial columns between days 100 and 130 although the magnitude of the drop is not the same for all. Columns 4 and 6 have lower $\mathrm{Ca}$ concentrations on average than 3 or 5 .

Since Magnesium (Figure 31) is chemically similar to Calcium it often substitutes for in it in the structure of calcite and other carbonates (Stanienda, 2016). 


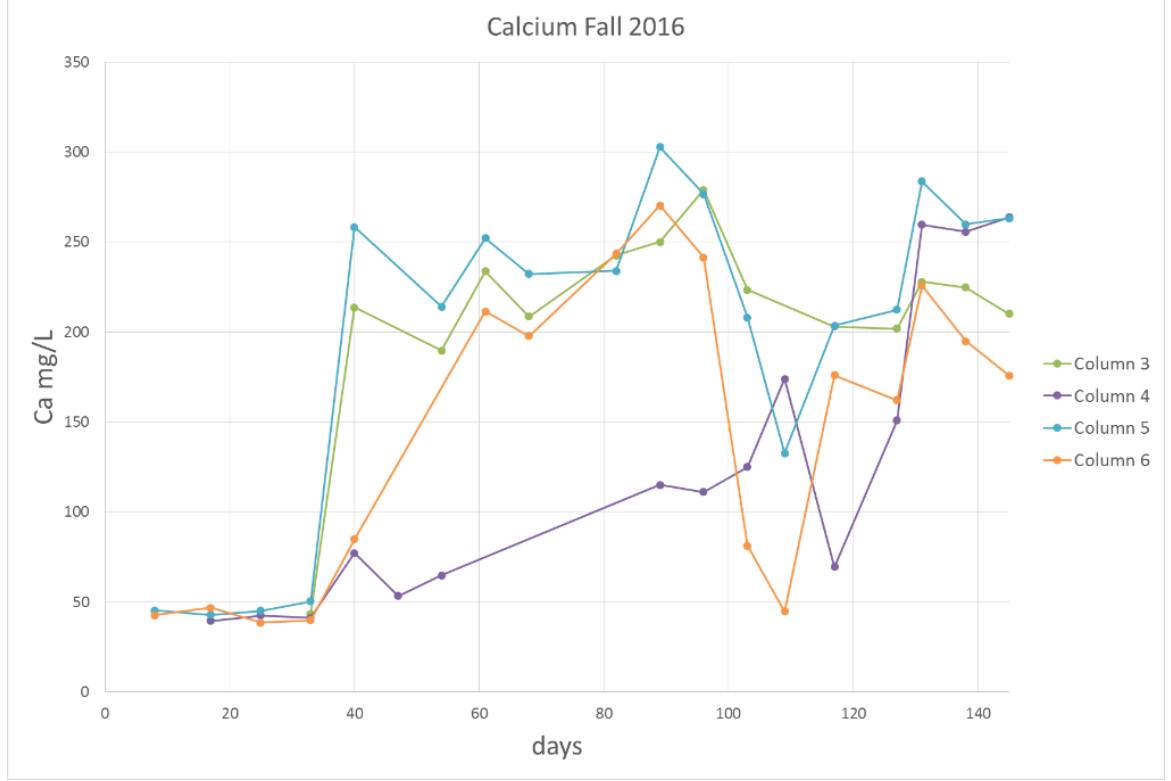

Figure 30 Calcium Concentrations for Columns 3,4,5, and 6, Fall 2016, Port 3.

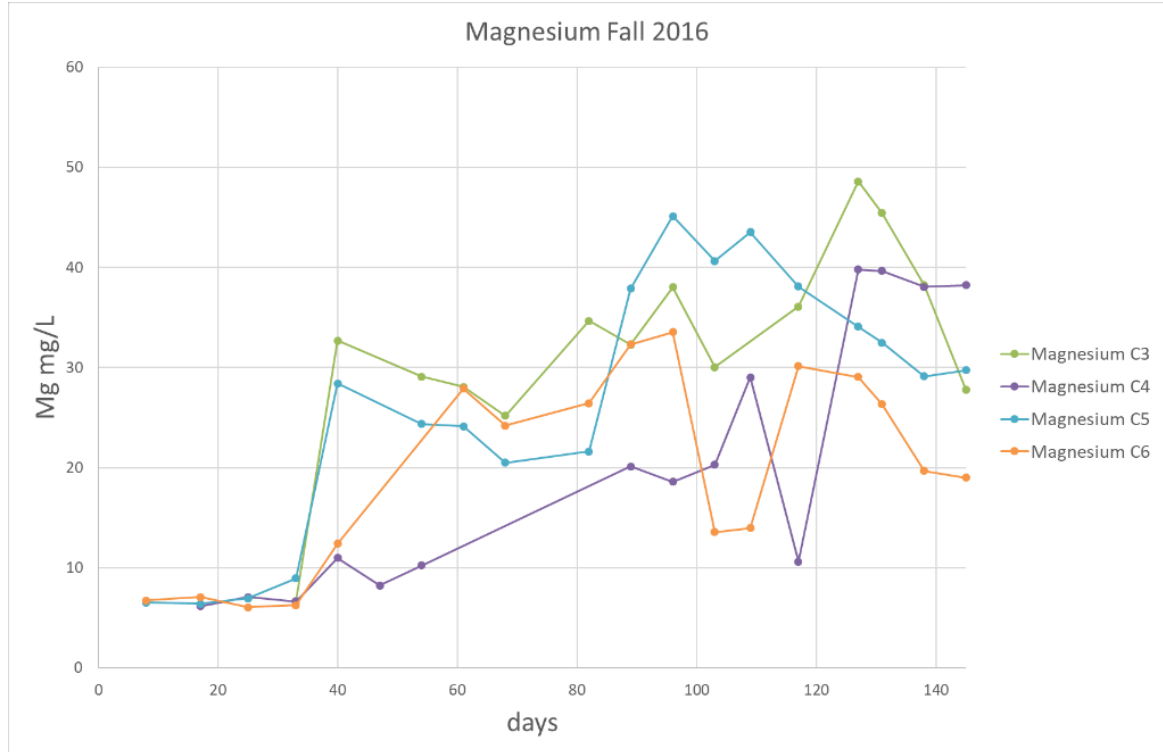

Figure 31 Magnesium Concentrations for Columns 3,4,5, and 6, Fall 2016, Port 3. 
Porewater conductivity (Figure 32) shows increases in columns 3,4,5, and 6 and is directly tied to increases in the real conductivity measured through SIP. Once again Column 4 seems to show retardation in comparison to the other columns. The shape of the plots for conductivity is similar to that of $\mathrm{Ca}$ and $\mathrm{Mg}$ which may indicate that these ions have a strong contribution to the conductivity.

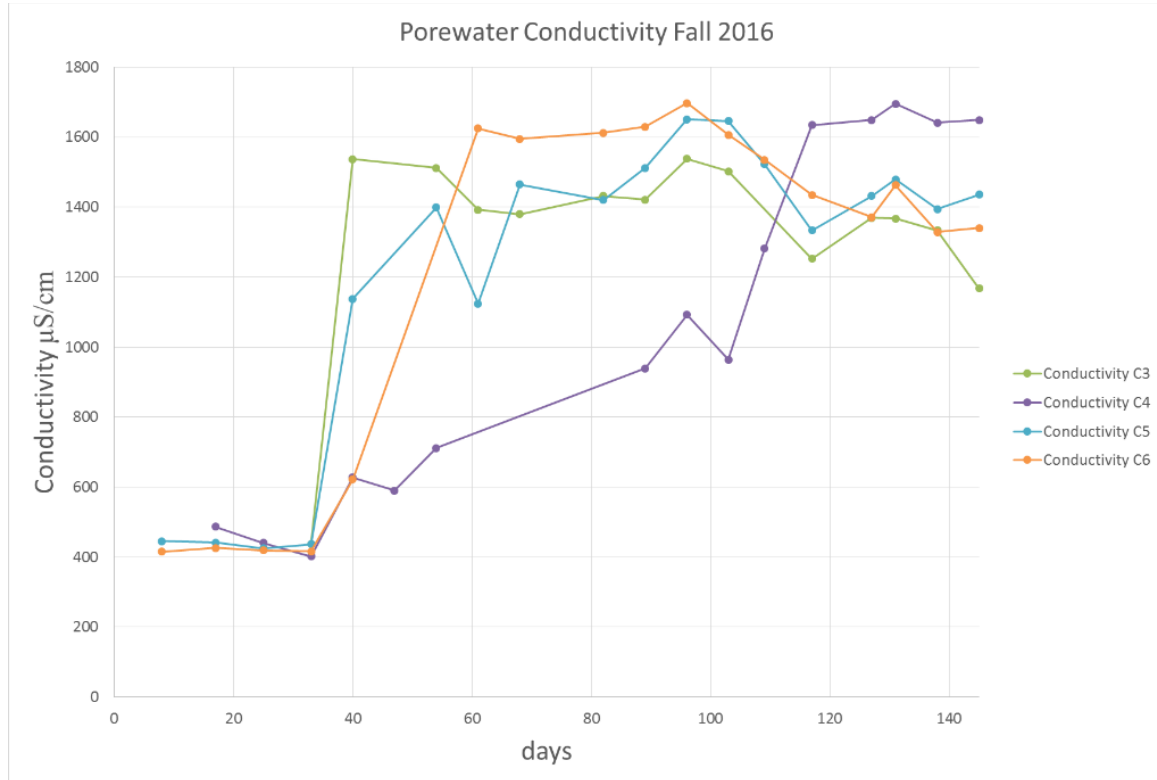

Figure 32 Porewater Conductivity for Columns 3,4,5, and 6, Fall 2016, Port 3. Spring 2017 SIP Results

Both Column 1 (Figure 33) and 2 (Figure 34) maintained the same phase that was measured at the end of Fall 2016 experiments. After inoculation (Day 9) both Column 1 and 2 show a significant decrease in the phase similar to that seen for columns $3,4,5$, and 6 during Fall 2016. We also see the loss of any apparent peak in the phase spectra between 0.1 and $100 \mathrm{~Hz}$. 


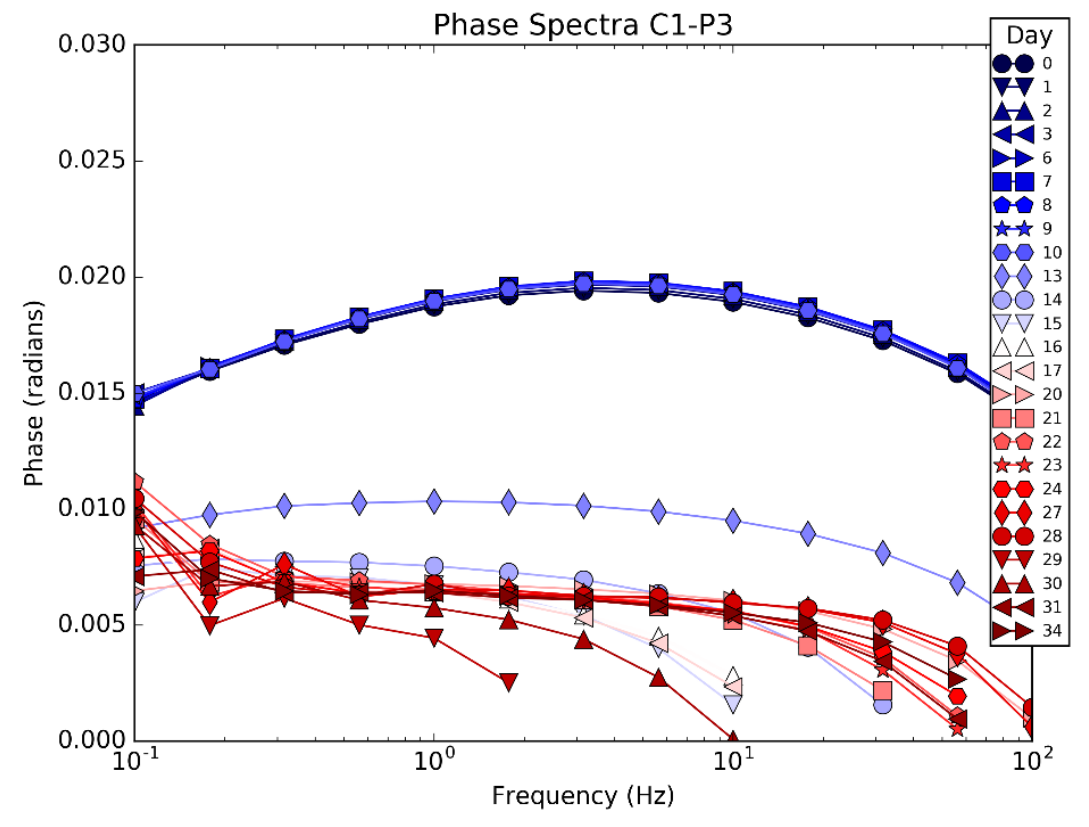

Figure 33 Phase spectra for Column 1, Spring 2017, Port 3 


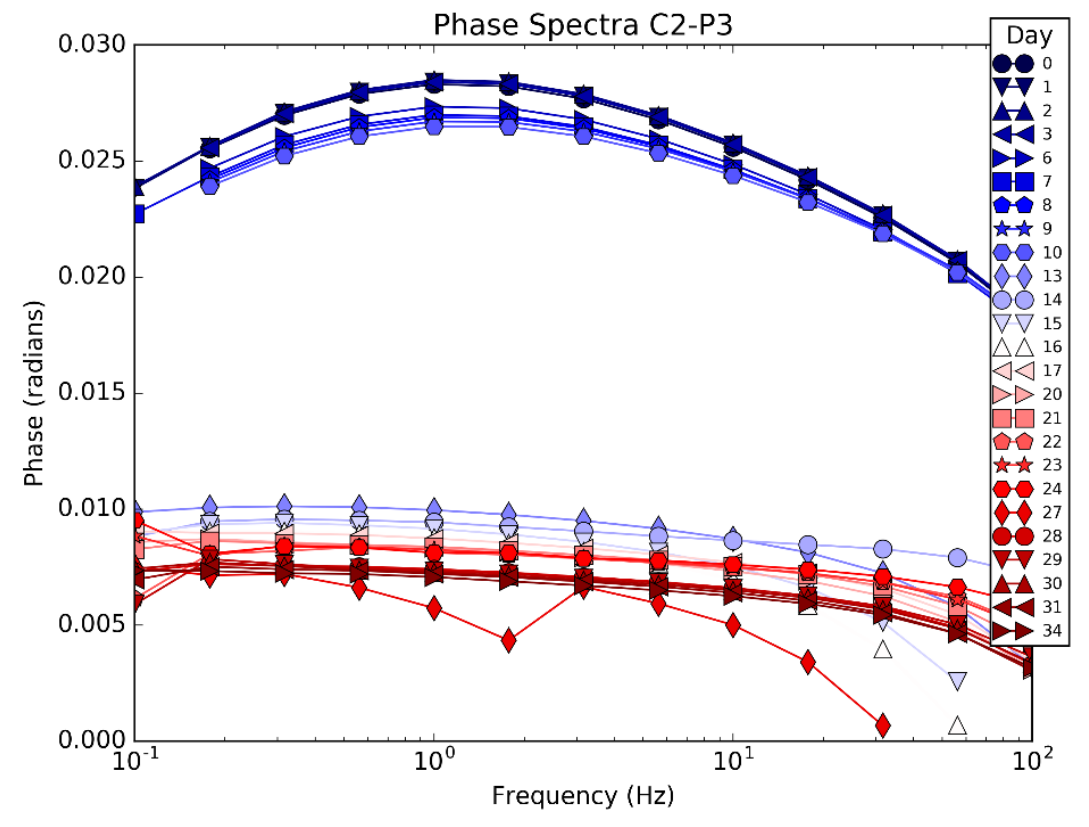

Figure 34 Phase Spectra for Column 2, Spring 2017, Port 3.

After inoculation and initiation of glucose pumping, columns 1 and 2 (Figures 35 and 36 respectively) show significant increases in the real conductivity. Interestingly enough, Column 2 experiences these changes starting at the top of the column opposite to where the solution is being pumped through (Figures A. 1 and A. 2). The changes in conductivity are comparable to those seen in the Fall 2016 experiment. 


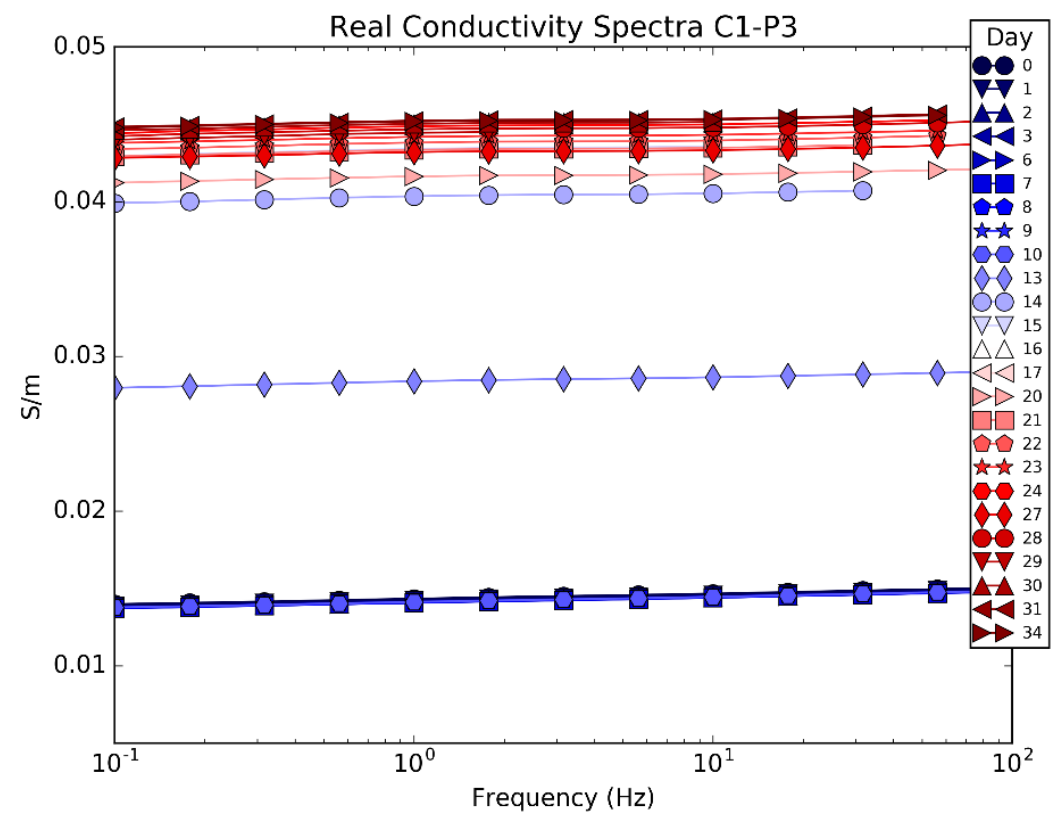

Figure 35 Real Conductivity for Column 1, Spring 2017, Port 3. 


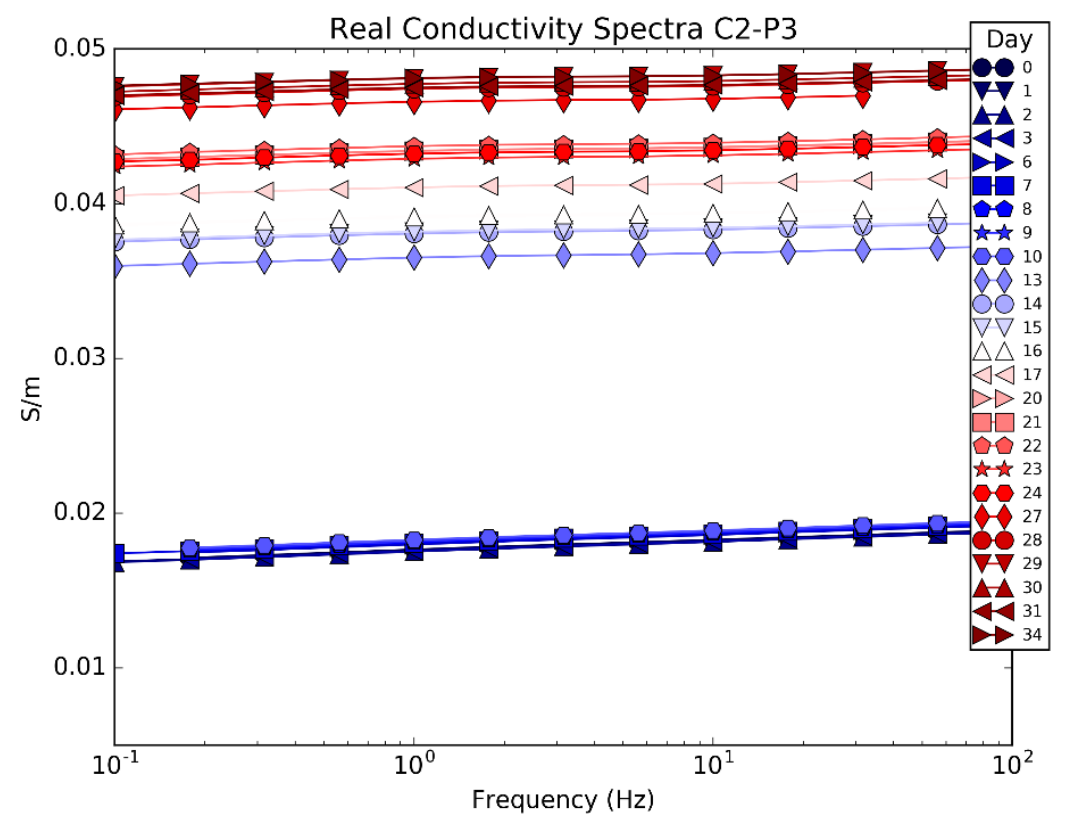

Figure 36 Real Conductivity for Column 2, Spring 2017, Port 3.

Due to the large amount of error present in the phase data for Column 1, the imaginary conductivity (Figure 37), which is calculated from the conductivity magnitude and phase, is also noisy. We can, however, see an increase at low frequencies similar to that seen in microbial columns during Fall 2016 as well as the same change in shape.

Column 2 (Figure 38) on the other hand shows a significant decrease in the imaginary conductivity through the frequency range displayed and a loss in any discernible peak. 


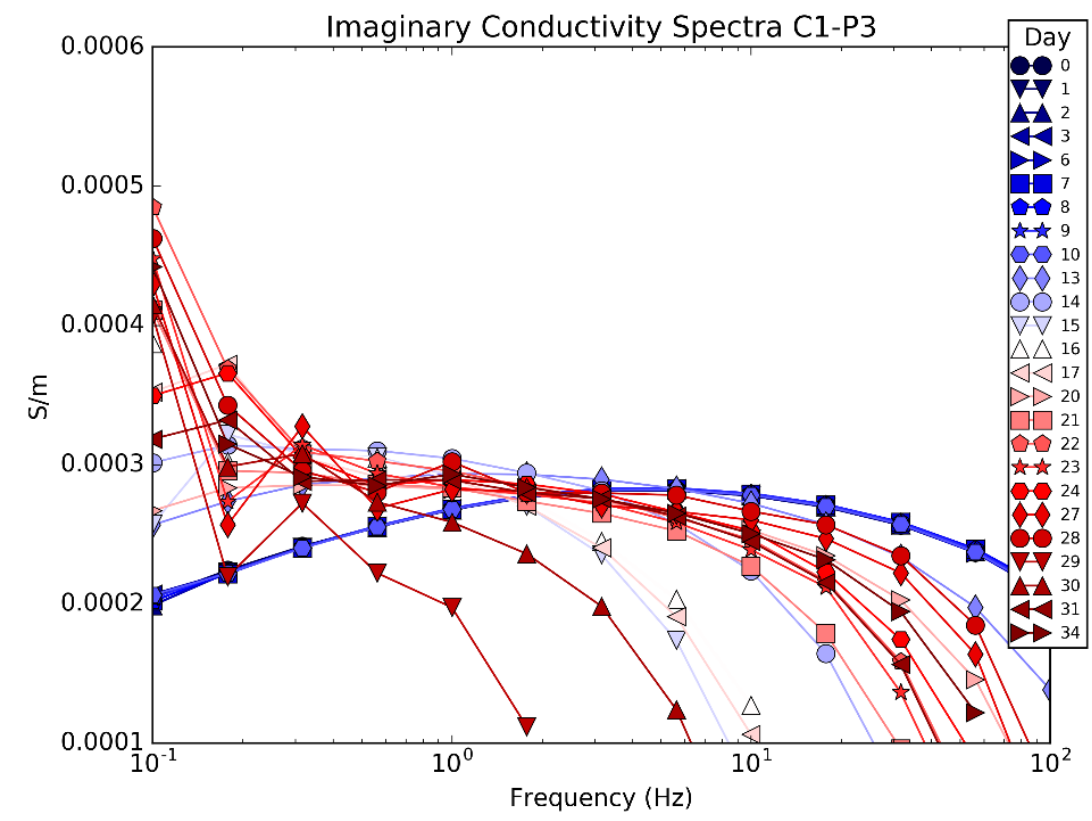

Figure 37 Imaginary Conductivity for Column 1, Spring 2017, Port 3. 


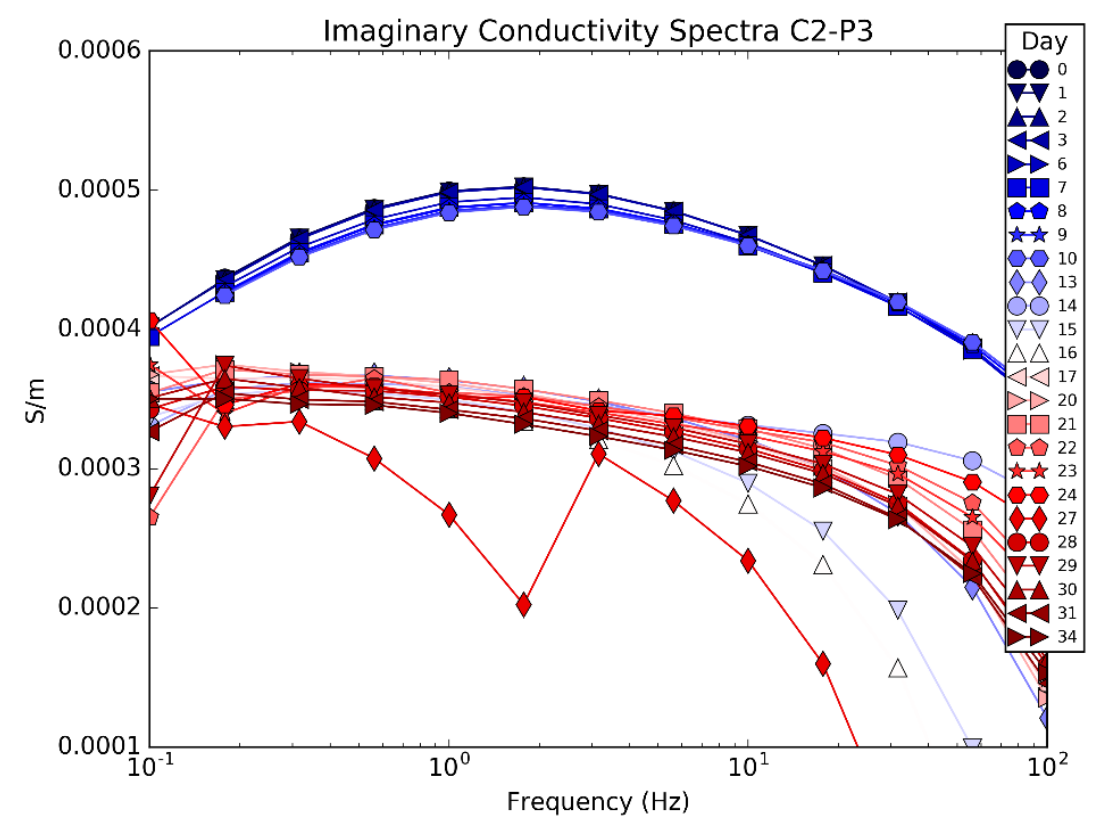

Figure 38 Imaginary Conductivity for Column 2, Spring 2017, Port 3.

Spring 2017 Porewater Composition Results

Uranium concentrations in Column 1 (Figure 39) increase quickly after inoculation (Day 9) then decrease over time similar to columns 3,4,5, and 6 during Fall 2016. Although Uranium concentrations do not reach zero, it is safe to assume based on prior results that given added time it would. There seems to be a second peak which seems to occur at the same time (Day 24) as the increase in iron similar to that observed in columns 3,4, and 5. A measurement error caused the data from Day 7 to be missing however it can be seen in port 2 (Figure A. 5).

Column 2 (Figure 39) maintains Uranium concentrations from the end of Fall 2016 experiments then seems to trend downwards until Day 17. Afterwards we see a local peak on Day 24 which also may correlate with increasing iron concentrations. After this peak concentrations seem to trend downward. 


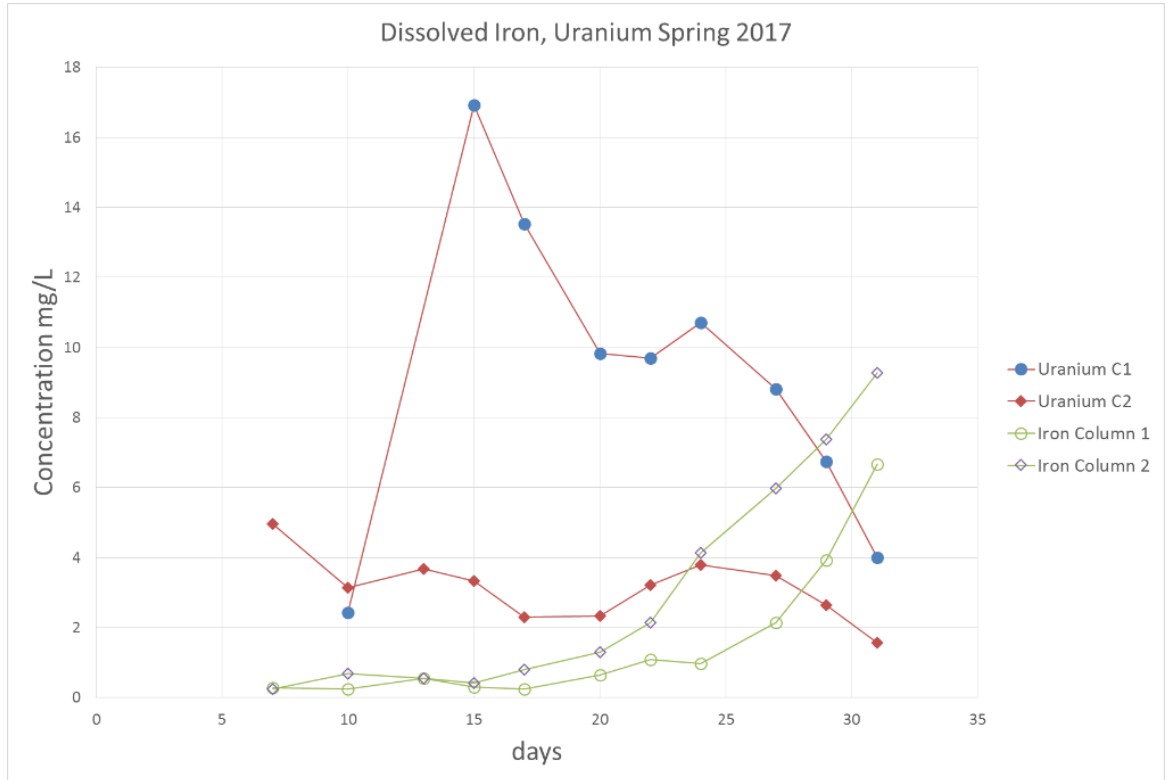

Figure 39 Dissolved Iron and Uranium for Columns 1 and 2, Spring 2017, Port 3.

Column 2 starts close to $\mathrm{pH} 8$ while Column 1 starts between 7.4 and 7.5 (figure 40). After inoculation, both seem to show similar $\mathrm{pH}$ with a downward trend being observed. Initial differences in $\mathrm{pH}$ are likely due to the $3 \mathrm{mM}$ bicarbonate in Column 2 acting as a weak base in solution and raising the $\mathrm{pH}$. 


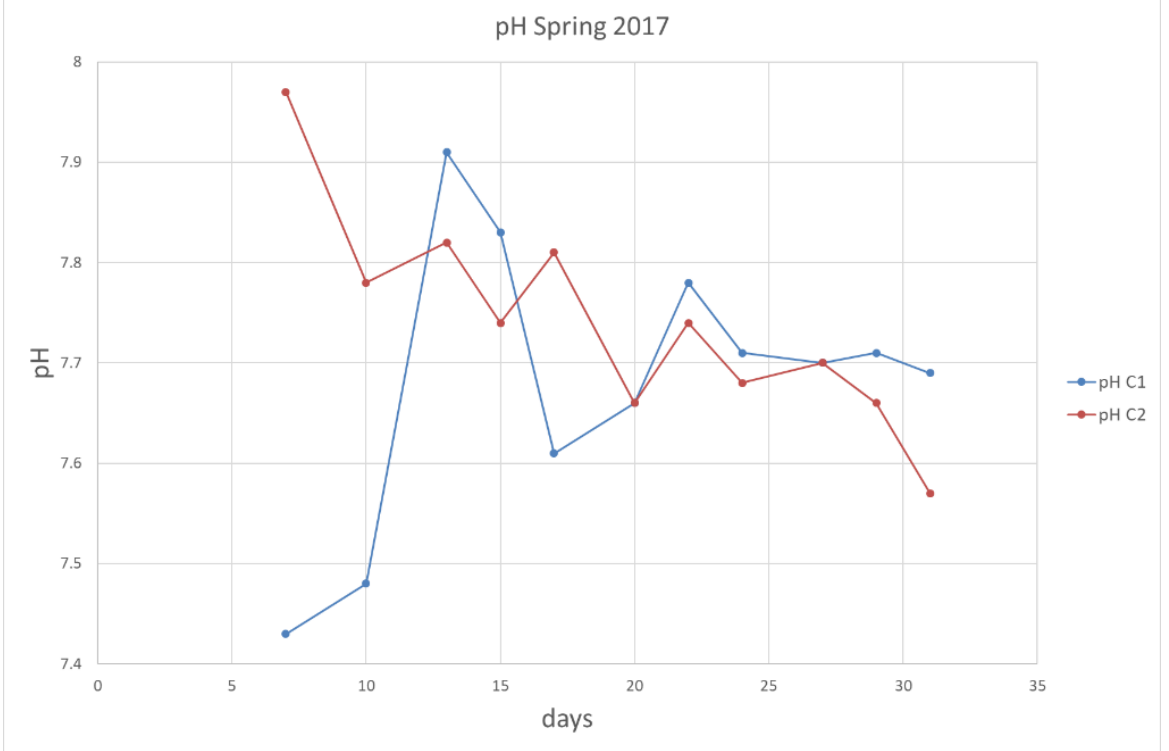

Figure 40 pH for Columns 1 and 2, Spring 2017, Port 3.

Both calcium and magnesium (Figures 41 and 42 respectively) show increases after inoculation on Day 9 for both columns. Column 2 however maintains significantly lower concentrations of either anion likely due to precipitation of $\mathrm{CaCO}_{3}$ or $\mathrm{MgCO}_{3}$.

Although Mg seems to show a positive trend after the initial spike (especially in Column 1), Ca seems to trend downward. 


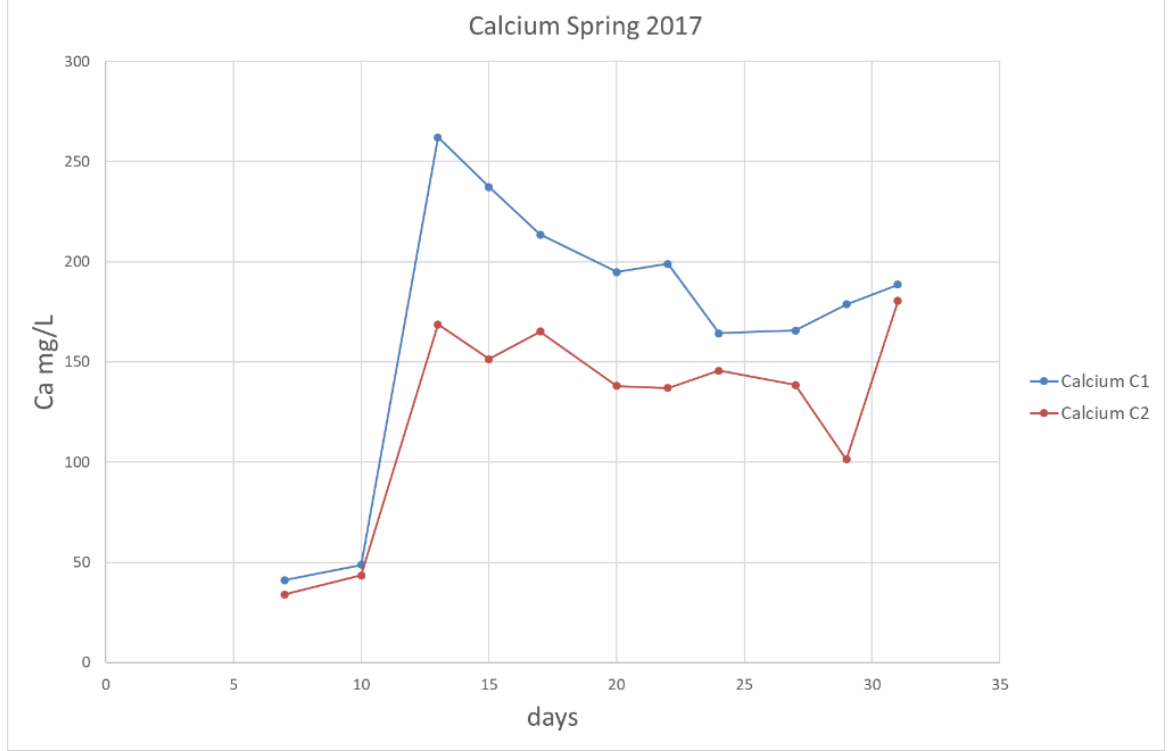

Figure 41 Calcium Concentrations for Columns 1 and 2, Spring 2017, Port 3.

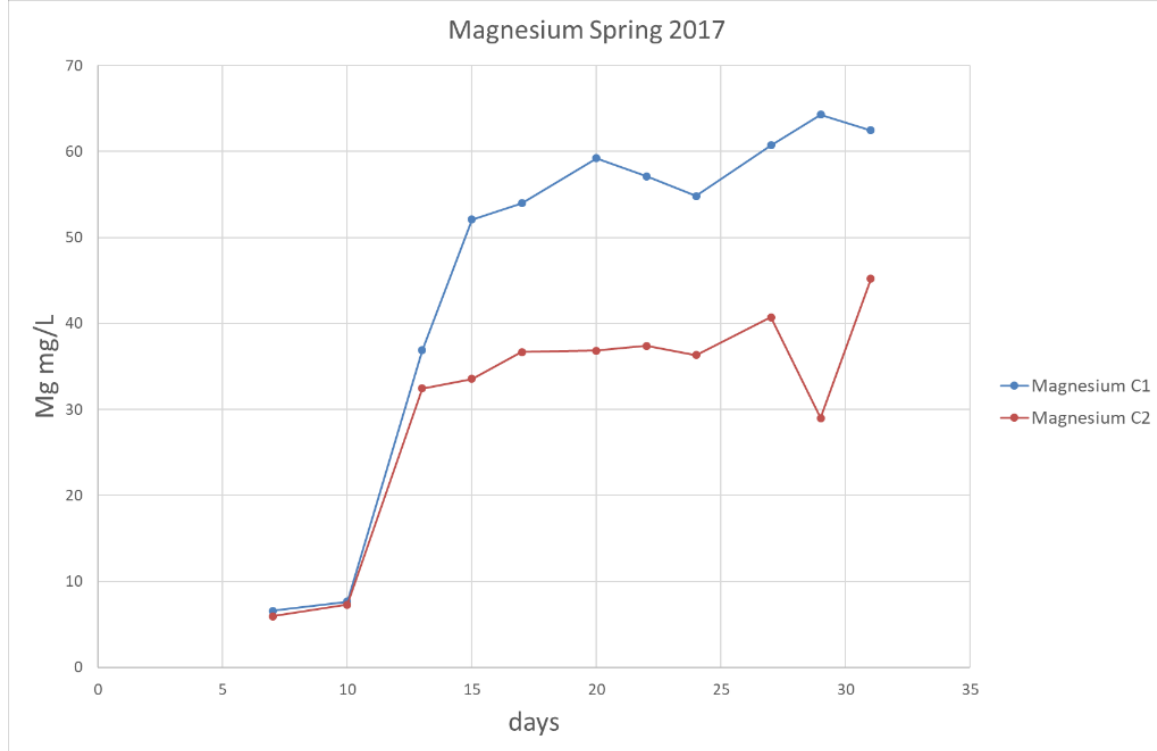

Figure 42 Magnesium Concentrations for Columns 1 and 2, Spring 2017, Port 3. 
Increases in porewater conductivity shown in Figure 43 are similar to those seen in Fall 2016. Increases are seen after inoculation on Day 9 of the experiment. Column 2 maintains a higher conductivity due to the added $3 \mathrm{mM}$ bicarbonate.

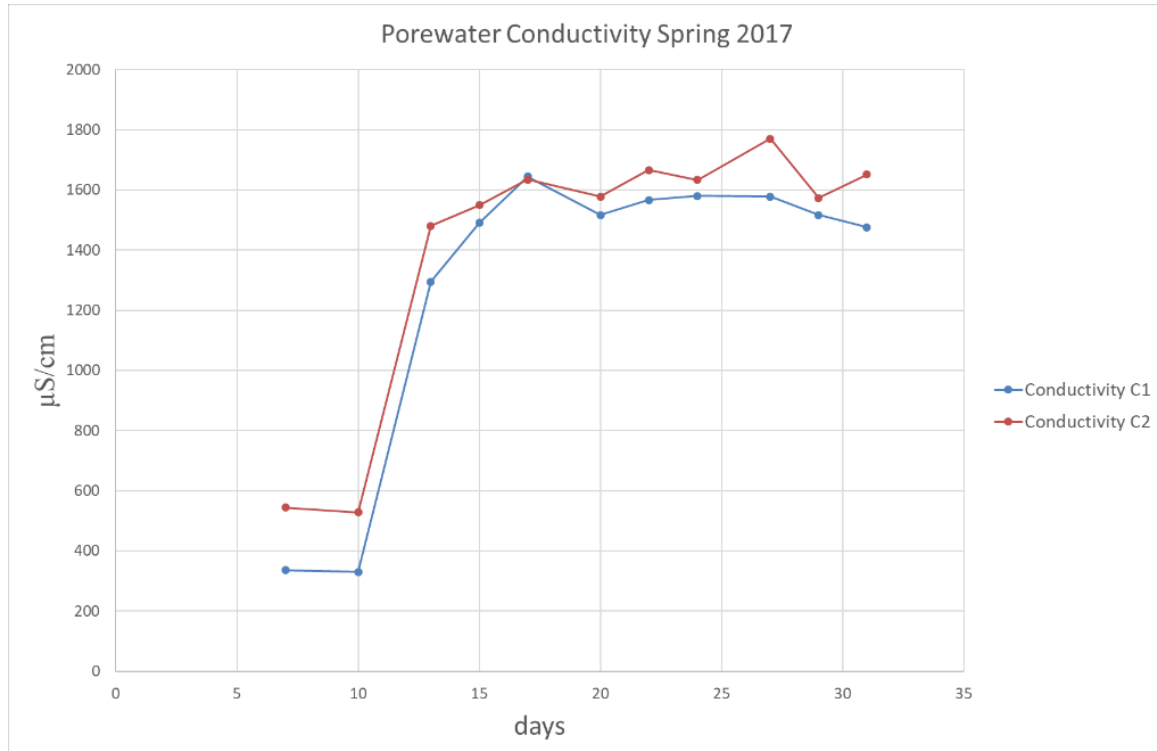

Figure 43 Porewater Conductivity for Columns 1 and 2, Spring 2017, Port 3. Spring 2018

Although these are only initial results, the Spring 2018 experiment manages to validate the soundness of prior measurements since these measurements of HFS match closely those obtained previously, even though this is a new column with a different design for the potential electrodes. SGW refers to pure simulated groundwater solution without sediment, tap water is local tap water, and SGW + HCO3 is the simulated groundwater solution with $3 \mathrm{mM}$ bicarbonate. HFS Aerobic and HFS Anaerobic refer to saturation of Hanford Fine Sand with SGW solution aerated with compressed air and 
sparged with nitrogen respectively. Heat-Deactivated Microbes were mixed with SGW solution for the final injection presented here.

Phase spectra (Figure 44) show little significant change when comparing heat deactivated microbes to the pure SGW solution. The equilibration of the SGW solution with the HFS sediment causes a small increase in the phase over time which can be seen by the difference between HFS Aerobic, HFS Anaerobic, and the Pre-Injection measurement which took place after. There is no difference in the observed phase between the Pre-Injection measurement and the measurement taken after the injection of heat-deactivated bacteria.

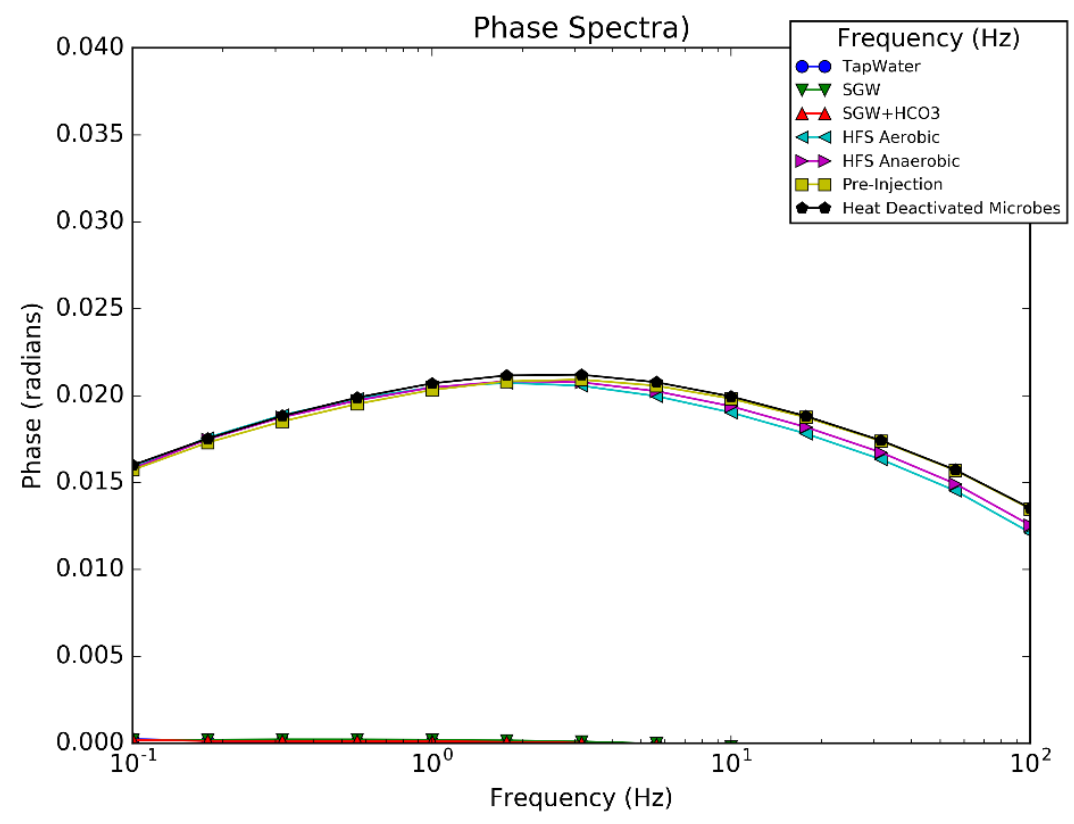

Figure 44 Phase spectra for Spring 2018 Column

Similar to the phase, there is a gradual decrease in conductivity (Figure 45) observed in the saturated sediment which can be attributed to the equilibration of the 
SGW solution with HFS. After injection of heat-deactivated microbes there is a small increase in $\sigma^{\prime}$.

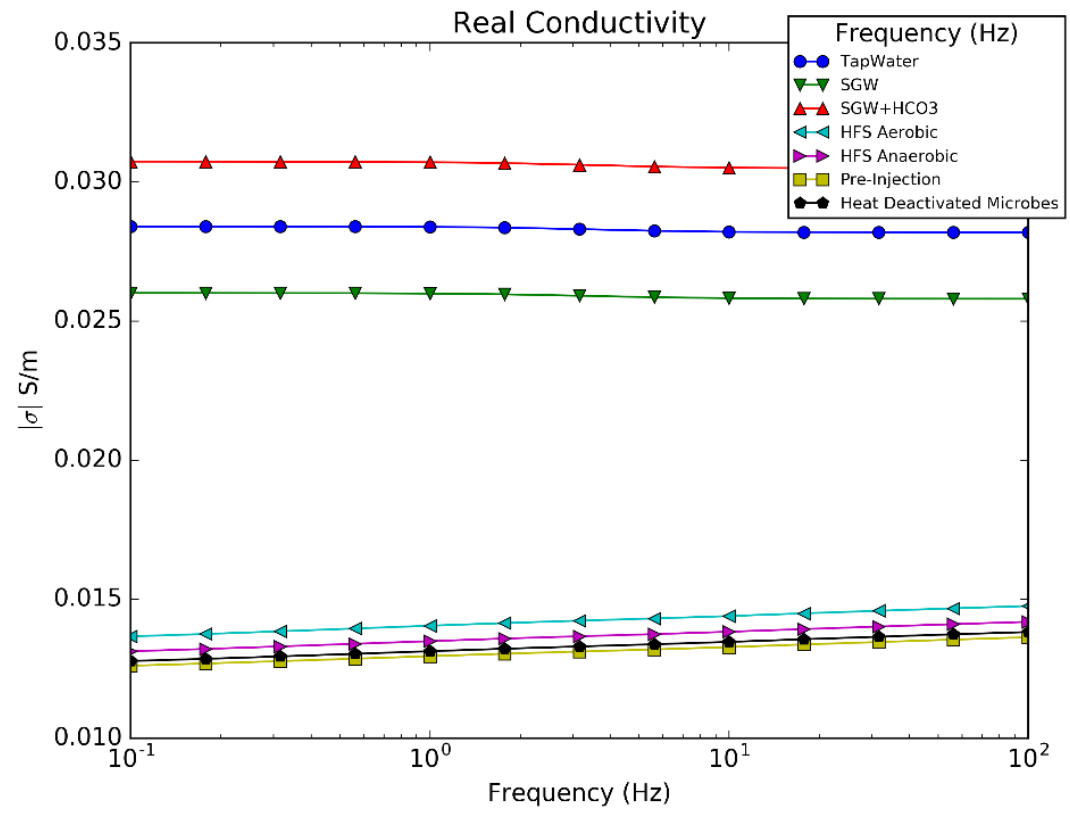

Figure 45 Real Conductivity Spring 2018 Column

There is a decrease observed over time in $\sigma^{\prime \prime}$ (Figure 46) as the SGW solution equilibrates with the sediment. After injection of heat-deactivated microbes there is an increase observed when compared to the pre-injection measurement. 


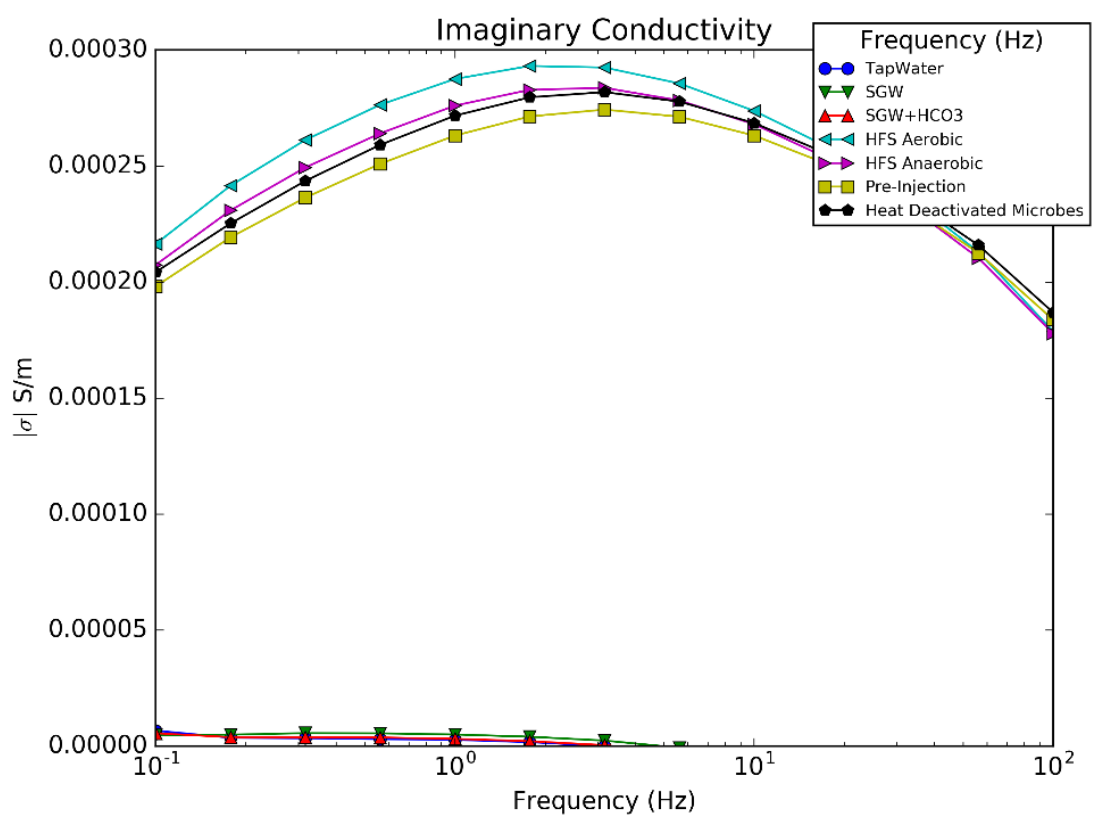

Figure 46 Imaginary Conductivity Spring 2018 Column

\section{DISCUSSION}

Here I discuss the results of the Fall 2016, Spring 2017, and Spring 2018

experiments. These experiments build off of each other and allow one to build a clearer picture of the changes occurring in the columns.

During initial Fall 2016 experiments columns 1 (no bicarbonate) and 2 (with $3 \mathrm{mM}$ bicarbonate) served as controls. Column 1 experienced little change in either $\varphi$ or $\sigma^{\prime}$ (Figures 9 and 11 respectively). Column 2 on the other hand saw significant increase in $\varphi$ and $\sigma^{\prime \prime}$ (Figures 10 and 14 respectively) as well as a small increase in $\sigma^{\prime}$ (Figure 12). Observations of Column 2 noted the formation of a white precipitate which is likely calcite $\left(\mathrm{CaCO}_{3}\right)$ due to the presence of ionic $\mathrm{Ca}^{2+}$ and $\mathrm{CO}_{3}{ }^{2-}$ in solution. The precipitate was not observed in Column 1 and there was no significant change in the phase or the imaginary conductivity of that column. As such, it is reasonable to believe that the 
bicarbonate is primarily responsible for the changes observed in Column 2. This precipitation likely had the effect of increasing constriction at pore throats which can affect the polarization of the sediment.

Column 2 also experienced a significant increase in Uranium concentrations (Figure 27) following the pumping of bicarbonate on Day 33. The only source of Uranium in the columns was in the form of the sparingly soluble Sodium Autunite. The high bicarbonate concentration likely favored the formation of more mobile Uranyl Carbonate species leading to the sudden increase seen after Day 33 as described in Gudavalli et al. (2013). While detailed analysis of the chemistry occurring inside the column may not be possible, the initial peak and subsequent drop until equilibrium concentrations is likely a result of Le Chatelier's principle (Jenkins, 2008); initially the system only contained reactants leading to a fast forward reaction which slowed down over time as the experiment proceeded until eventually achieving equilibrium after Day 120.

Columns 4 and 6 which contained glucose in addition to $\mathrm{HCO}_{3}^{-}$, saw a significant reduction in measured phase (Figures 21 and 22) very similar to that seen in columns 3 and 5 (Figures 15 and 16)(glucose, no bicarbonate) although equilibrium values seen on Day 149 remain slightly higher. The phase spectra for these columns also lost their parabolic shape and became almost linear on a logarithmic scale. Although phase decreases consistently in both columns, initially $\sigma^{\prime \prime}$ actually increases until reaching peak values on Day 44 or 51. In fact Column 4 shows the highest imaginary conductivity of any column outside of Column 2. This increase is similar to that seen in Column 2 (which 
shows a significant increase starting Day 44) and is much more subdued in columns 3 and 5. I can postulate that the reason this increase in the phase is so much higher in columns 4 and 6 is due in part to the precipitation of bicarbonate similar to Column 2 .

After 149 days all microbial columns show similar results. These include a significant increase in $\sigma^{\prime}$, a reduction of phase and loss of parabolic shape, and an increase in the imaginary conductivity at low frequency.

The increase in the real conductivity of these columns is controlled mainly by the release of ionic species into the porewater. We see after Day 33 an immediate increase in $\mathrm{Ca}^{2+}, \mathrm{Mg}^{2+}$, and $\mathrm{U}$ (likely in the soluble 6+ state). The small decrease in conductivity seen in most Fall 2016 microbial columns might be linked to significant reductions in Uranium concentrations at the time, although because $U$ concentrations are generally less than $10 \mathrm{mg} / \mathrm{L}$, the effect on the conductivity might be minor. The likely cause of this decrease in Uranium concentration is the reduction of soluble $\mathrm{U}^{6+}$ to insoluble $\mathrm{U}^{4+}$ due to microbially induced reducing conditions.

As microbes metabolize glucose they consume all available oxygen. Reducing conditions are present in all columns with microbial activity. This is evidenced by a variety of observations and results, namely a blackening of the sediment coupled with increases in dissolved iron. Iron in oxidixing conditions is found primarily as $\mathrm{Fe}^{3+}$ (insoluble) versus $\mathrm{Fe}^{2+}$ (soluble) which only forms from the reduction of $\mathrm{Fe}^{3+}$. This reduction of iron inside of the column resulted in high concentrations of soluble iron in the pore fluid; this was further evidenced by the precipitation of iron oxide at the outflows of effluent tubing as dissolved iron came into contact with the outside oxic 
environment. The formation of a reducing environment within the columns is likely one of the primary drivers of the observed changes in pore water chemistry.

After injection of glucose on Day 33 of Fall 2016 experiments there is a sudden increase in dissolved Uranium. We consider two possible explanations for this increase: the first is direct biodissolution of the autunite by microbes in order to use it as a phosphate source, the second is the release of bicarbonate naturally occurring in the sediment by microbial action favoring the formation of mobile uranyl carbonates as seen in control Column 2. When Column 2, which previously served as a control column with bicarbonate, was inoculated in Spring 2017, it saw no significant change in Uranium concentrations when compared to Day 149 of Fall 2016. This lack of a response to the pumping of glucose and inoculation with microbes lends support to the hypothesis that it is the release of naturally occurring bicarbonate which drives the release of uranium into the pore fluid since a column that already had bicarbonate saw no significant change.

The increase in imaginary conductivity at low frequencies and change in the shape of the $\sigma^{\prime \prime}$ spectra seen in microbial columns (both Fall 2016 and Spring 2017) may be unique to microbial growth. The Spring 2018 experiment seems to show that there is little to no change in the phase and only a minor increase in the imaginary conductivity after the injection of heat-deactivated bacteria. As such, it is unlikely that the increase in $\sigma^{\prime \prime}$ seen in microbial columns is due to polarization at bacterial cell wall surfaces; rather, it is more likely that changes in the imaginary conductivity are a combination of mineral precipitation/dissolution and constriction of flow pathways by microbial biomass as described in (Ntarlagiannis et al., 2005b). 


\section{CONCLUSIONS}

Geophysical columns experiments have shown that under saturating conditions the presence of $\mathrm{HCO}_{3}{ }^{-}$will cause a significant release of Uranium from sparingly soluble Na-Autunite. This is likely due to the formation of highly soluble Uranyl Carbonate species. $\mathrm{HCO}_{3}{ }^{-}$in the presence of $\mathrm{Ca}^{2+}$ ions seems to precipitate calcite $\left(\mathrm{CaCO}_{3}\right)$ which is detectable as an increase in phase and imaginary conductivity and mainly represents an increase in chargeability of the sediment $(m)$.

Microbes have a complex effect on the chemistry of the porewater as well as the SIP response. Microbial growth causes sharp increases in Uranium concentrations when Na-Autunite is found in the sediment. This may be due to direct biodissolution of the Autunite mineral in order to utilize it as a phosphate source. Another possibility is the release of naturally occurring $\mathrm{HCO}_{3}{ }^{-}$; however, measurements of inorganic carbon would be needed to prove this. The metabolism of glucose by microbes within a restricted column environment leads to a gradual decrease in Oxygen. This produces reducing conditions which are evidenced by increases in dissolved iron as well as decreases in dissolved uranium.

Columns with microbes all experience increases in the real conductivity (tied to increases in porewater conductivity) as well as a decrease in phase. . The shape of the phase spectra also shifts from a parabolic form to a linear form when plotted on a logarithmic frequency axis. The imaginary conductivity shows an increase at very low frequencies $(<10 \mathrm{~Hz})$. This may be due to constriction of pore throats. It is, however, difficult to know if this change is unique to microbial activity without a control 
experiment involving higher conductivity solutions with similar chemical compositions as the porewater after microbial growth began. Heat-deactivated microbes, at the concentrations injected, had no significant effect on the SIP response

Spectral Induced Polarization provides a useful tool for the monitoring of changes in the electric properties of sediments due to microbial growth. Microbes cause significant changes to the chemistry of the sediment and pore fluid which leads to significant increases in pore fluid conductivity. SIP has potential for field scale investigations as a supplement to existing ERT studies by adding information on polarization effects in the subsurface including the possibility of being able to distinguish microbial effects during polyphosphate injection. Since SIP measurements generally use similar equipment to DC resistivity, it should be relatively straight forward to retrofit existing setups for SIP measurements.

Microbes have a significant effect on the release of Uranium from autunite. Initially under oxic conditions this results in a spike in Uranium concentrations which slowly approache 0 as the columns become anoxic. While the initial spike in Uranium under oxic conditions is a definite negative for the purpose of sequestration, the formation of an anoxic environment by microbes through glucose (or equivalent carbon source) injection may prove effective in greatly reducing the mobility of Uranium by transforming the naturally occurring $\mathrm{U}^{6+}$ into $\mathrm{U}^{4+}$ effectively preventing additional leaching into pore fluids. 


\section{REFERENCES}

Aal, G. Z. A., Atekwana, E. A., Slater, L. D., and Atekwana, E. A., 2004, Effects of microbial processes on electrolytic and interfacial electrical properties of unconsolidated sediments: Geophysical Research Letters, v. 31, no. 12.

Atekwana, E. A., and Slater, L. D., 2009, Biogeophysics: A new frontier in Earth science research: Reviews of Geophysics, v. 47, no. 4.

Binley, A., 2015, 11.08 - Tools and Techniques: Electrical Methods A2 - Schubert, Gerald, Treatise on Geophysics (Second Edition): Oxford, Elsevier, p. 233-259.

Cole, K. S., and Cole, R. H., 1941, Dispersion and absorption in dielectrics I. Alternating current characteristics: The Journal of chemical physics, v. 9, no. 4, p. 341-351.

De Vivo, B., Ippolito, F., Capaldi, G., and Simpson, P., 1984, Uranium geochemistry, mineralogy, geology, exploration and resources, Springer.

Fadrus, H., and Malý, J., 1975, Suppression of iron (III) interference in the determination of iron (II) in water by the 1, 10-phenanthroline method: Analyst, v. 100, no. 1193, p. 549-554.

Gudavalli, R., Katsenovich, Y., Wellman, D., Lagos, L., and Tansel, B., 2013, Quantification of kinetic rate law parameters of uranium release from sodium autunite as a function of aqueous bicarbonate concentrations: Environmental Chemistry, v. 10, no. 6, p. 475-485.

Huisman, J. A., Zimmermann, E., Esser, O., Haegel, F.-H., Treichel, A., and Vereecken, H., 2016, Evaluation of a novel correction procedure to remove electrode impedance effects from broadband SIP measurements: Journal of Applied Geophysics, v. 135, p. 466-473.

Jenkins, H. D., 2008, Le Chatelier's Principle, Chemical Thermodynamics at a Glance.

Johnson, T. C., Rucker, D. F., and Glaser, D. R., 2015a, 11.17 - Near-Surface Geophysics at the Hanford Nuclear Site, the United States A2 - Schubert, Gerald, Treatise on Geophysics (Second Edition): Oxford, Elsevier, p. 571-595.

Johnson, T. C., Versteeg, R. J., Day-Lewis, F. D., Major, W., and Lane, J. W., Jr., 2015b, TimeLapse Electrical Geophysical Monitoring of Amendment-Based Biostimulation: Ground Water, v. 53, no. 6, p. 920-932.

Kemna, A., 2014, An overview of the spectral induced polarization method for near-surface applications.

Mellage, A., Smeaton, C. M., Furman, A., Atekwana, E. A., Rezanezhad, F., and Van Cappellen, P., 2018, Linking Spectral Induced Polarization (SIP) and Subsurface Microbial Processes: Results from Sand Column Incubation Experiments: Environmental Science \& Technology, v. 52, no. 4, p. 2081-2090. 
Neu, M. P., Boukhalfa, H., and Merroun, M. L., 2011, Biomineralization and biotransformations of actinide materials: MRS Bulletin, v. 35, no. 11, p. 849-857.

Ntarlagiannis, D., and Ferguson, A., 2008, SIP response of artificial biofilms: GEOPHYSICS, v. 74, no. 1, p. A1-A5.

Ntarlagiannis, D., Williams, K. H., Slater, L., and Hubbard, S., 2005a, Low-frequency electrical response to microbial induced sulfide precipitation: Journal of Geophysical Research, v. 110, no. G2.

Ntarlagiannis, D., Yee, N., and Slater, L., 2005b, On the low- frequency electrical polarization of bacterial cells in sands: Geophysical Research Letters, v. 32, no. 24.

Pelton, W. H., Ward, S. H., Hallof, P. G., Sill, W. R., and Nelson, P. H., 1978, MINERAL DISCRIMINATION AND REMOVAL OF INDUCTIVE COUPLING WITH MULTIFREQUENCY IP: GEOPHYSICS, v. 43, no. 3, p. 588-609.

Peterson, R. A., Buck, E. C., Chun, J., Daniel, R. C., Herting, D. L., Ilton, E. S., Lumetta, G. J., and Clark, S. B., 2018, Review of the Scientific Understanding of Radioactive Waste at the U.S. DOE Hanford Site: Environmental Science \& Technology, v. 52, no. 2, p. 381396.

Serne, R., Bjornstad, B. N., Schaef, H. T., Williams, B. A., Lanigan, D. C., Horton, D., Clayton, R. E., Mitroshkov, A., Legore, V. L., O'Hara, M., Brown, C. F., Parker, K. E., Kutnyakov, I., Serne, J., Last, G., Smith, S. C., Lindenmeier, C., Zachara, J. M., and Burke, D. S., 2008, Characterization of Vadose Zone Sediment: Uncontaminated RCRA Borehole Core Samples and Composite Samples . PNNL-13757-1 Rev. 1.

Slater, L., Comas, X., Ntarlagiannis, D., and Moulik, M. R., 2007, Resistivity- based monitoring of biogenic gases in peat soils: Water Resources Research, v. 43, no. 10.

Slater, L., Ntarlagiannis, D., and Wishart, D., 2006, On the relationship between induced polarization and surface area in metal-sand and clay-sand mixtures: GEOPHYSICS, v. 71, no. 2, p. A1-A5.

Slater, L. D., Choi, J., and Wu, Y., 2005, Electrical properties of iron-sand columns: Implications for induced polarization investigation and performance monitoring of iron-wall barriers: GEOPHYSICS, v. 70, no. 4, p. G87-G94.

Stanienda, K. J., 2016, Carbonate phases rich in magnesium in the Triassic limestones of the eastern part of the Germanic Basin: Carbonates and Evaporites, v. 31, no. 4, p. 387-405.

Stookey, L. L., 1970, Ferrozine---a new spectrophotometric reagent for iron: Analytical chemistry, v. 42, no. 7, p. 779-781.

Szecsody, J. E., Truex, M. J., Zhong, L., Johnson, T. C., Qafoku, N. P., Williams, M. D., Greenwood, W. J., Wallin, E. L., Bargar, J. D., and Faurie, D. K., 2012, Geochemical and Geophysical Changes during Ammonia Gas Treatment of Vadose Zone Sediments for Uranium Remediation: Vadose Zone Journal, v. 11, no. 4, p. 0. 
Um, W., Icenhower, J. P., Brown, C. F., Serne, R. J., Wang, Z., Dodge, C. J., and Francis, A. J., 2010, Characterization of uranium-contaminated sediments from beneath a nuclear waste storage tank from Hanford, Washington: Implications for contaminant transport and fate: Geochimica et Cosmochimica Acta, v. 74, no. 4, p. 1363-1380.

Vermeul, V. R., Bjornstad, B. N., Fritz, B. G., Fruchter, J. S., Mackley, R. D., Newcomer, D. R., Mendoza, D. P., Rockhold, M. L., Wellman, D. M., and Williams, M. D., 2009, 300 Area Uranium Stabilization Through Polyphosphate Injection: Pacific Northwest National Laboratory (PNNL), Richland, WA (US). 


\section{APPENDIX A. SPRING 2017 RESULTS}
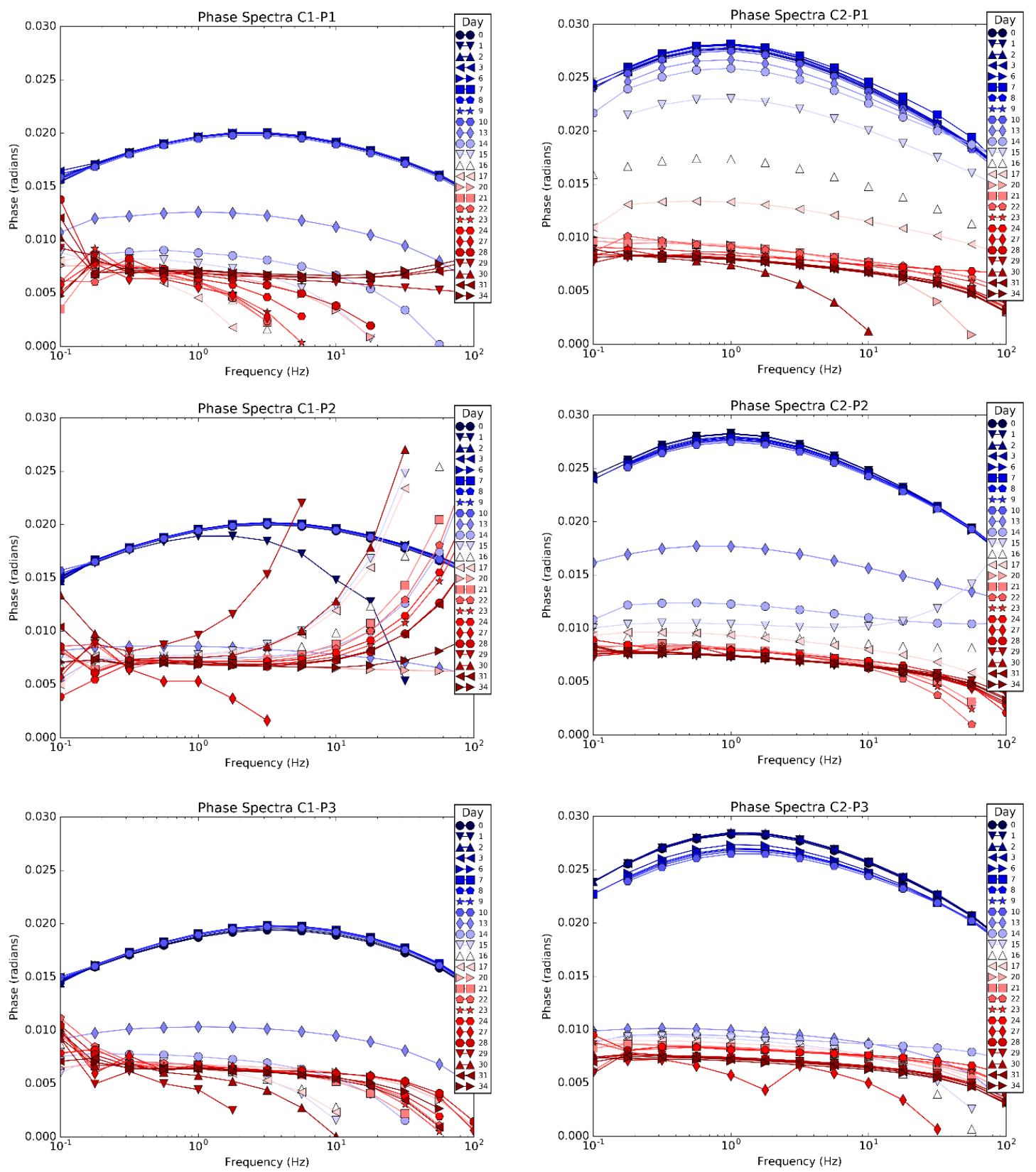

Figure A. 1 Phase Spectra for Columns 1 and 2, Spring 2017. 

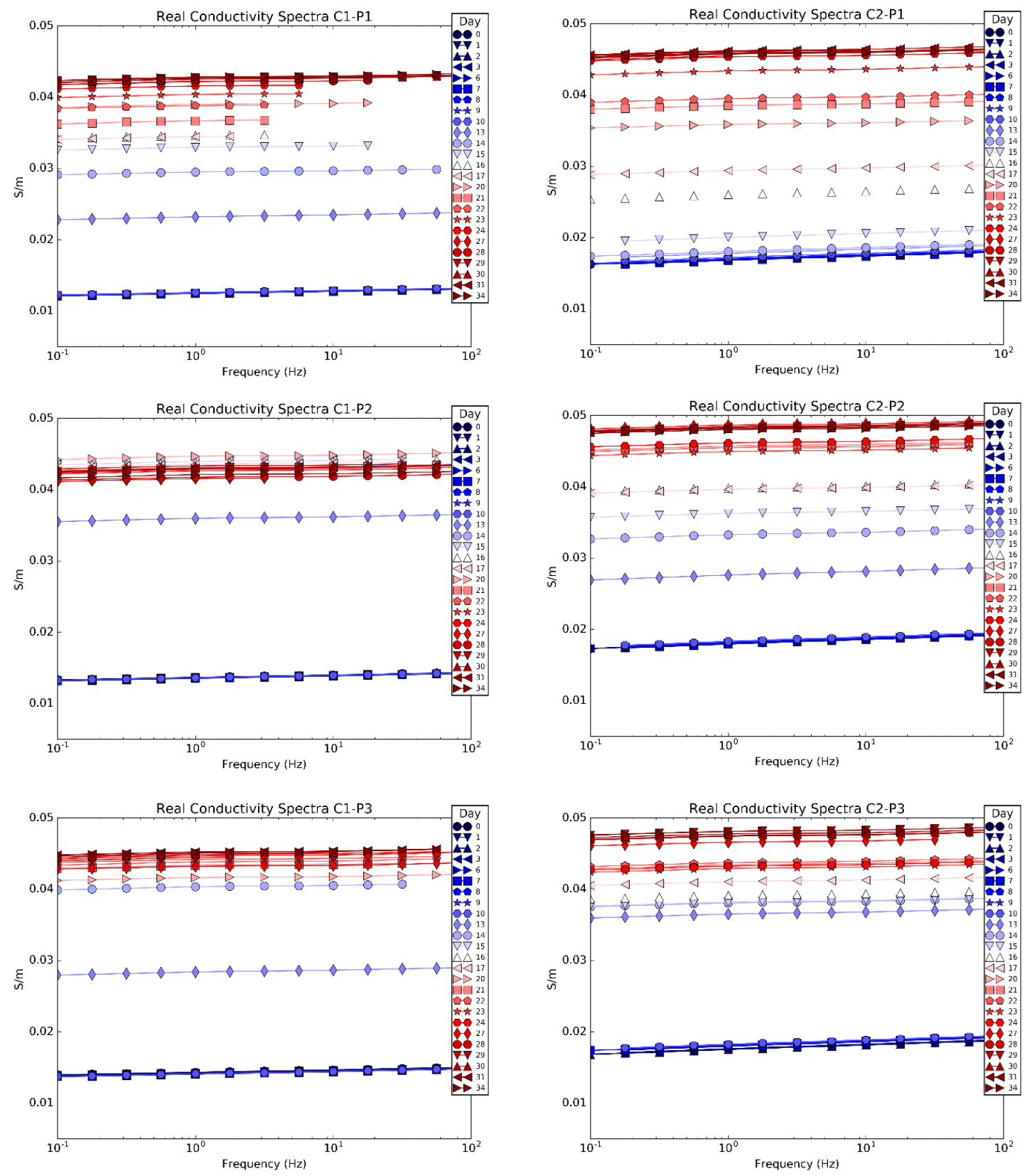

Figure A. 2 Real Conductivity Spectra for Columns 1 and 2, Spring 2017 

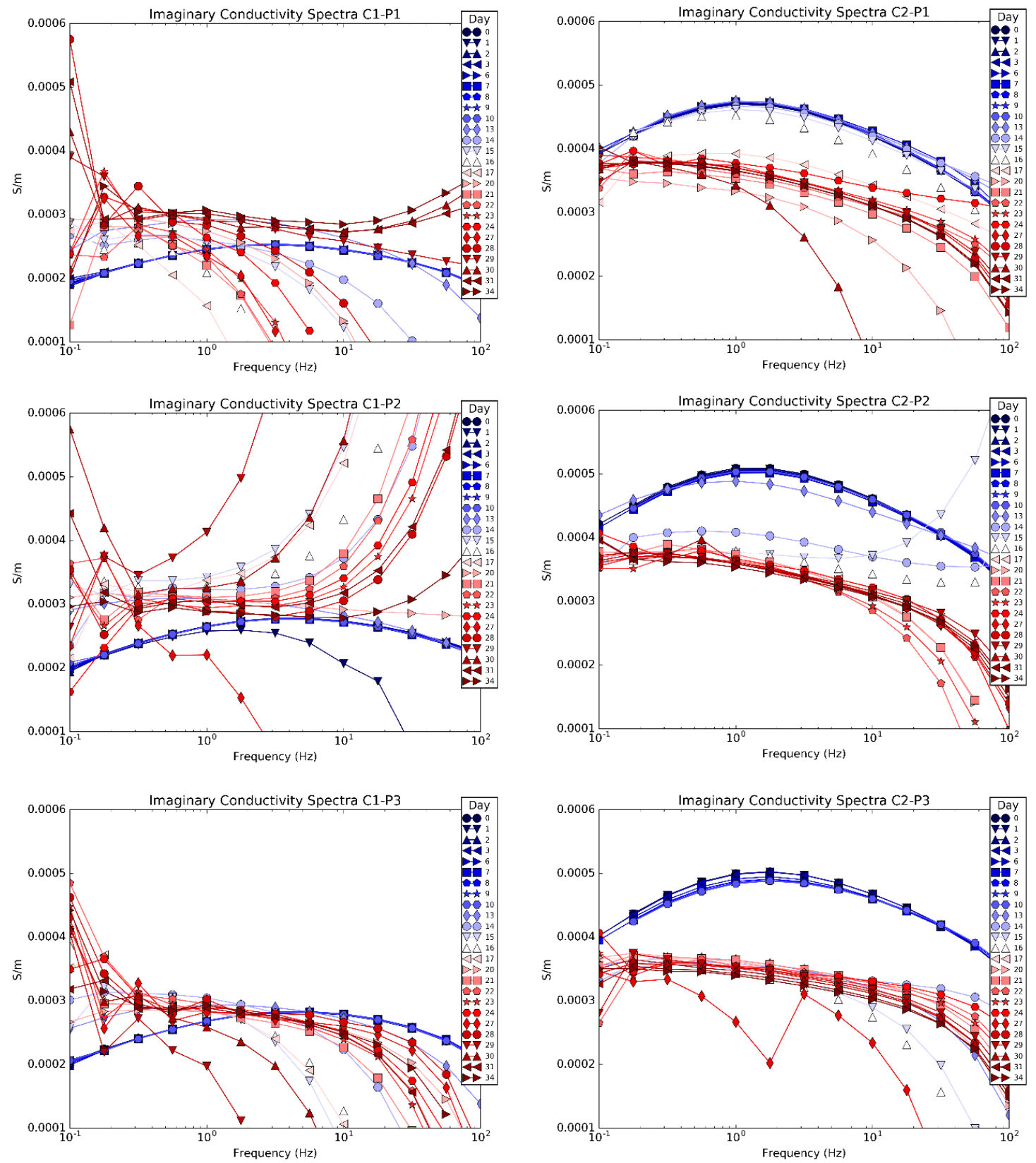

Figure A. 3 Imaginary Conductivity Spectra for Columns 1 and 2, Spring 2017 

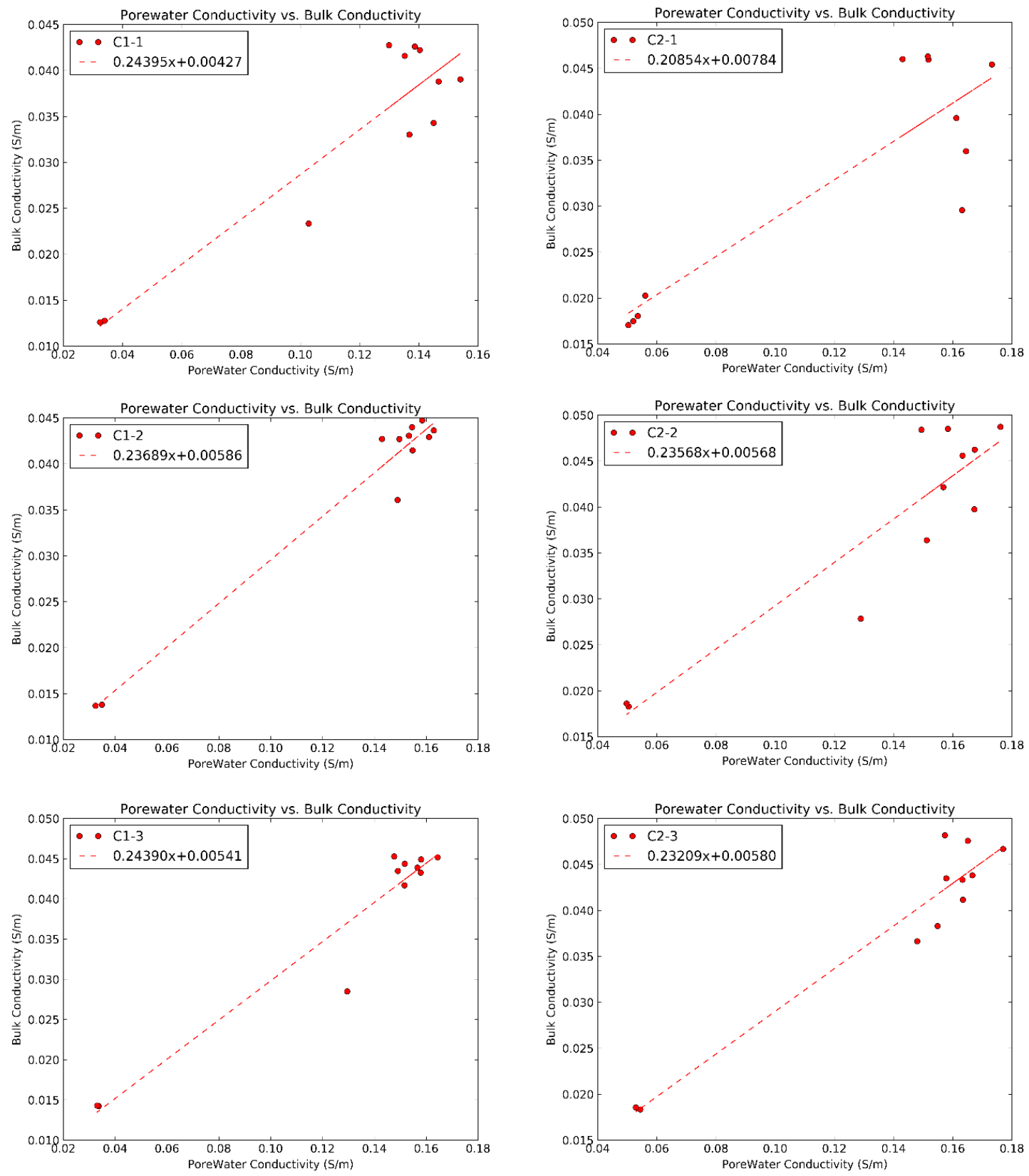

Figure A. 4 Plot of Bulk Conductivity vs. Pore Fluid Conductivity for Columns 1 and 2, Spring 2017 


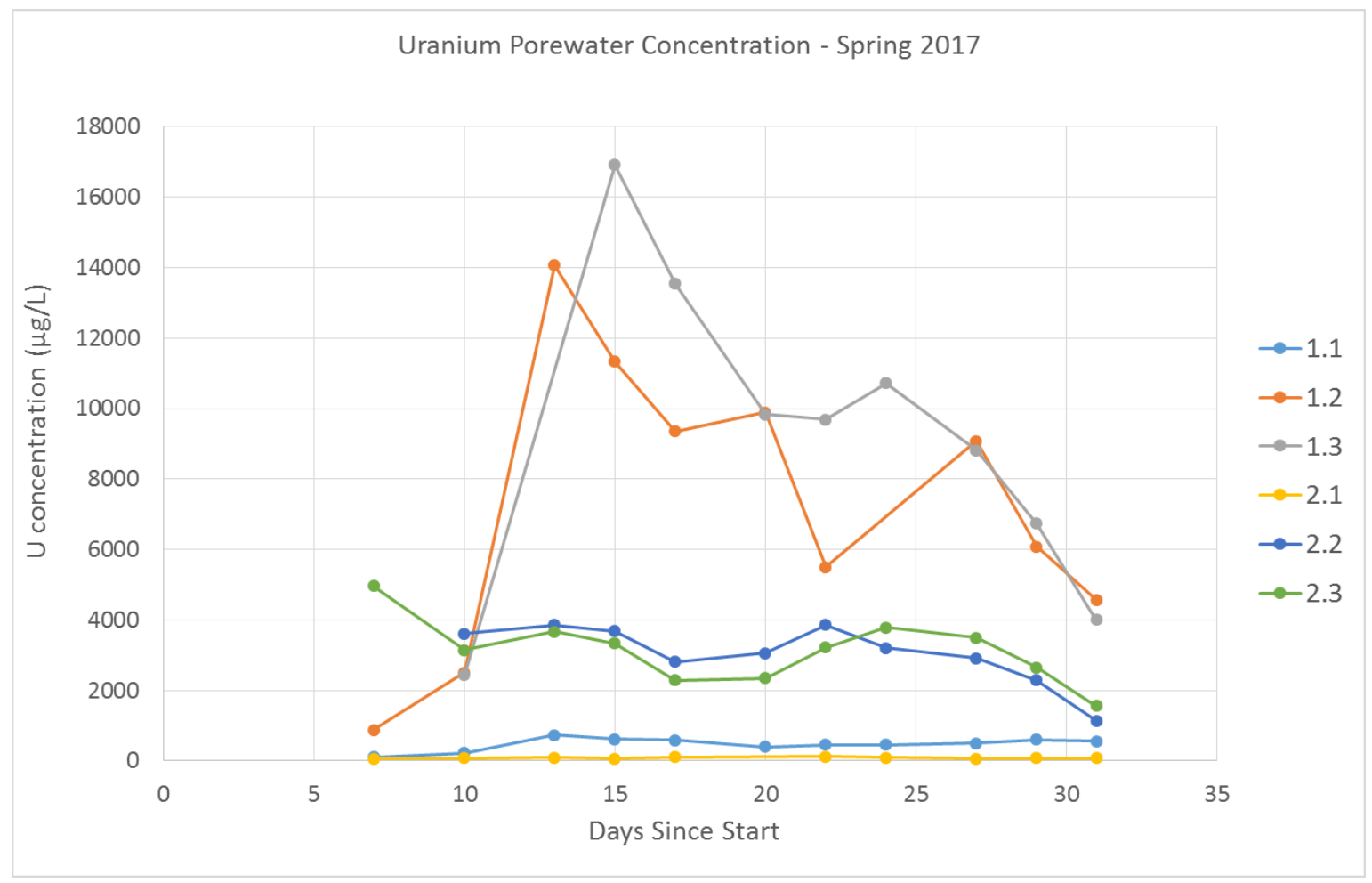

Figure A. 5 Uranium Concentrations for Columns 1 and 2, Spring 2017

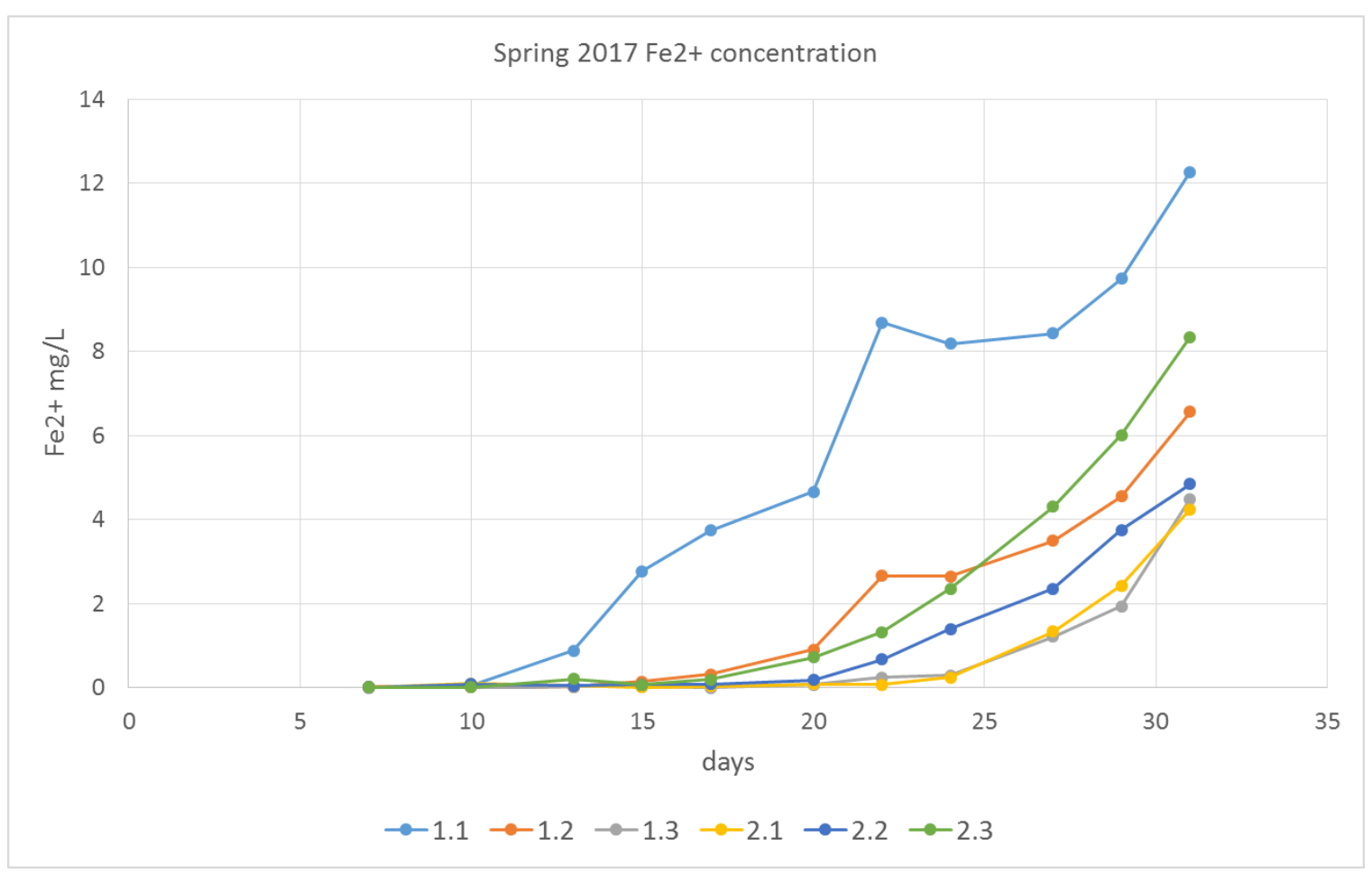

Figure A. 6 Iron Concentrations for Columns 1 and 2, Spring 2017 


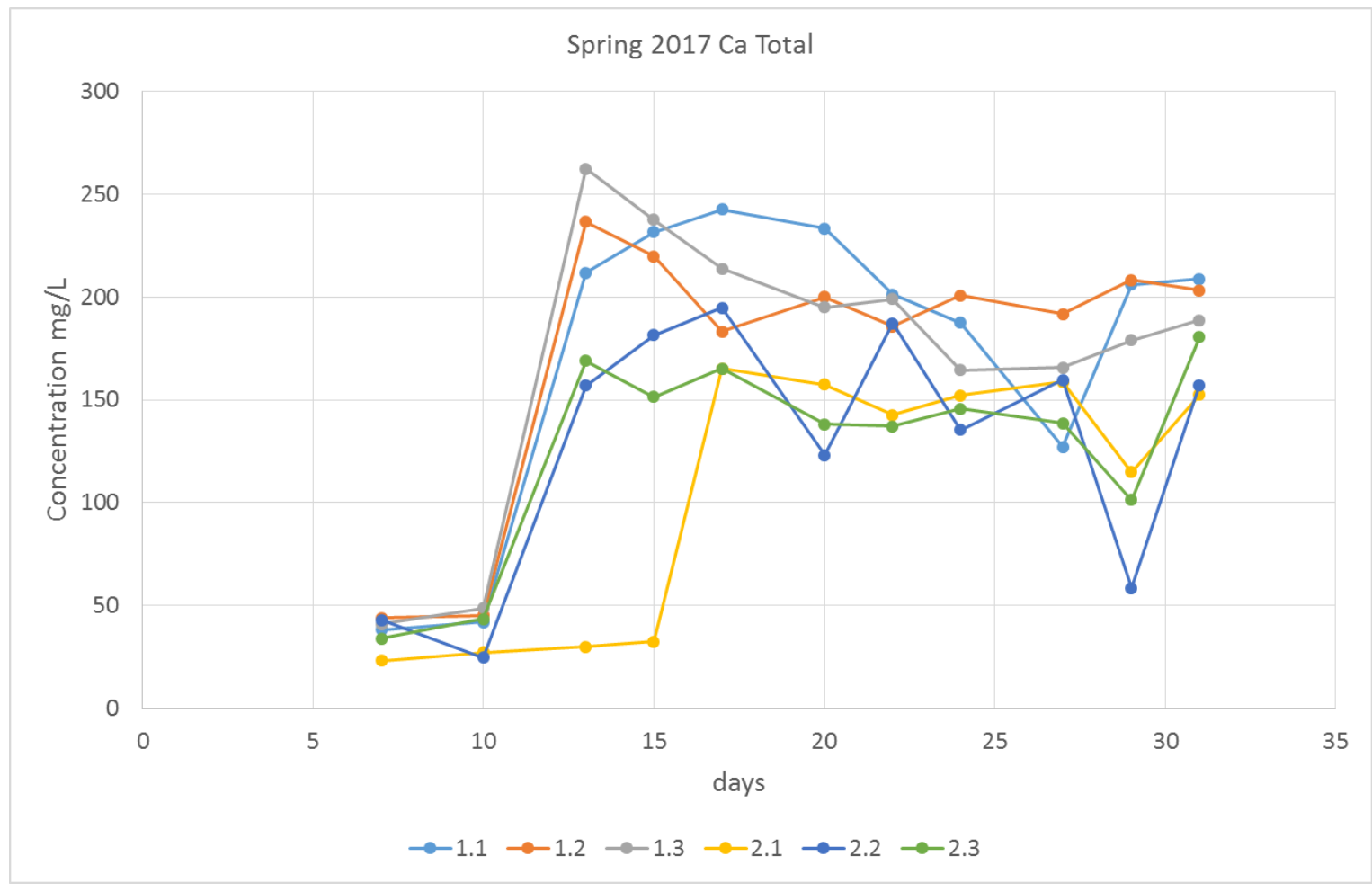

Figure A. 7 Calcium Concentrations for Columns 1 and 2, Spring 2017

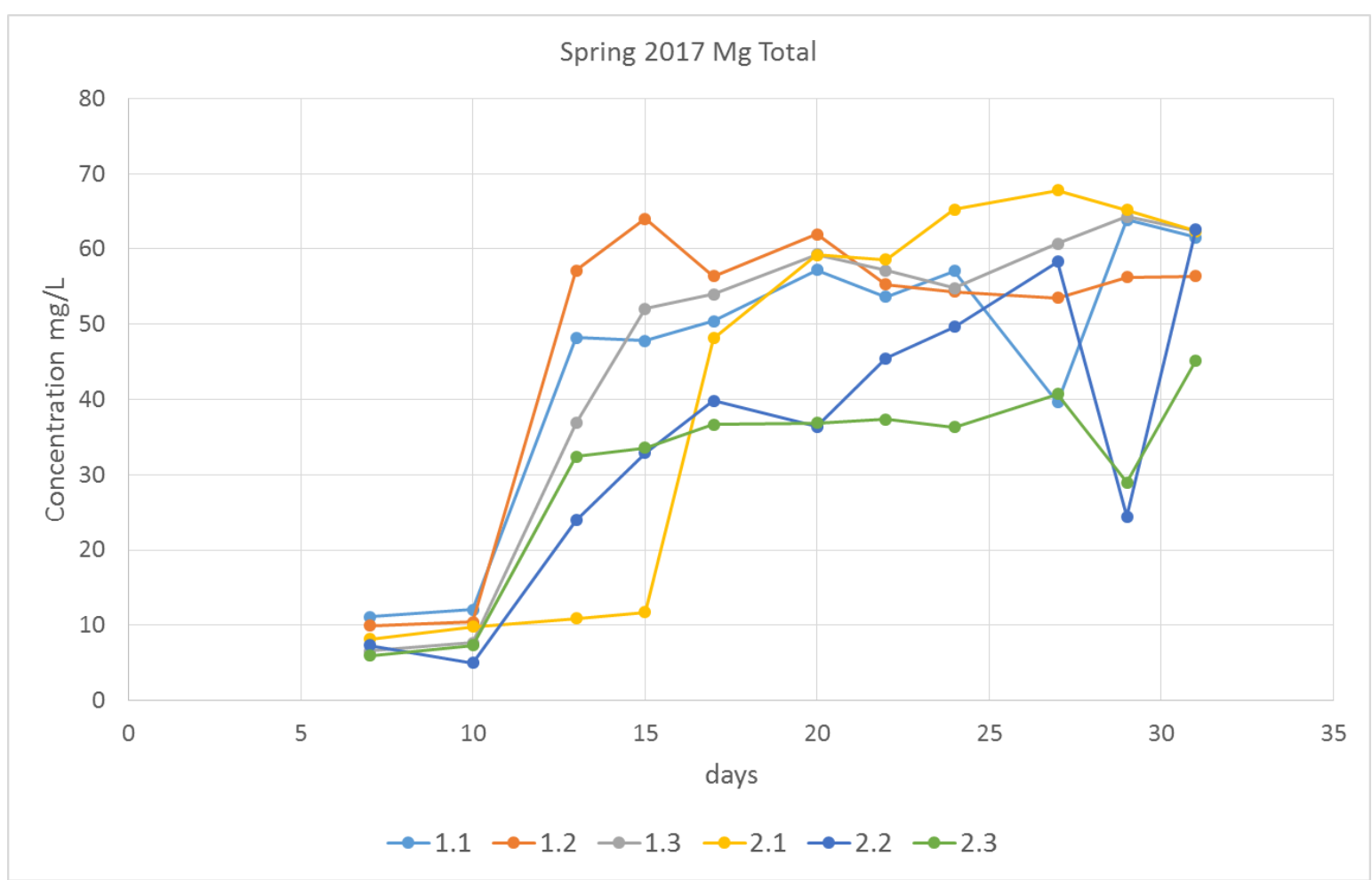

Figure A. 8 Magnesium Concentrations for Columns 1 and 2, Spring 2017 


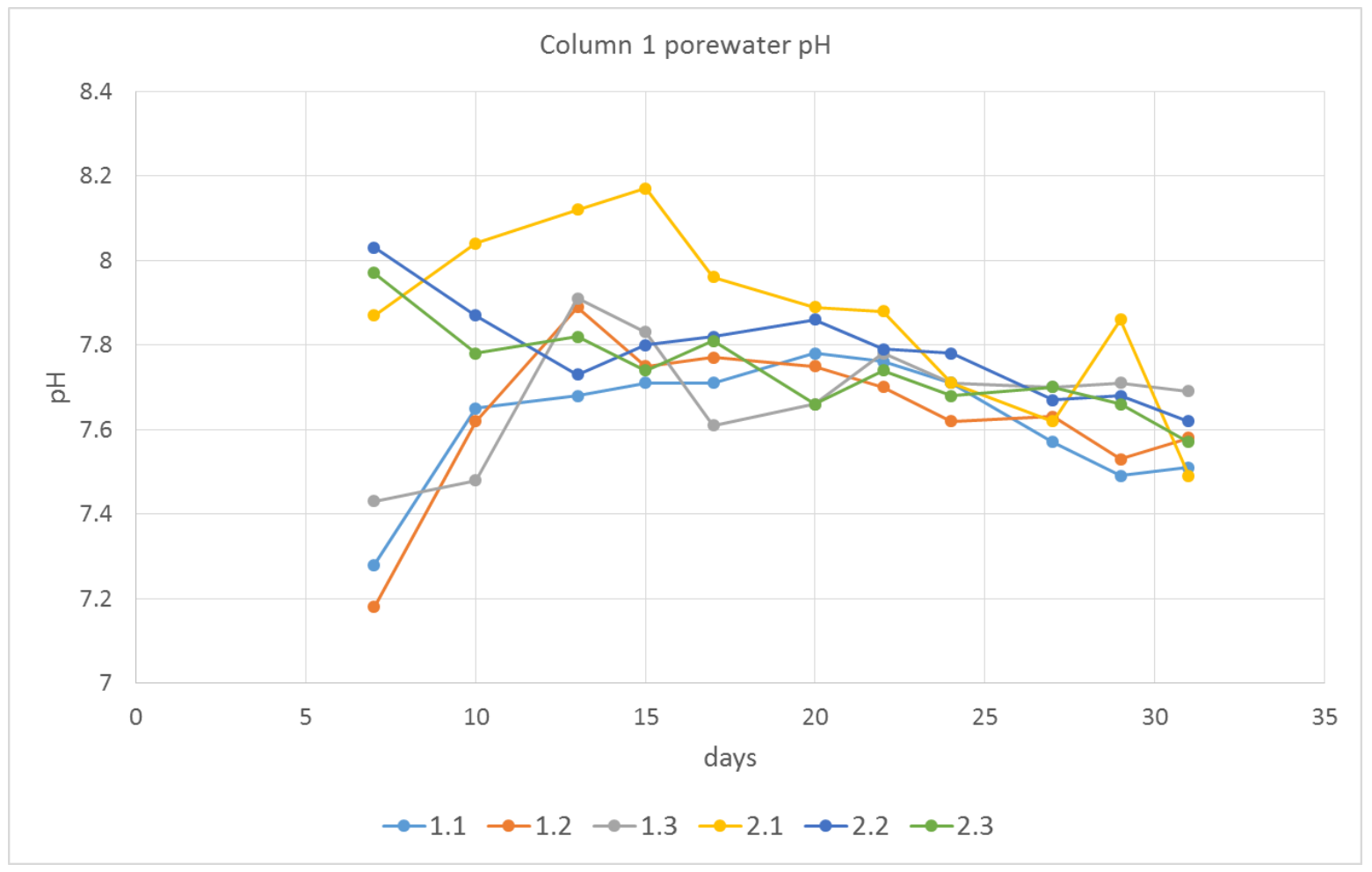

Figure A. 9 Porewater pH for Columns 1 and 2, Spring 2017

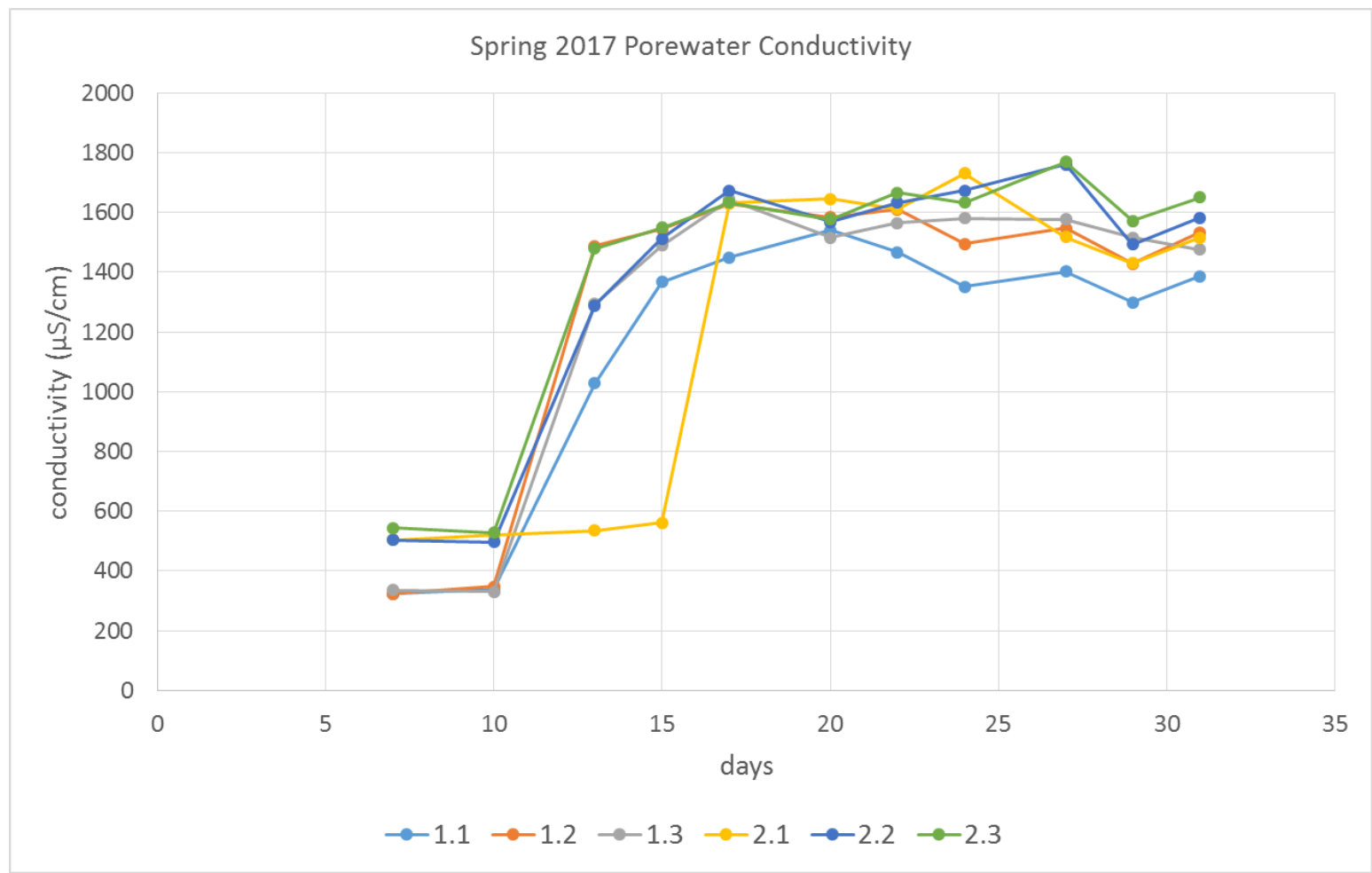

Figure A. 10 Porewater Conductivity for Columns 1 and 2, Spring 2017 
Table A. 1 Uranium concentrations, Spring 2017

\begin{tabular}{|r|r|r|r|r|r|r|r|}
\hline \multicolumn{2}{|c|}{ Uranium $\mu \mathrm{g} / \mathrm{L}$} & & & & \\
\hline & Sample: & 1.1 & 1.2 & 1.3 & 2.1 & 2.2 & 2.3 \\
\hline Day & 7 & 102.8412 & 880.6519 & & 63.1708 & & 4959.136 \\
\hline 10 & 222.6059 & 2508.704 & 2426.944 & 77.91314 & 3612.096 & 3139.058 \\
\hline 13 & 729.8824 & 14059.14 & & 87.37111 & 3860.156 & 3670.714 \\
\hline 15 & 621.6456 & 11334.54 & 16916.73 & 66.59006 & 3687.442 & 3331.954 \\
\hline 17 & 584.7579 & 9360.885 & 13541.38 & 108.8675 & 2809.629 & 2292.044 \\
\hline 20 & 394.3233 & 9888.686 & 9832.64 & & 3060.492 & 2345.22 \\
\hline 22 & 461.0753 & 5508.476 & 9695.9 & 121.4703 & 3856.212 & 3211.086 \\
\hline 24 & 452.0763 & & 10722.56 & 86.40734 & 3206.028 & 3786.088 \\
\hline & 27 & 499.8169 & 9075.99 & 8823.792 & 67.92021 & 2913.058 & 3491.792 \\
\hline 29 & 606.1474 & 6085.378 & 6736.998 & 81.32796 & 2288.786 & 2646.084 \\
\hline 31 & 558.5287 & 4575.227 & 4009.237 & 70.81504 & 1133.899 & 1563.083 \\
\hline
\end{tabular}

Table A. 2 Fe2+ Concentrations, Spring 2017

\begin{tabular}{|l|r|r|r|r|r|r|r|}
\hline \multicolumn{5}{|l|}{ Fe2+ mg/L } & \multicolumn{1}{l|}{} & \\
\hline & Sample: & 1.1 & 1.2 & 1.3 & 2.1 & 2.2 & 2.3 \\
\hline Day & 7 & 0.019558 & 0.029337 & 0.003912 & 0.011735 & 0.011735 & 0.009779 \\
\hline & 10 & 0.066498 & 0.013691 & -0.00587 & 0.105615 & 0.088012 & 0.009779 \\
\hline 13 & 0.889902 & 0.021514 & 0.029337 & 0.050852 & 0.04694 & 0.213185 \\
\hline 15 & 2.777277 & 0.144731 & 0.031293 & 0.009779 & 0.072366 & 0.074321 \\
\hline 17 & 3.743456 & 0.324668 & 0.005867 & 0.037161 & 0.091924 & 0.203406 \\
\hline 20 & 4.66074 & 0.905549 & 0.076277 & 0.09388 & 0.181892 & 0.729524 \\
\hline 22 & 8.687791 & 2.669706 & 0.24839 & 0.074321 & 0.674761 & 1.32214 \\
\hline 24 & 8.187099 & 2.650148 & 0.291418 & 0.242523 & 1.402329 & 2.360685 \\
\hline & 27 & 8.431577 & 3.495066 & 1.21457 & 1.333875 & 2.352862 & 4.306735 \\
\hline 29 & 9.730247 & 4.559036 & 1.93627 & 2.435007 & 3.757147 & 6.014173 \\
\hline 31 & 12.27087 & 6.571584 & 4.498406 & 4.24806 & 4.850455 & 8.341609 \\
\hline
\end{tabular}

Table A. 3 Calcium concentrations, Spring 2017

\begin{tabular}{|l|r|r|r|r|r|r|r|r|r|r|r|r|}
\hline \multicolumn{1}{|c|}{ Calcium mg/L } & \multicolumn{2}{l|}{} & \multicolumn{1}{l|}{} & & & & \\
\hline & \multicolumn{1}{|c|}{ Day } & 7 & 10 & 13 & 15 & 17 & 20 & 22 & 24 & 27 & 29 & 31 \\
\hline Sample & 1.1 & 38.34 & 41.85 & 211.8 & 231.4 & 242.4 & 233.3 & 201.1 & 187.4 & 127.2 & 206 & 208.7 \\
\hline & 1.2 & 44.04 & 45.22 & 236.6 & 219.8 & 183.3 & 199.9 & 185.8 & 200.7 & 191.6 & 208.2 & 203.2 \\
\hline & 1.3 & 41.05 & 48.82 & 262.2 & 237.4 & 213.6 & 194.9 & 198.9 & 164.4 & 165.7 & 178.8 & 188.7 \\
\hline & 2.1 & 23.28 & 27.26 & 29.86 & 32.35 & 165.2 & 157.3 & 142.6 & 152.2 & 158.7 & 114.9 & 152.3 \\
\hline & 2.2 & 42.96 & 24.64 & 156.9 & 181.4 & 194.8 & 123 & 187.3 & 135.4 & 159.6 & 58.57 & 157.2 \\
\hline & 2.3 & 33.95 & 43.49 & 168.8 & 151.5 & 165.2 & 138.1 & 137 & 145.7 & 138.5 & 101.3 & 180.5 \\
\hline
\end{tabular}


Table A. 4 Magnesium concentrations, Spring 2017

\begin{tabular}{|l|r|r|r|r|r|r|r|r|r|r|r|r|}
\hline \multicolumn{4}{|c|}{ Magnesium mg/L } & & & & & & & \\
\hline & \multicolumn{1}{|c|}{} & 7 & 10 & 13 & 15 & 17 & 20 & 22 & 24 & 27 & 29 & 31 \\
\hline Sample & 1.1 & 11.1 & 12.08 & 48.18 & 47.83 & 50.44 & 57.18 & 53.66 & 57.06 & 39.61 & 63.87 & 61.54 \\
\hline & 1.2 & 9.967 & 10.41 & 57.17 & 63.99 & 56.37 & 61.96 & 55.26 & 54.31 & 53.52 & 56.28 & 56.38 \\
\hline & 1.3 & 6.587 & 7.664 & 36.9 & 52.08 & 53.99 & 59.24 & 57.11 & 54.83 & 60.71 & 64.3 & 62.46 \\
\hline & 2.1 & 8.167 & 9.816 & 10.89 & 11.75 & 48.16 & 59.23 & 58.55 & 65.23 & 67.82 & 65.21 & 62.36 \\
\hline & 2.2 & 7.315 & 4.962 & 23.93 & 32.92 & 39.84 & 36.41 & 45.47 & 49.67 & 58.28 & 24.47 & 62.61 \\
\hline & 2.3 & 5.93 & 7.313 & 32.44 & 33.57 & 36.68 & 36.84 & 37.38 & 36.31 & 40.71 & 28.99 & 45.2 \\
\hline
\end{tabular}

Table A. 5 pH, Spring 2017

\begin{tabular}{|l|r|r|r|r|r|r|r|}
\hline & \multicolumn{1}{|l|}{ pH } & & & & & & \\
\hline & Sample: & 1.1 & 1.2 & 1.3 & 2.1 & 2.2 & 2.3 \\
\hline Day & 7 & 7.28 & 7.18 & 7.43 & 7.87 & 8.03 & 7.97 \\
\hline & 10 & 7.65 & 7.62 & 7.48 & 8.04 & 7.87 & 7.78 \\
\hline 13 & 7.68 & 7.89 & 7.91 & 8.12 & 7.73 & 7.82 \\
\hline & 15 & 7.71 & 7.75 & 7.83 & 8.17 & 7.8 & 7.74 \\
\hline 17 & 7.71 & 7.77 & 7.61 & 7.96 & 7.82 & 7.81 \\
\hline 20 & 7.78 & 7.75 & 7.66 & 7.89 & 7.86 & 7.66 \\
\hline & 7.76 & 7.7 & 7.78 & 7.88 & 7.79 & 7.74 \\
\hline & 24 & 7.71 & 7.62 & 7.71 & 7.71 & 7.78 & 7.68 \\
\hline 27 & 7.57 & 7.63 & 7.7 & 7.62 & 7.67 & 7.7 \\
\hline 29 & 7.49 & 7.53 & 7.71 & 7.86 & 7.68 & 7.66 \\
\hline 31 & 7.51 & 7.58 & 7.69 & 7.49 & 7.62 & 7.57 \\
\hline
\end{tabular}

Table A. 6 Pore water conductivity, Spring 2017

\begin{tabular}{|c|c|c|c|c|c|c|c|}
\hline & \multicolumn{3}{|c|}{ Conductivity $(\mu \mathrm{S} / \mathrm{cm})$} & \multirow[b]{2}{*}{1.3} & \multirow[b]{2}{*}{2.1} & \multirow[b]{2}{*}{2.2} & \multirow[b]{2}{*}{2.3} \\
\hline & Sample: & 1.1 & 1.2 & & & & \\
\hline \multirow[t]{11}{*}{ Day } & 7 & 323.5 & 324 & 336.4 & 503.5 & 504.2 & 544 \\
\hline & 10 & 339.5 & 348.7 & 330.2 & 520.2 & 497.6 & 528.9 \\
\hline & 13 & 1028 & 1489 & 1295 & 535.7 & 1289 & 1480 \\
\hline & 15 & 1368 & 1545 & 1490 & 561.1 & 1512 & 1549 \\
\hline & 17 & 1450 & 1629 & 1644 & 1631 & 1673 & 1634 \\
\hline & 20 & 1540 & 1584 & 1516 & 1645 & 1568 & 1578 \\
\hline & 22 & 1467 & 1610 & 1566 & 1612 & 1633 & 1666 \\
\hline & 24 & 1352 & 1496 & 1580 & 1732 & 1674 & 1633 \\
\hline & 27 & 1403 & 1547 & 1578 & 1518 & 1761 & 1770 \\
\hline & 29 & 1299 & 1429 & 1517 & 1430 & 1494 & 1573 \\
\hline & 31 & 1386 & 1533 & 1476 & 1516 & 1583 & 1651 \\
\hline
\end{tabular}




\section{APPENDIX B. FALL 2016 RESULTS}
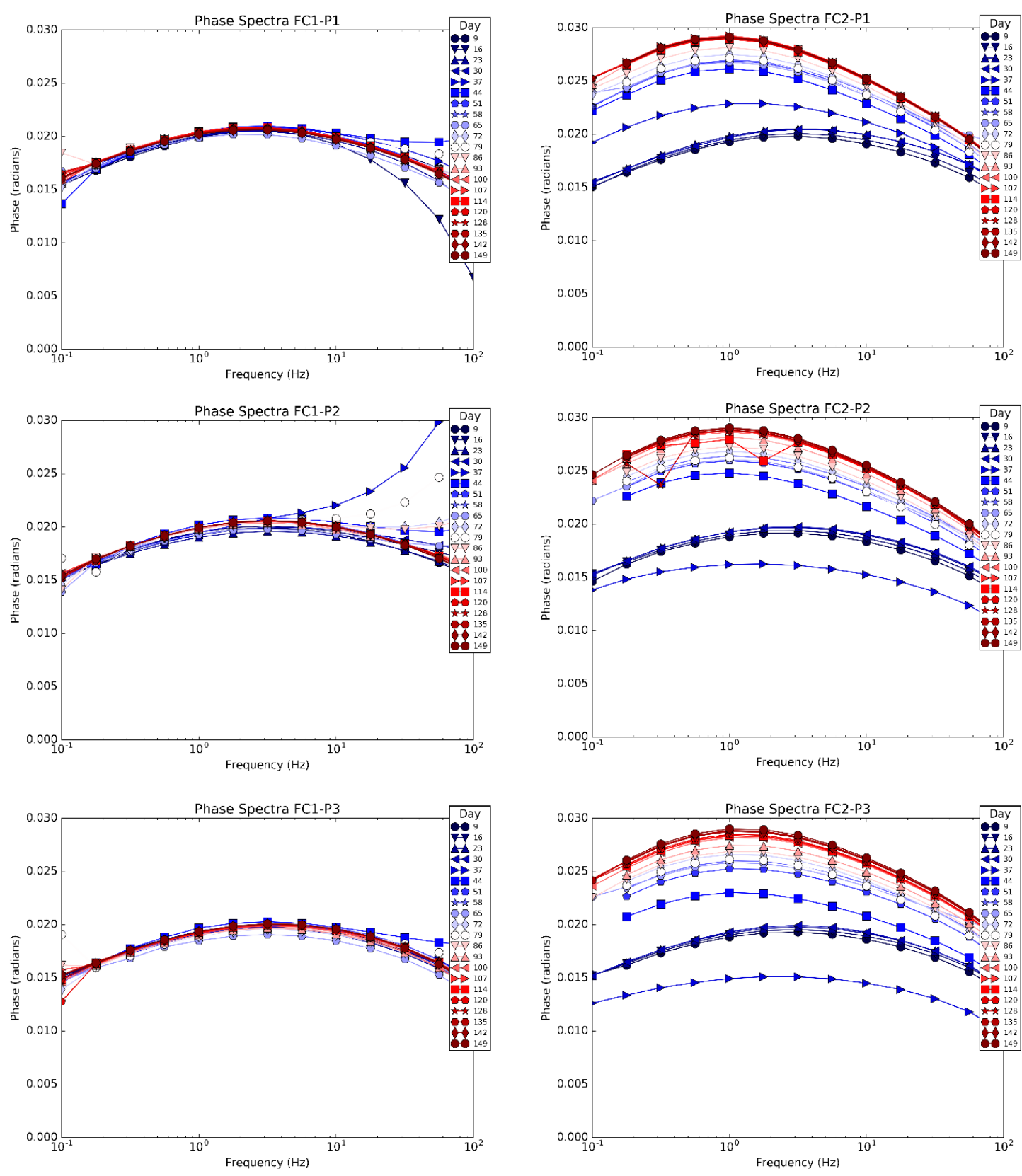

Figure B. 1 Phase spectra for columns 1 and 2, Fall 2016 

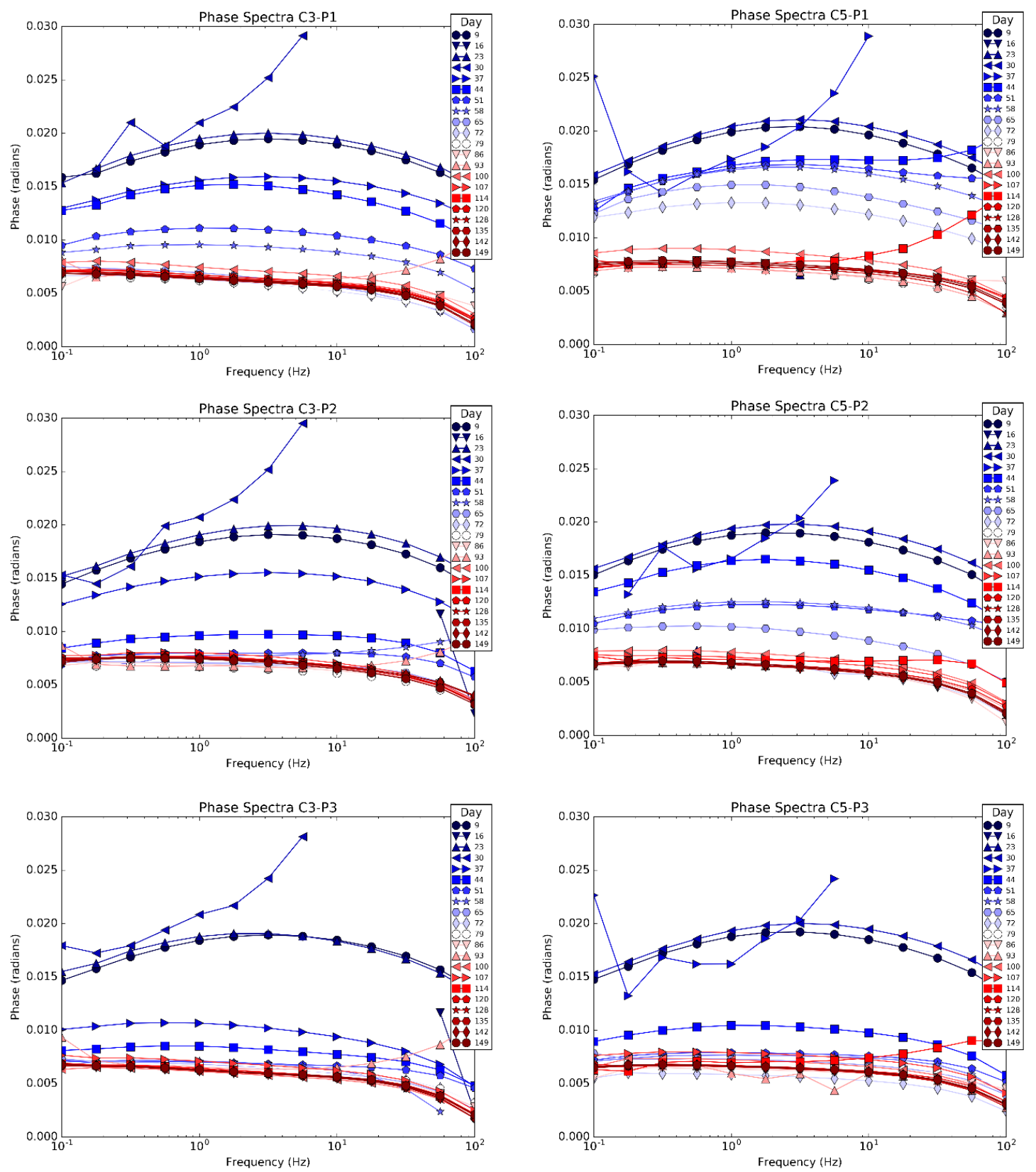

Figure B. 2 Phase spectra for columns 3 and 5, Fall 2016 

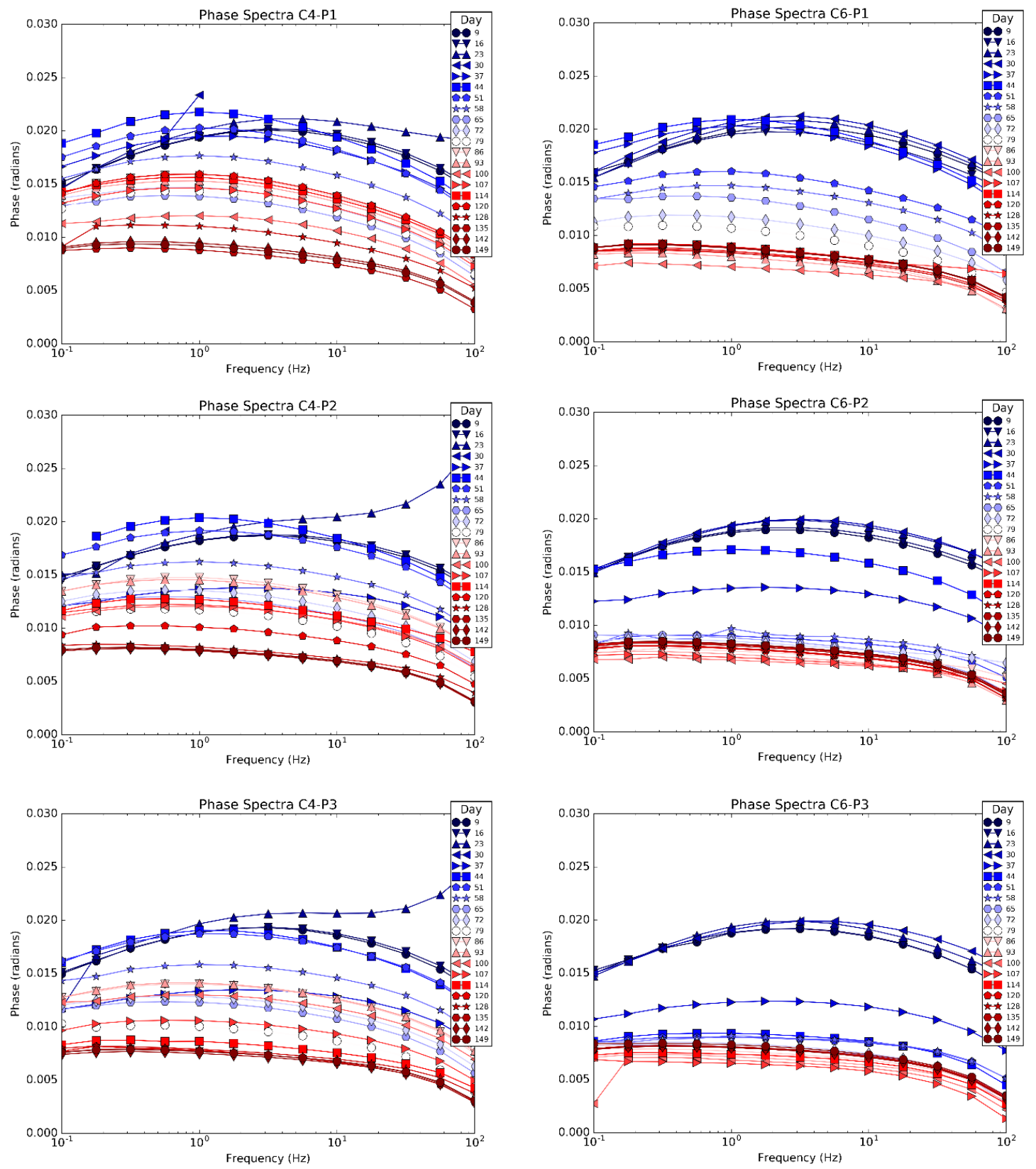

Figure B. 3 Phase spectra for columns 4 and 6, Fall 2016 

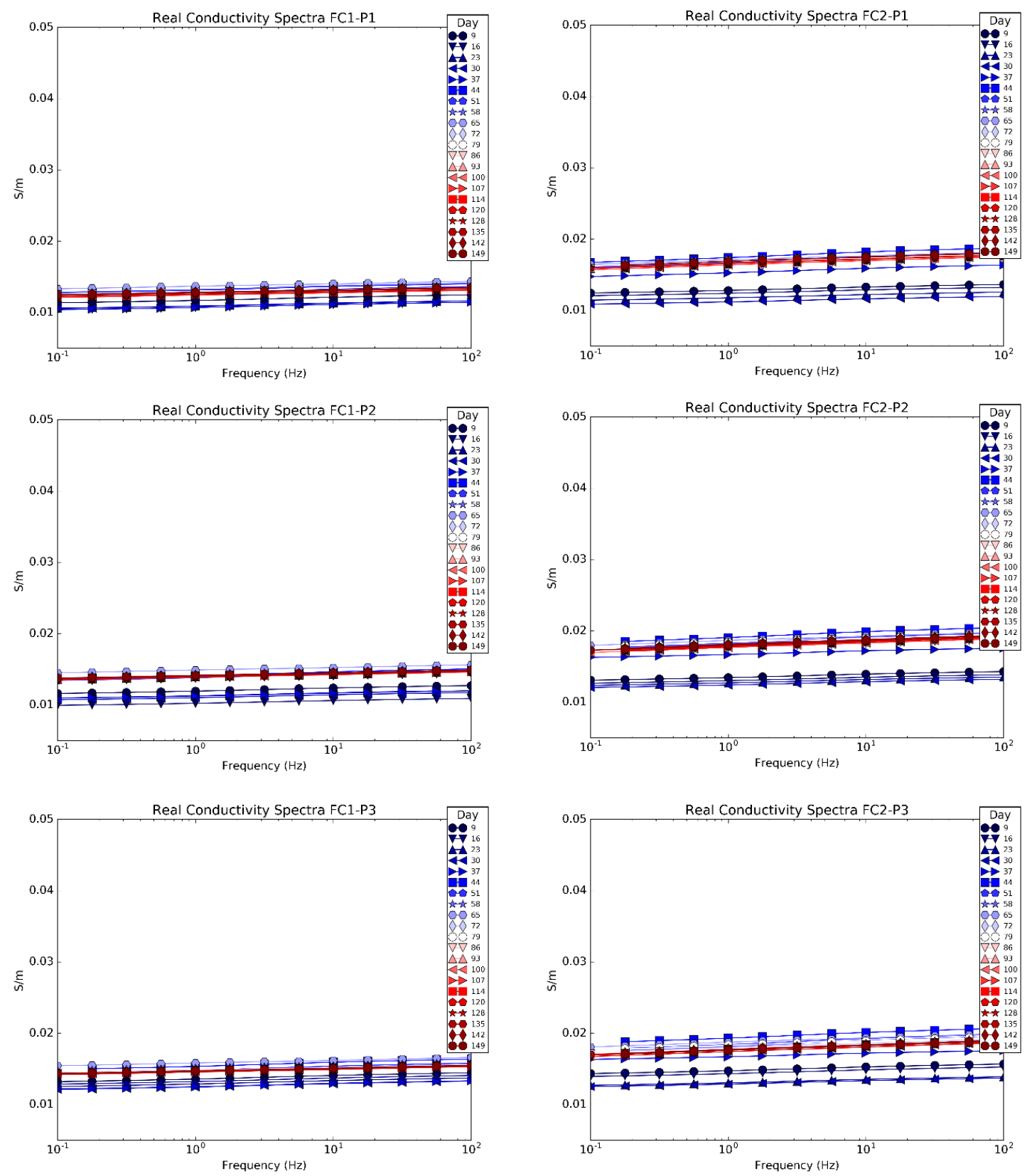

Figure B. 4 Real conductivity for columns 1 and 2, Fall 2016 

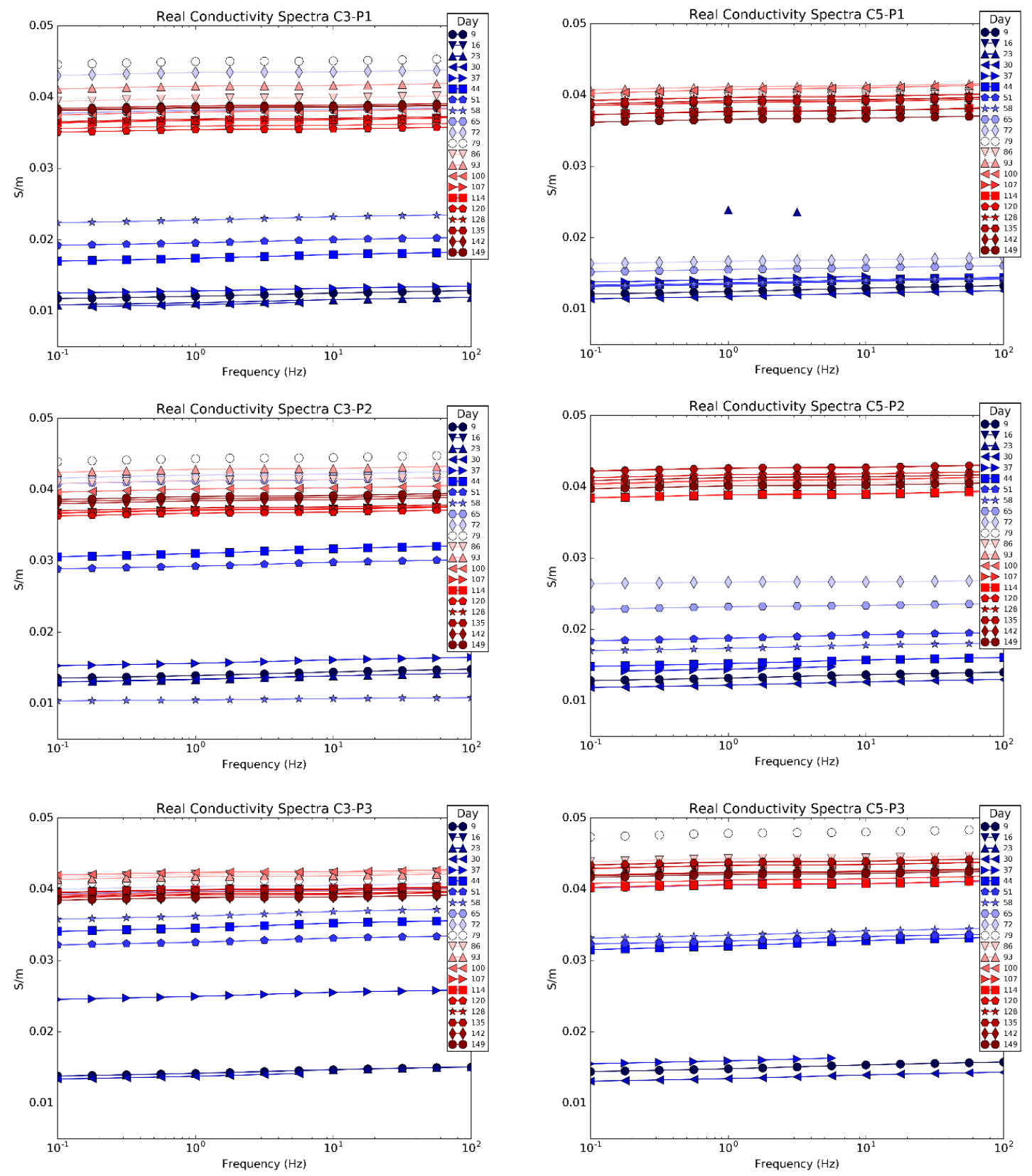

Figure B. 5 Real conductivity for columns 3 and 5, Fall 2016 

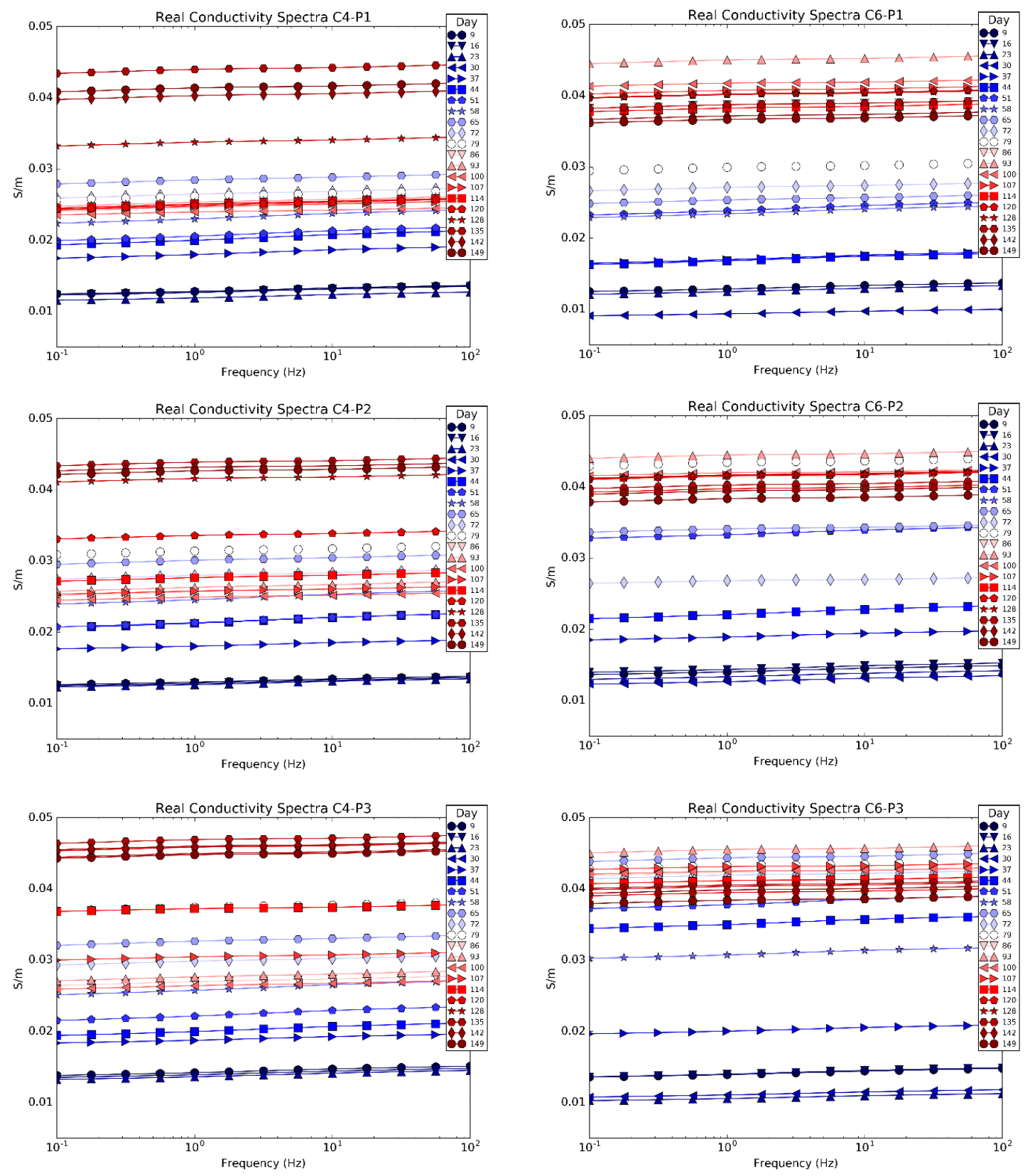

Figure B. 6 Real conductivity for columns 4 and 6, Fall 2016 

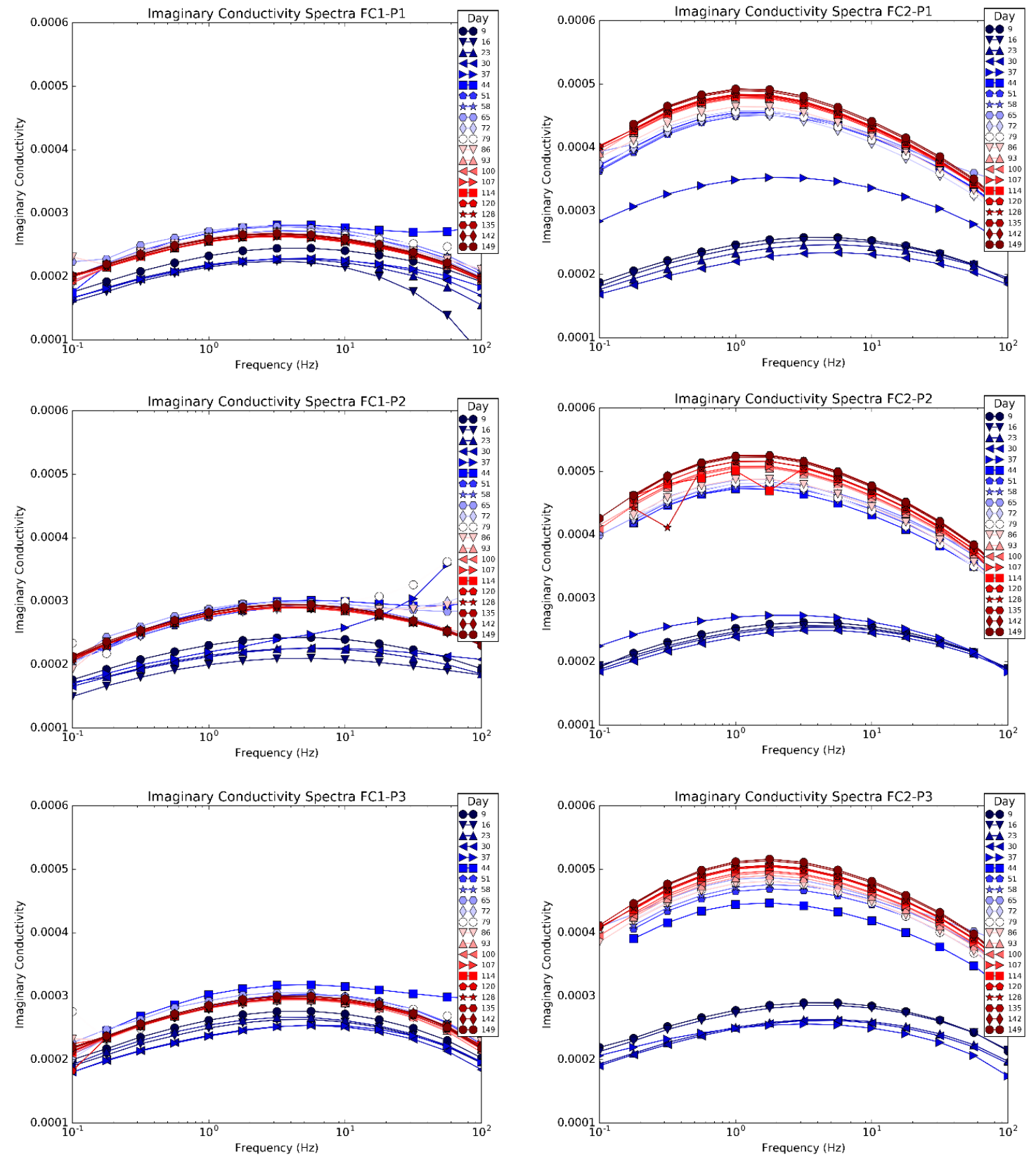

Figure B. 7 Imaginary conducitivty for columns 1 and 2, Fall 2016 

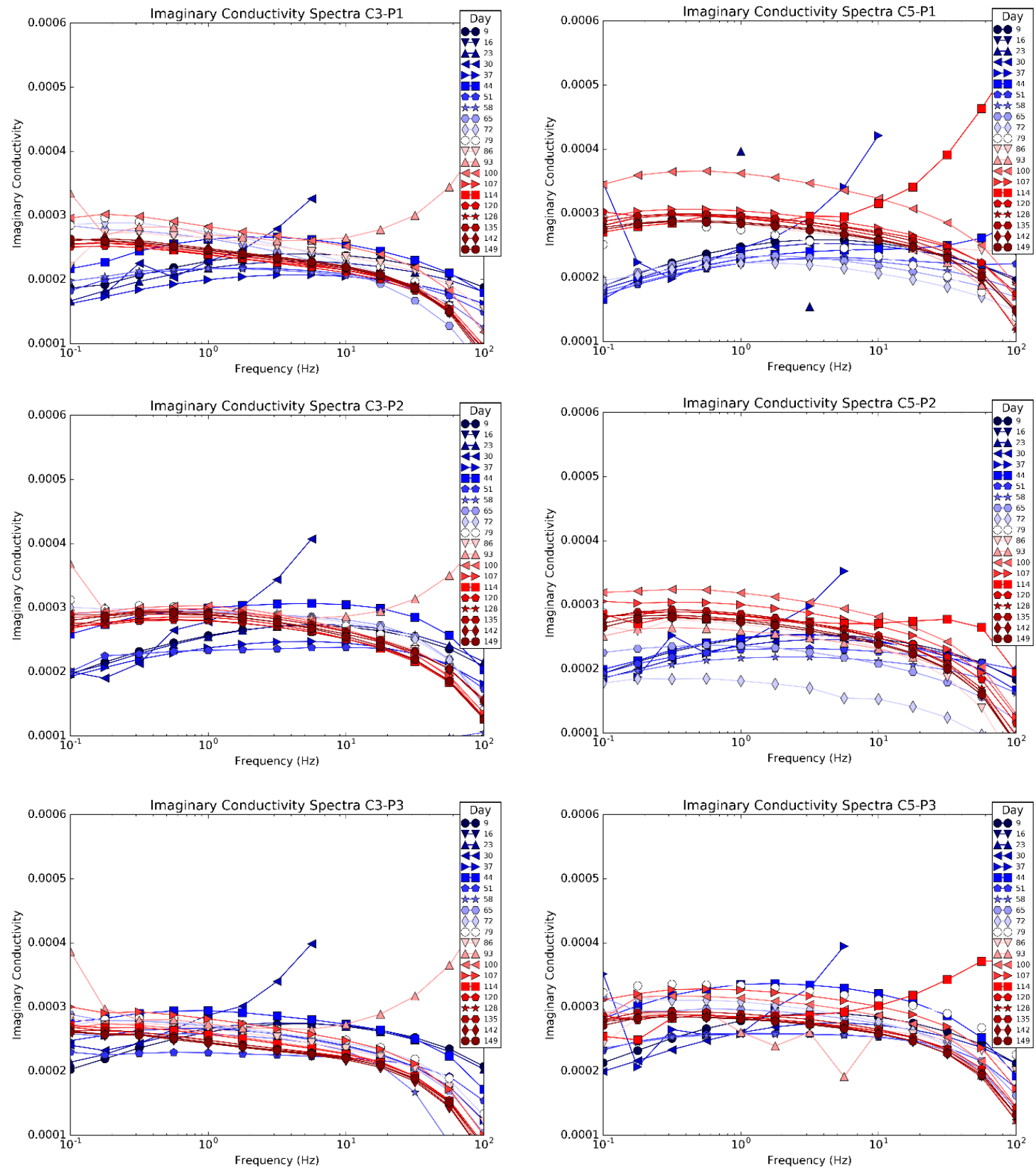

Figure B. 8 Imaginary conducitivty for columns 3 and 5, Fall 2016 

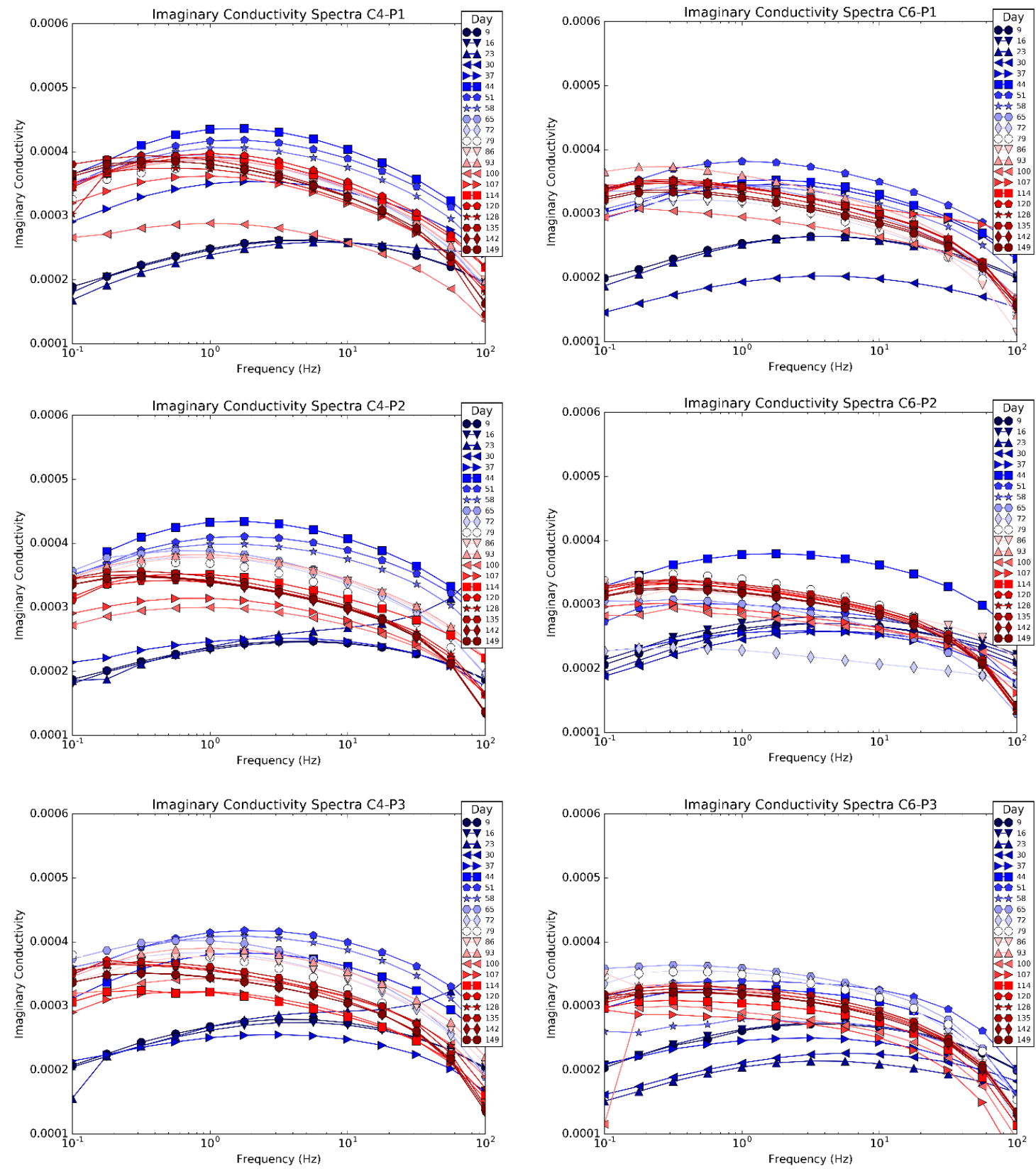

Figure B. 9 Imaginary conductivity for columns 4 and 6, Fall 2016 

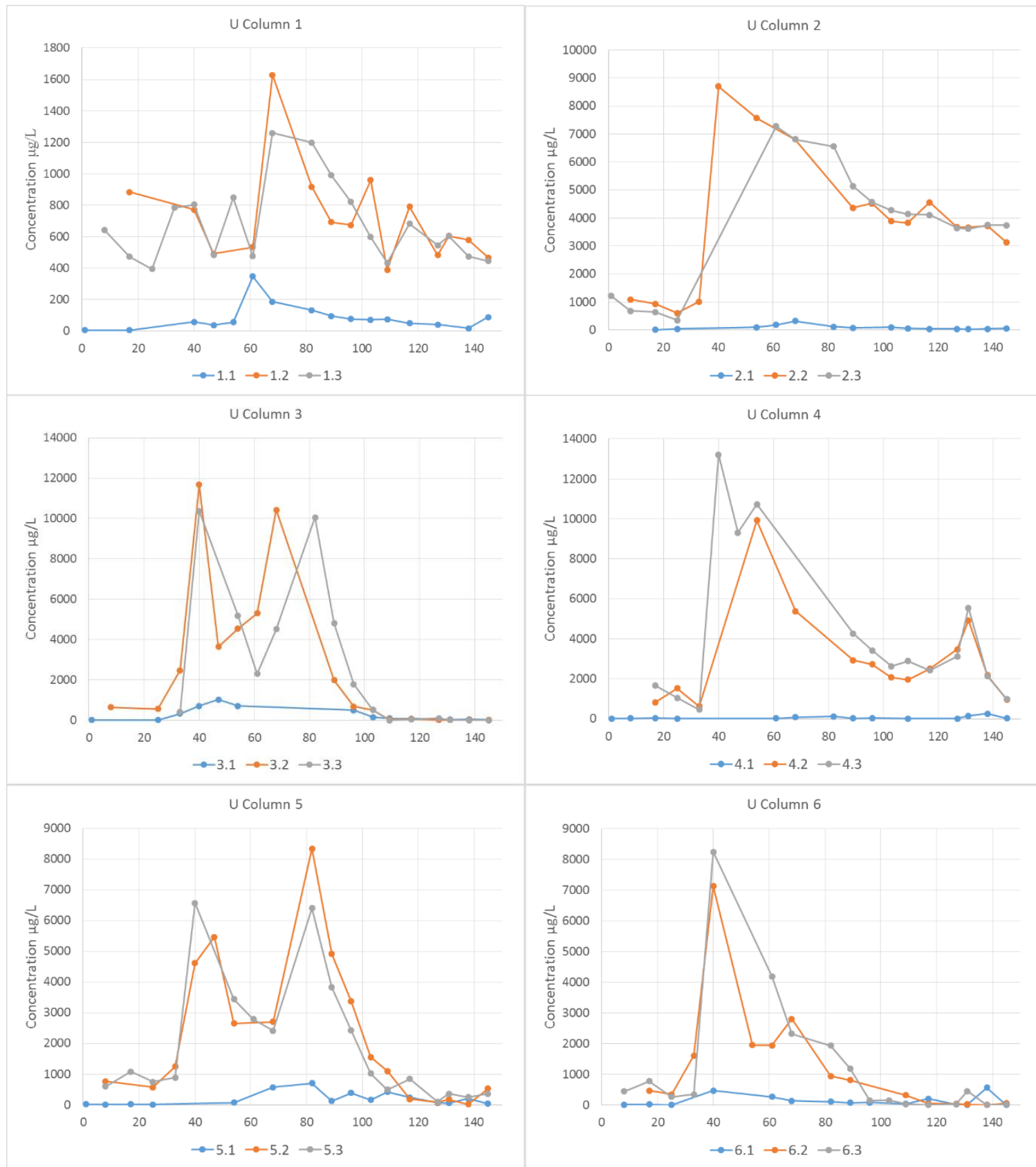

Figure B. 10 Uranium concentrations, Fall 2016 


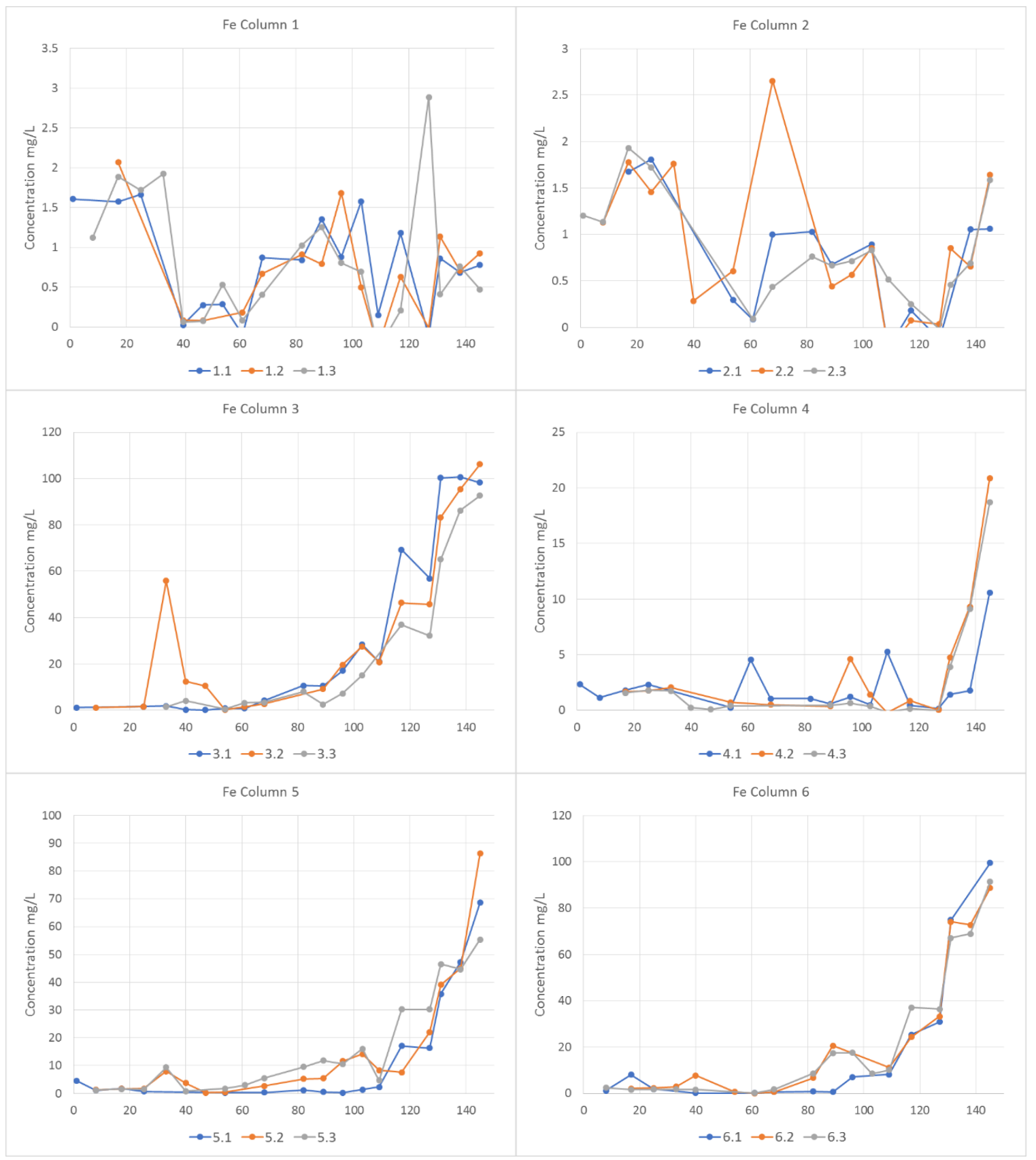

Figure B. 11 Iron concentrations, Fall 2016 

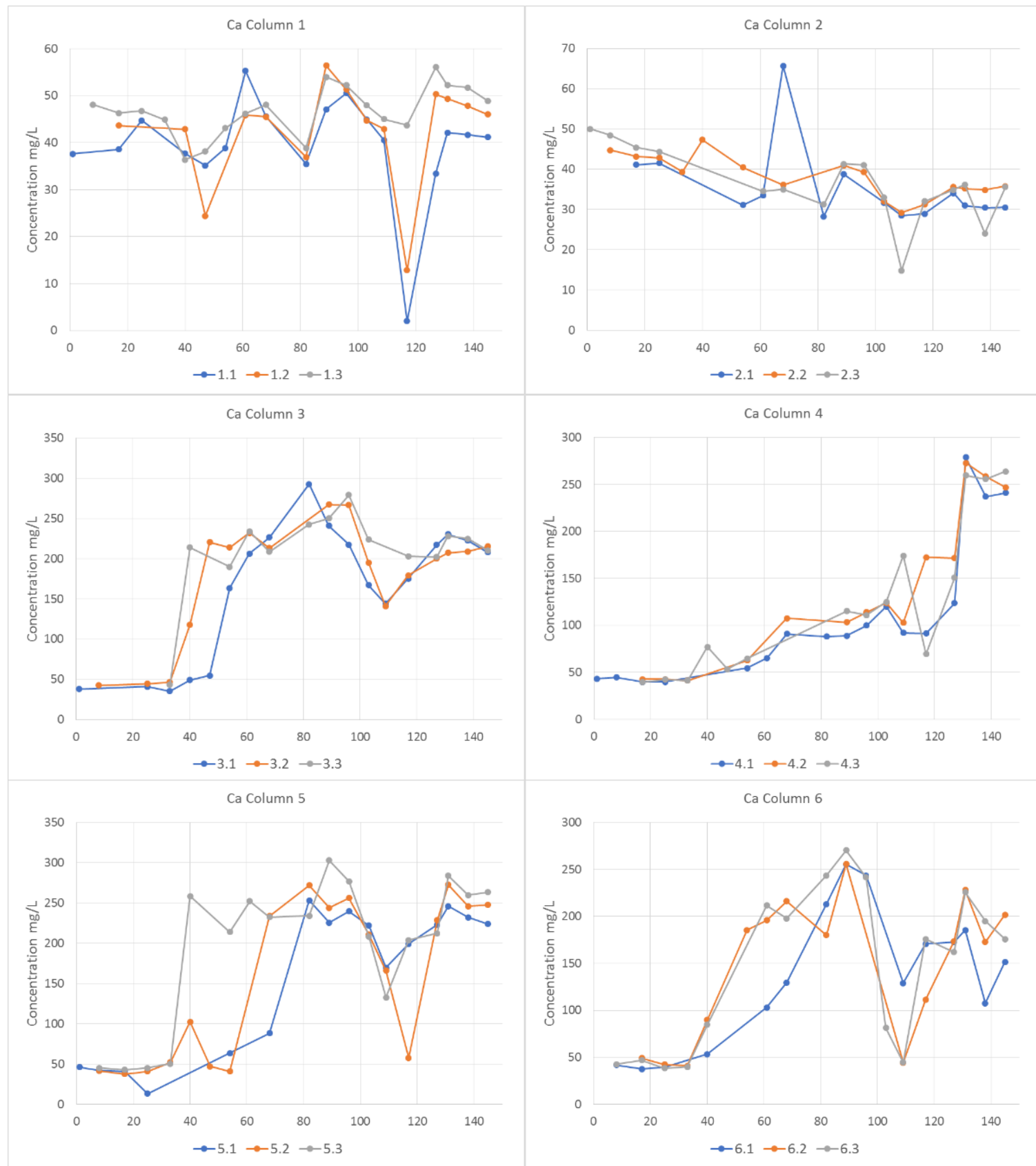

Figure B. 12 Calcium concentrations, Fall 2016 

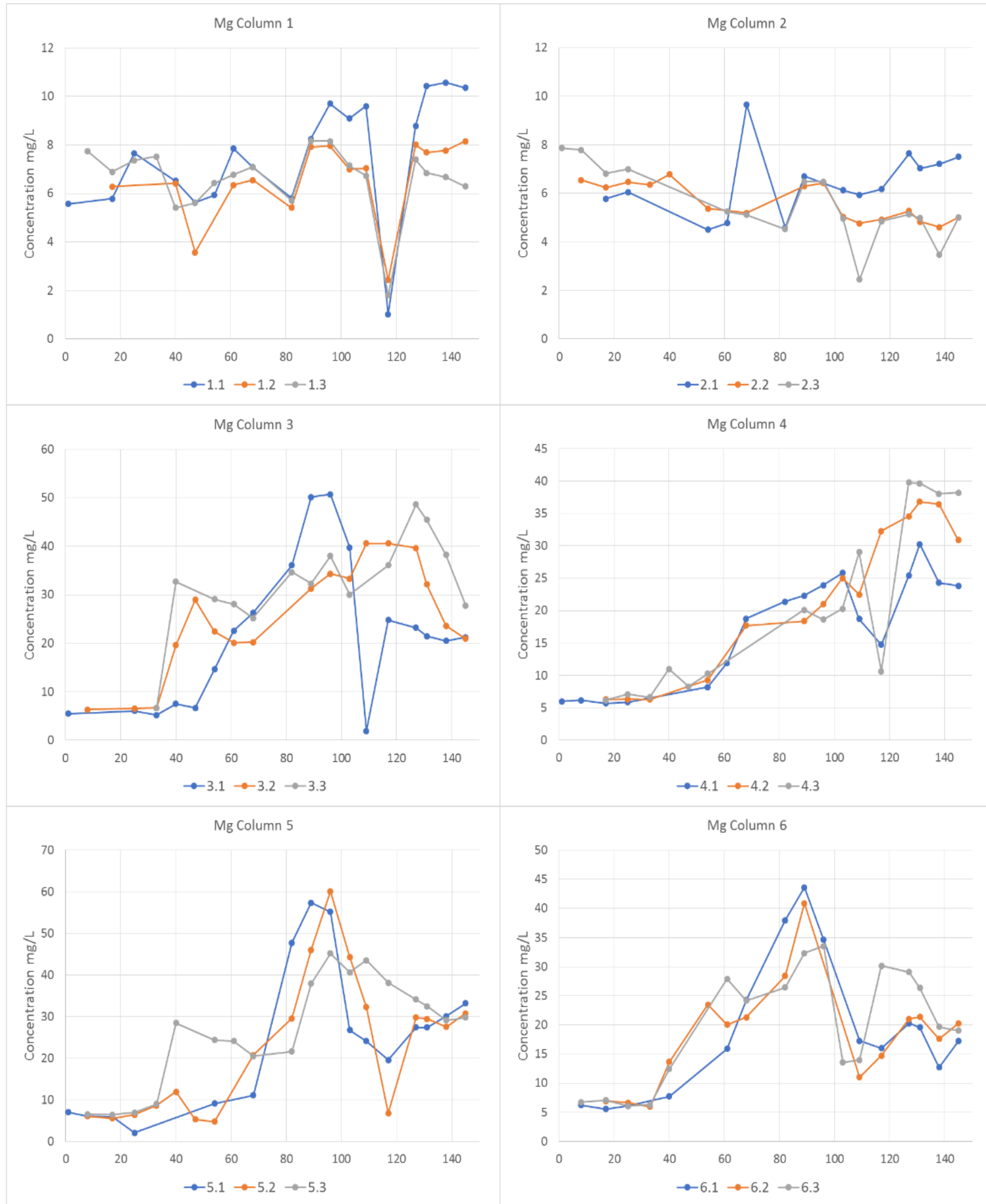

Figure B. 13 Magnesium concentrations, Fall 2016 

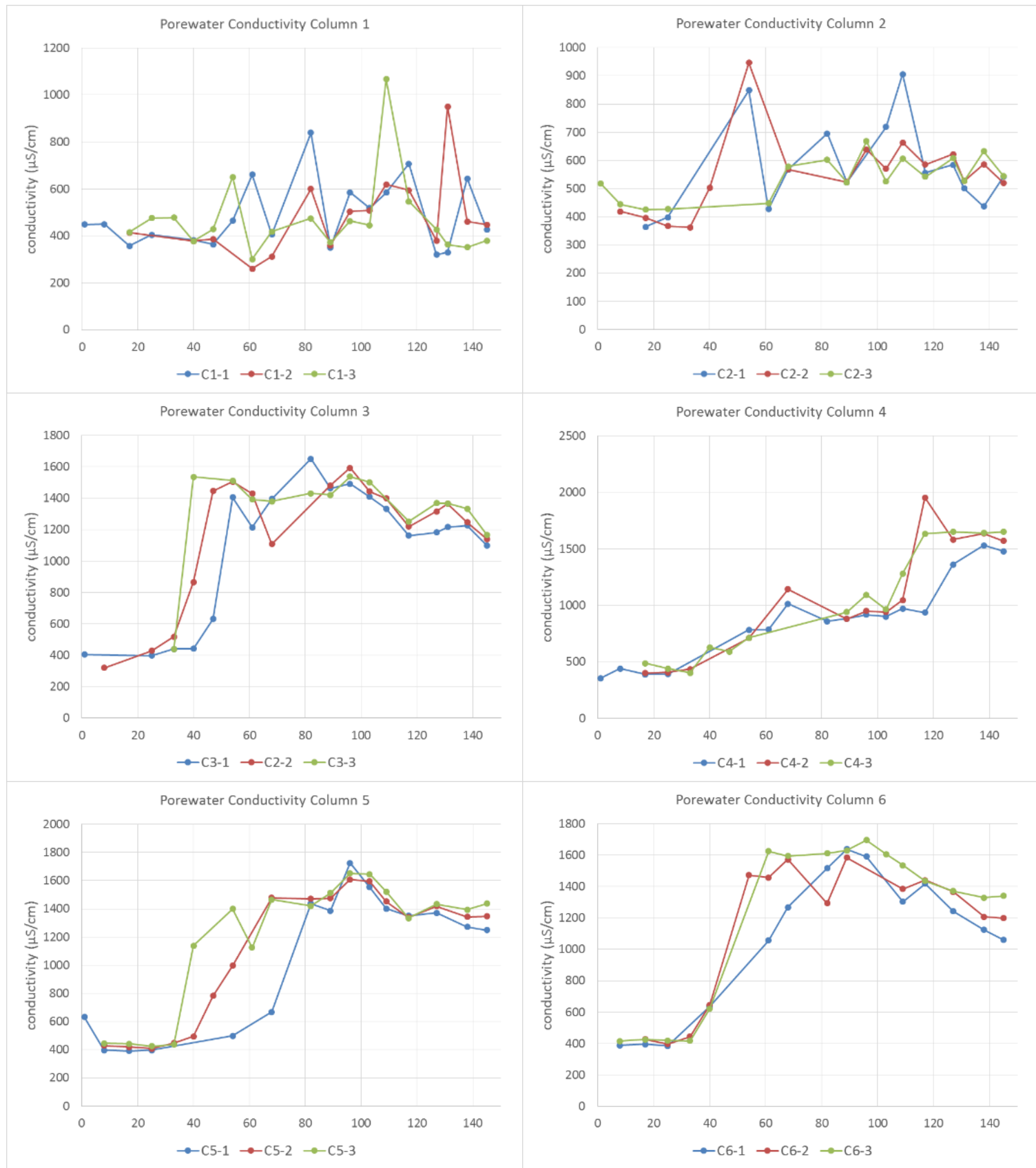

Figure B. 14 Pore water conductivity, Fall 2016 


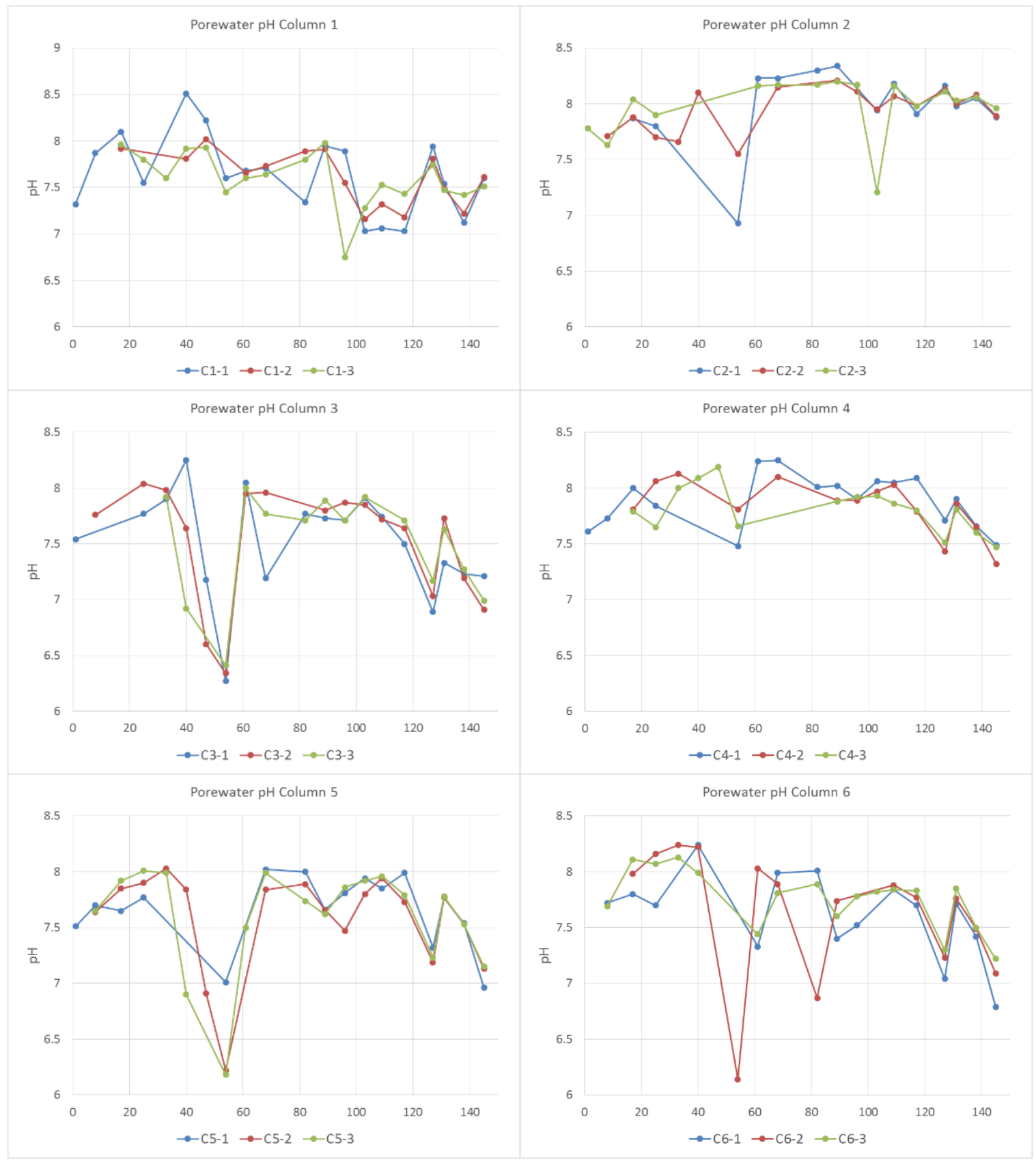

Figure B. 15 pH, Fall 2016 
Table B. 1 Uranium concentrations, Fall 2016

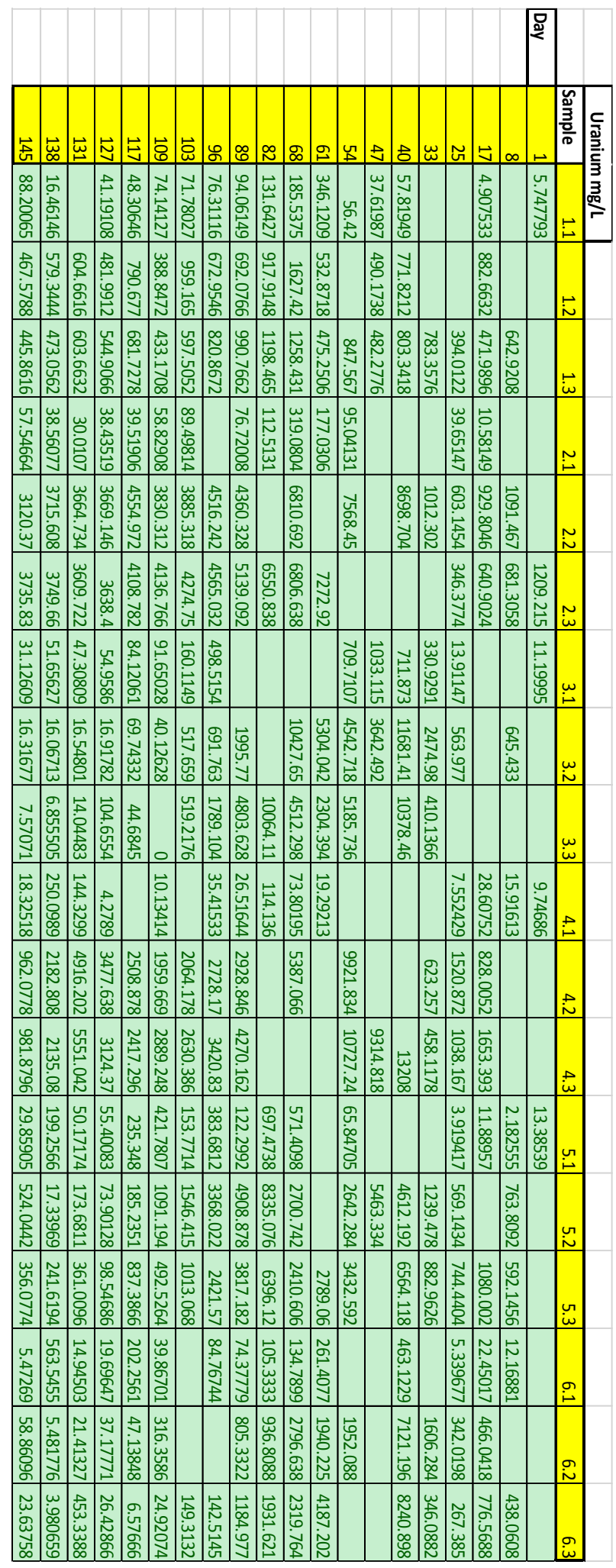


Table B. 2 Iron concentrations, Fall 2016

\begin{tabular}{|c|c|c|c|c|c|c|c|c|c|c|c|c|c|c|c|}
\hline & & & & & & & & & & & & & & \begin{tabular}{|l|}
$\frac{\widetilde{Z}}{\sigma}$ \\
$\frac{\bar{z}}{\sigma}$
\end{tabular} & \\
\hline & & & & & & & & & & & & & & & \\
\hline 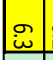 & 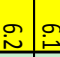 & & & & $\vec{f} f$ & & $\underset{\omega}{w}$ & & & $\tilde{\tilde{\omega}}$ & $\widetilde{\sim}$ & & $\vec{u}$ & 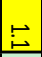 & \\
\hline & & & & $\begin{array}{c}0 \\
\text { : } \\
6\end{array}$ & & $\hat{i}$ & & & & 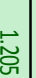 & & & & 它 & \\
\hline 莕 & & 曷 & & & & 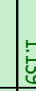 & & 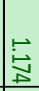 & & & $\vec{\omega}$ & 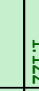 & & & $\infty$ \\
\hline $\overrightarrow{9}$ & 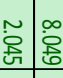 & 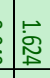 & & 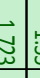 & : & 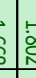 & & & & 总 & ș & $\overrightarrow{0}$ & $\begin{array}{l}0 \\
0\end{array}$ & $\overrightarrow{\mathrm{y}}$ & $\underline{\underline{\Delta}}$ \\
\hline$\stackrel{\vec{\varpi}}{\vec{w}}$ & & 猋 & $\infty$ & & 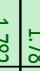 & 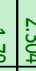 & & & 量 & 空 & 点 & $\overrightarrow{0}$ & & \begin{tabular}{|l|} 
\\
\\
\\
\end{tabular} & $\tilde{G}$ \\
\hline 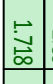 & & 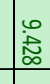 & נָ. & & $\vec{v}$ & & 窵 & & $\begin{array}{r} \\
\text { o }\end{array}$ & & t. & 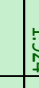 & & & $\underline{\omega}$ \\
\hline 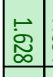 & 光总芯 & 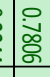 & & & & & $\overrightarrow{\stackrel{\vec{\theta}}{\vec{\theta}}}$ & & ت্ত্ّ & & $\begin{array}{l}0 \\
0 \\
0 \\
0\end{array}$ & & $\begin{array}{l}\text { 总 } \\
\text { 总 }\end{array}$ & 运 & 8 \\
\hline & & & & & & & & & 兽 & & & & 宓 & $\begin{array}{l}\text { 悹 } \\
\text { s. }\end{array}$ & \\
\hline & 迢 & : & & & 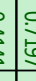 & & 惫 & & $\begin{array}{l}\text {. } \\
0 \\
0 \\
\end{array}$ & & 总 & 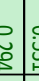 & & 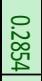 & ي \\
\hline 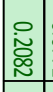 & & $\tilde{\infty}$ & & & & & $\underset{\substack{\tilde{N} \\
\sim}}{w}$ & 掿 & & : & & '. & $\begin{array}{c}: \\
\text { : }\end{array}$ & 离 & \& \\
\hline$\vec{w}$ & & 学 & & & 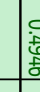 & 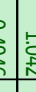 & $\begin{array}{c}w \\
\bar{\omega} \\
\omega\end{array}$ & \begin{tabular}{|l}
$\widetilde{w}$ \\
$\tilde{u}$ \\
\end{tabular} & $\vec{t}$ & 意 & 嵬 & 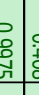 & : & 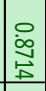 & ळ \\
\hline 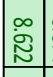 & & 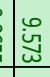 & & $\overrightarrow{\tilde{u}}$ & & & \begin{tabular}{l}
$\infty$ \\
\multirow{2}{2}{} \\
$\tilde{\sigma}$
\end{tabular} & & & 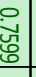 & & & 怘递 & 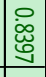 & $\stackrel{\infty}{\sim}$ \\
\hline $\begin{array}{c}\vec{\Delta} \\
\vec{E}\end{array}$ & & 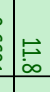 & & $\begin{array}{l}0 \\
0 \\
0 \\
0.03\end{array}$ & 结 & $\begin{array}{l}4 \\
\text { to } \\
\end{array}$ & 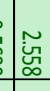 & 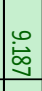 & 悹 & $\begin{array}{l}8 \\
8 \\
\\
\end{array}$ & 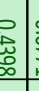 & 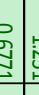 & : & 荵 & 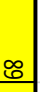 \\
\hline ज্ & & 兽 & & : & 窎 & & $\vec{s}$ & 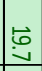 & 5 & 号 & 앵 & & $\begin{array}{l}0 \\
0 \\
0\end{array}$ & \begin{tabular}{|c|} 
\\
0 \\
0 \\
0 \\
0
\end{tabular} & $\varnothing$ \\
\hline 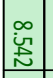 & & $\begin{array}{l}\text { ì } \\
\dot{2} \\
\end{array}$ & & $\vec{w}$ & 帘 & 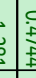 & $\underbrace{\vec{\omega}}_{i}$ & 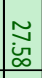 & 舀 & 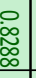 & 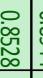 & 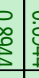 & $\begin{array}{l}: \\
:\end{array}$ & $\overrightarrow{\mathrm{y}}$ & 总 \\
\hline $\mid \begin{array}{l} \\
\vdots \\
\\
\end{array}$ & & 总 & & $\vec{w}$ & 客 & $\begin{array}{c}0 \\
4 \\
4\end{array}$ & & $\widetilde{\widetilde{J}}$ & & is & : & 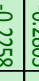 & 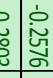 & 悹 & ప్రి \\
\hline \begin{tabular}{|l|}
$\vec{w}$ \\
$\vec{\omega}$ \\
\end{tabular} & & $\begin{array}{l}\tilde{U} \\
\tilde{U} \\
\end{array}$ & & 至 & $\vec{b}$ & $\begin{array}{lll}0 \\
b \\
b\end{array}$ & 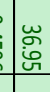 & $\begin{array}{l}\text { 点 } \\
\text { i } \\
\text { in }\end{array}$ & : & 宛 & : & 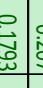 & 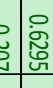 & $\vec{\Delta}$ & $\xi$ \\
\hline 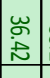 & \begin{tabular}{|c|c}
$\underset{\sim}{w}$ \\
$\underset{\sim}{w}$ \\
\end{tabular} & 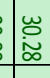 & 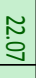 & $\begin{array}{l}\vec{w} \\
\overrightarrow{\underline{E}}\end{array}$ & 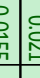 & 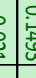 & 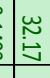 & $\begin{array}{l}\text { 岕 } \\
9 \\
9\end{array}$ & $\begin{array}{l}\text { 学 } \\
\text { de }\end{array}$ & & 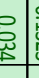 & : & \begin{tabular}{l|l}
0 \\
0
\end{tabular} & 兽 & $\vec{\exists}$ \\
\hline $\begin{array}{l}\stackrel{\partial}{2} \\
\ddot{\varnothing}\end{array}$ & 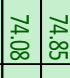 & 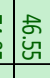 & 8 & 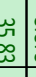 & : & 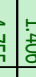 & \% & 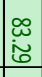 & 悹 & 㤐 & $\begin{array}{l}0 \\
0 \\
0 \\
0 \\
0\end{array}$ & & 宽宫 & \begin{tabular}{|l|} 
\\
0 \\
0 \\
$心$
\end{tabular} & 岕 \\
\hline $\begin{array}{l}\mathscr{0} \\
0 \\
0\end{array}$ & & $\begin{array}{l}\mathrm{E} \\
\mathrm{g}\end{array}$ & 吿 & 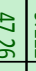 & $\vec{U}$ & 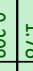 & 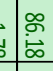 & 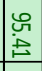 & & 吕 & & 突 & 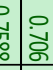 & 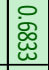 & $\overleftrightarrow{\varpi_{\infty}}$ \\
\hline & & & & & & & & & & & & & & : & \\
\hline
\end{tabular}


Table B. 3 Calcium concentrations, Fall 2016

\begin{tabular}{|c|c|c|c|c|c|c|c|c|c|c|c|c|c|c|c|}
\hline & & & & & & & & & & & & & & & \\
\hline is & & & בִיב & $\stackrel{\vec{\omega}}{\mathrm{i}}$ & $\stackrel{\sim}{\sim}$ & $\vec{\forall}$ & & & $: \tilde{\omega}$ & $\tilde{N}$ & $\stackrel{\sim}{ \pm}$ & $\vec{n}$ & 官 & & \\
\hline & & & 离 & & & $\underset{\sim}{\stackrel{d}{\sim}}$ & & 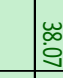 & ". & & & & w్ & & \\
\hline $\begin{array}{l}\stackrel{P}{\tilde{O}} \\
\stackrel{\infty}{\circ} \\
\end{array}$ & 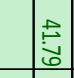 & 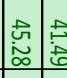 & $\vec{F}$ & & & 点 & & 疍 & \begin{tabular}{|l}
$\mathbf{b}$ \\
0 \\
0 \\
$\vdots$
\end{tabular} & $\mid$\begin{tabular}{|l|}
$E$ \\
0 \\
0
\end{tabular} & 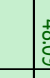 & & & $\infty$ & \\
\hline 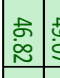 & & & & 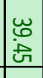 & & 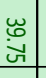 & & & 点 & 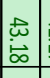 & 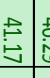 & $\stackrel{u}{u}$ & 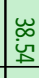 & $\Xi$ & \\
\hline 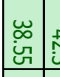 & 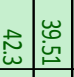 & 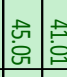 & 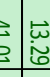 & 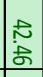 & 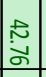 & 岕 & & 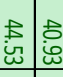 & 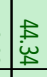 & \begin{tabular}{|c|c} 
\\
0 \\
$\infty$ \\
$\infty$
\end{tabular} & 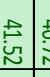 & & $\underset{\underset{\omega}{ \pm}}{F}$ & $\tilde{r}$ & \\
\hline 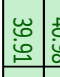 & & 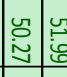 & & $\vec{E}$ & \begin{tabular}{|l|l}
$\vec{*}$ \\
$\vdots$ \\
$\vdots$
\end{tabular} & & & 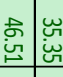 & & $\mid$ & $\stackrel{f}{g}$ & & & $w$ & \\
\hline 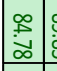 & 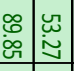 & 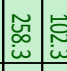 & & 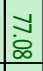 & & & & $\begin{array}{c}\text { 空 } \\
0\end{array}$ & & $\mid$ & $\begin{array}{l}\longleftarrow \\
\vdots \\
\vdots\end{array}$ & 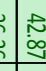 & $\underset{\ddot{g}}{\tilde{g}}$ & 8 & \\
\hline & & \pm & & 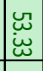 & & & & \begin{tabular}{l|l}
\multirow{Z}{*}{} \\
\\
\end{tabular} & & & 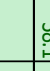 & 点 & 岕 & \pm & \\
\hline & 包 & & & 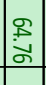 & 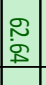 & $\left|\begin{array}{l|}u \\
\vdots \\
\omega \\
\omega\end{array}\right|$ & 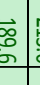 & & & & 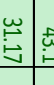 & & $\begin{array}{l}w \\
\infty \\
\infty \\
\infty \\
\end{array}$ & 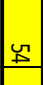 & \\
\hline $\begin{array}{c}\tilde{E} \\
\vec{v}\end{array}$ & & 莡 & & & & \begin{tabular}{l|}
0 \\
$\tilde{0}$ \\
0
\end{tabular} & 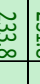 & 怨| & 岕 & & 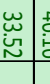 & $\begin{array}{l}n \\
\vdots \\
\vdots \\
\infty\end{array}$ & 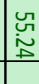 & 9 & \\
\hline : & 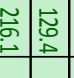 & 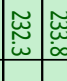 & & & 㲾 & $\left|\begin{array}{l}0 \\
0 \\
0 \\
\vdots\end{array}\right|$ & : & & 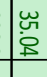 & & ته & 点 & 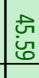 & $\infty$ & \\
\hline $\begin{array}{l}\text { 思 } \\
\text { in }\end{array}$ & & 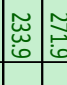 & & & & 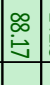 & $\begin{array}{c}\tilde{c} \\
\text { c } \\
\text {. }\end{array}$ & $\mid \begin{array}{c}\widetilde{N} \\
\tilde{\omega} \\
\end{array}$ & $\underline{\tilde{\sigma}}$ & & 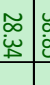 & $\begin{array}{l}u \\
\vdots \\
\vdots\end{array}$ & $\begin{array}{l}w \\
w \\
\vec{s}\end{array}$ & $\infty$ & \\
\hline 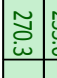 & & 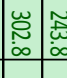 & & $\overrightarrow{\mathrm{v}}$ & 悹 & \begin{tabular}{|l|}
$\infty$ \\
0 \\
0 \\
0
\end{tabular} & $\tilde{c}$ & & $\stackrel{\vec{w}}{\mathrm{w}}$ & 点 & 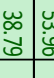 & 学 & $\begin{array}{l}\hat{0} \\
\text { 。 }\end{array}$ & $\infty$ & \\
\hline 芯 & 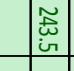 & नू. & 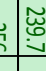 & 志 & 点 & 8 & $\mathbb{O}$ & & & \begin{tabular}{|l|}
$\tilde{心}$ \\
$\tilde{U}$ \\
\end{tabular} & 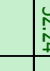 & 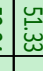 & 总 & 8 & \\
\hline 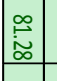 & & $\approx$ & & 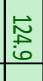 & 芦 & \begin{tabular}{|l|}
$\overrightarrow{0}$ \\
0 \\
0
\end{tabular} & 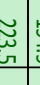 & & $\begin{array}{l}\tilde{\omega} \\
\infty\end{array}$ & 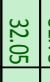 & $\stackrel{\omega}{\sim}$ & $\frac{N}{N}$ & 怘 & 悹 & \\
\hline 志 & 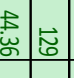 & 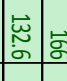 & & $\vec{\nabla}$ & $\mid \begin{array}{c}\overrightarrow{0} \\
\substack{\infty \\
\infty} \\
\end{array}$ & $\begin{array}{l}0 \\
\stackrel{0}{9} \\
\end{array}$ & & 点空 & 点 & \begin{tabular}{|l}
$\tilde{0}$ \\
$\tilde{\tilde{\sigma}}$ \\
\end{tabular} & 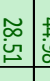 & 董 & 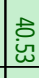 & 5 & \\
\hline ث્ل & & & & & 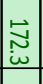 & \begin{tabular}{|l|l}
0 \\
0 \\
0 \\
\end{tabular} \mid & & & \begin{tabular}{|l}
$\tilde{\tilde{\sigma}}$ \\
\end{tabular} & $\mid \begin{array}{l}\overrightarrow{\tilde{ت}} \\
\stackrel{\vec{\sim}}{*}\end{array}$ & \begin{tabular}{l|l}
$\widetilde{0}$ \\
$\tilde{0}$ \\
$\dot{0}$
\end{tabular} & 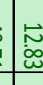 & 莙 & 5 & \\
\hline 苞 & & 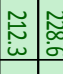 & & $\begin{array}{l}\text { ज্ } \\
\infty \\
\end{array}$ & 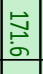 & $\mid$\begin{tabular}{c}
$\vec{w}$ \\
\hdashline \\
$o$
\end{tabular} & & 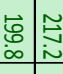 & 崫 & \begin{tabular}{|c|}
$\omega$ \\
$\tilde{\omega}$ \\
$\ddot{\omega}$
\end{tabular} & 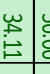 & 总 & بّ & ت & \\
\hline $\begin{array}{c}\widetilde{N} \\
\infty \\
\infty\end{array}$ & 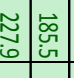 & 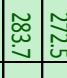 & 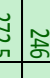 & $\begin{array}{c}\widetilde{\sigma} \\
\sigma \\
\sigma\end{array}$ & 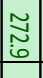 & 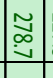 & $\mathbb{Z}$ & 芯| & $\underset{\sim}{\stackrel{\sim}{N}}$ & $\mid \begin{array}{l}w \\
\tilde{\omega}\end{array}$ & 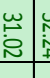 & 离 & $\begin{array}{c}\stackrel{8}{8} \\
\dot{8}\end{array}$ & 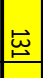 & \\
\hline$\vec{s}$ & 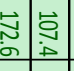 & \begin{tabular}{|c|c}
$\tilde{G}$ \\
0 \\
$\infty$
\end{tabular} & $\underset{\sim}{\widetilde{N}}$ & & $\left|\begin{array}{c}\tilde{y} \\
0 \\
i \pi \\
\end{array}\right|$ & $\mid \begin{array}{c}\widetilde{\sim} \\
\dot{\Xi}\end{array}$ & $\widetilde{\widetilde{N}}$ & 芯| & $\tilde{\underline{\partial}}$ & 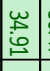 & 崖 & : & 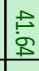 & $\underset{\omega}{\breve{\infty}}$ & \\
\hline $\begin{array}{c}: \\
\infty \\
\infty\end{array}$ & & 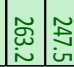 & & & & & & & & & & & & & \\
\hline
\end{tabular}


Table B. 4 Magnesium concentrations, Fall 2016

\begin{tabular}{|c|c|c|c|c|c|c|c|c|c|c|c|c|c|c|c|c|}
\hline & & & & & & & & & & & & & & & & \\
\hline & & & & & & $i$ & & & $\mid \omega$ & $\tilde{\omega}$ & & & $\ddot{\omega}$ & $\stackrel{1}{\sim}$ & 5 & 幽 \\
\hline & & & & $\ddot{\infty}$ & & 乌. & & & & 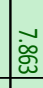 & & & & & $\underline{y}$ & \\
\hline ज्जे & 灾 & 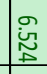 & & 总 & & 竞 & & 离 & & & 总 & & $\ddot{\Delta}$ & & & $\infty$ \\
\hline$\ddot{\ddot{\alpha}}$ & & & 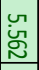 & $i$ & & & & & & & 用 & $\stackrel{\breve{\omega}}{\breve{\omega}}$ & $\begin{array}{l}\circ \\
\vdots \\
\circ \\
\end{array}$ & 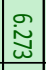 & ఝّ & $\underline{\Delta}$ \\
\hline \begin{tabular}{|l|l}
$\circ$ \\
$\dot{\delta}$ \\
$\dot{\delta}$
\end{tabular} & & 密 & 总 & $\ddot{\otimes}$ & 官 & $\begin{array}{c}4 \\
ن\end{array}$ & & 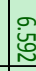 & $\begin{array}{r}\mathscr{O} \\
\dot{\theta}\end{array}$ & 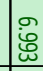 & 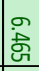 & $\ddot{\circ}$ & ్ֶ & & 岁 & ज \\
\hline$\underset{\sim}{\sim}$ & & 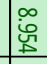 & 㐫 & & 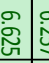 & & : & 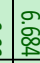 & 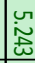 & & 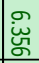 & & 悹 & & & $w$ \\
\hline $\begin{array}{lll}5 \\
\vdots \\
\vdots\end{array}$ & & $\mid \begin{array}{c}\tilde{a} \\
\tilde{\omega}\end{array}$ & $\begin{array}{l}\vec{\forall} \\
\dot{8} \\
\end{array}$ & & 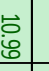 & & 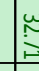 & $\begin{array}{l}: \\
\vdots \\
\vdots \\
9\end{array}$ & نِّ & & 灾 & & $\begin{array}{l}n \\
\text { 莹 } \\
\end{array}$ & $\begin{array}{l}0 \\
0 \\
0 \\
0\end{array}$ & 童 & s \\
\hline & & & & & 怨 & & & 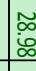 & 离 & & & & 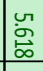 & 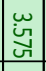 & 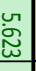 & \pm \\
\hline & & 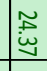 & & & 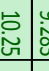 & & 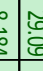 & $\mid \begin{array}{r}\tilde{N} \\
\mathbb{E}\end{array}$ & 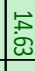 & & 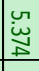 & 点 & 悹 & & 岕 & un \\
\hline$\approx$ & & $\tilde{\tilde{z}}$ & & & & & 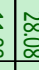 & 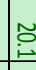 & 䒫 & 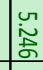 & & $\stackrel{\vec{*}}{\vec{*}}$ & जे & 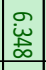 & 亗 & 8 \\
\hline \begin{tabular}{|l}
$\tilde{E}$ \\
$\hat{E}$ \\
\end{tabular} & & \begin{tabular}{|l}
$\tilde{0}$ \\
0 \\
0
\end{tabular} & 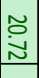 & 点 & & & 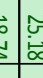 & 岌 & $\underset{\widetilde{N}}{\tilde{N}}$ & $\stackrel{u}{\vec{\omega}}$ & $\dot{i}$ & 密 & $\ddot{\ddot{\circ}}$ & i & 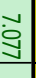 & $\infty$ \\
\hline \begin{tabular}{|l}
$\tilde{\sigma}$ \\
$\tilde{E}$ \\
\end{tabular} & 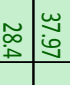 & $\mid$\begin{tabular}{l}
0 \\
\hdashline \\
\end{tabular} & 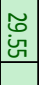 & $\stackrel{\vec{t}}{\overrightarrow{ \pm}}$ & & 急 & 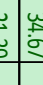 & & 岕 & 兽 & & if & 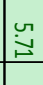 & $\begin{array}{l}u \\
\text { 今. }\end{array}$ & 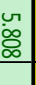 & $\infty$ \\
\hline 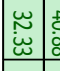 & & $\underset{\widetilde{w}}{\omega}$ & 点 & v & & $\hat{u}$ & 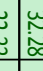 & $\mid \begin{array}{c}w \\
\tilde{G}\end{array}$ & 岂 & 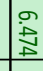 & 峞 & ஜे & $\begin{array}{l}\infty \\
\text { 曷 } \\
\end{array}$ & 菺 & 串 & $\infty$ \\
\hline $\begin{array}{l}\text { 岕 } \\
\dot{\omega}\end{array}$ & & 点 & . & ज্. & & $\begin{array}{c}: \\
b \\
b\end{array}$ & 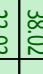 & 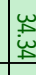 & 总 & 辛 & $\begin{array}{l}\text { 点 } \\
\text { 点 }\end{array}$ & & $\begin{array}{l}\infty \\
\dot{\theta} \\
\end{array}$ & 总 & 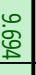 & 8 \\
\hline $\mid \begin{array}{l}\stackrel{\omega}{\ddot{m}} \\
\dot{m}\end{array}$ & & 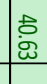 & & & & 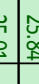 & 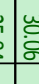 & | & ఝّ & 迢 & & $\stackrel{\circ}{\underline{\omega}}$ & $\overrightarrow{\mathrm{i}}$ & $\ddot{\circ}$ & 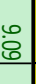 & 总 \\
\hline \begin{tabular}{|l}
$\vec{w}$ \\
$\dot{\infty}$ \\
$\infty$
\end{tabular} & & 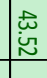 & $\mathbb{U}$ & 8 & 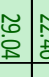 & 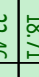 & & 容 & 突 & 莟 & 茨 & 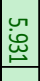 & 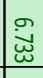 & 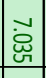 & 兽 & 家 \\
\hline $\mid \begin{array}{l}w \\
\vec{b} \\
\vec{E}\end{array}$ & & $\begin{array}{l}w \\
\substack{\infty \\
i \\
i}\end{array}$ & o & $\begin{array}{l}\text { to } \\
\text { in }\end{array}$ & 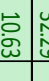 & \begin{tabular}{l|l}
$\mathrm{u}$ \\
$\mathrm{u}$
\end{tabular} & 表 & 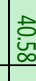 & ث્ث & $\begin{array}{l}\stackrel{8}{8} \\
\text { 总 }\end{array}$ & $\sigma$ & 总 & \begin{tabular}{|l|} 
\\
\\
\end{tabular} & \begin{tabular}{|l} 
芯 \\
总
\end{tabular} & 总 & $\underline{s}$ \\
\hline 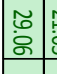 & & 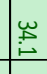 & $\left.\mid \begin{array}{c}\widetilde{\widetilde{o}} \\
\tilde{\omega}\end{array}\right]$ & & 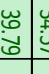 & 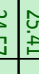 & $\left\{\begin{array}{l}\infty \\
0 \\
0 \\
0\end{array}\right.$ & $\begin{array}{l}\tilde{\omega} \\
\dot{\sigma}\end{array}$ & 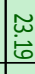 & $\stackrel{u}{\underline{\omega}}$ & స్ & $\dot{a}$ & 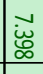 & $\stackrel{\infty}{\circ}$ & 趈 & 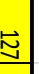 \\
\hline $\begin{array}{c}\tilde{a} \\
\ddot{\varpi} \\
\end{array}$ & 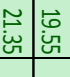 & \begin{tabular}{|l}
$\tilde{W}$ \\
$\tilde{B}$ \\
\end{tabular} & $\begin{array}{l}0 \\
1 \\
1\end{array}$ & $\begin{array}{r}\widetilde{N} \\
\pm\end{array}$ & 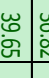 & $\begin{array}{c}: \\
\vdots \\
0\end{array}$ & 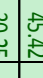 & 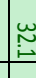 & \begin{tabular}{|l}
$\tilde{B}$ \\
$\vec{\theta}$ \\
\end{tabular} & i & 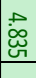 & 포 & 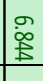 & 兽 & $\begin{array}{l}\text { : } \\
\text { : }\end{array}$ & : \\
\hline 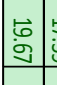 & & $\begin{array}{l}\widetilde{0} \\
\vdots \\
5\end{array}$ & w & 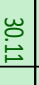 & 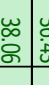 & 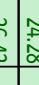 & 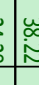 & $\begin{array}{l}\tilde{w} \\
\tilde{w}\end{array}$ & $\begin{array}{r}\tilde{O} \\
\text { in } \\
\end{array}$ & $\begin{array}{c}\omega \\
\dot{a}\end{array}$ & 总 & $\hat{B}$ & 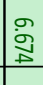 & ठัँ & 窇 & $\underline{\underline{\omega}}$ \\
\hline & & & & & & & & & & & & & & & & \\
\hline
\end{tabular}


Table B. 5 pH, Fall 2016

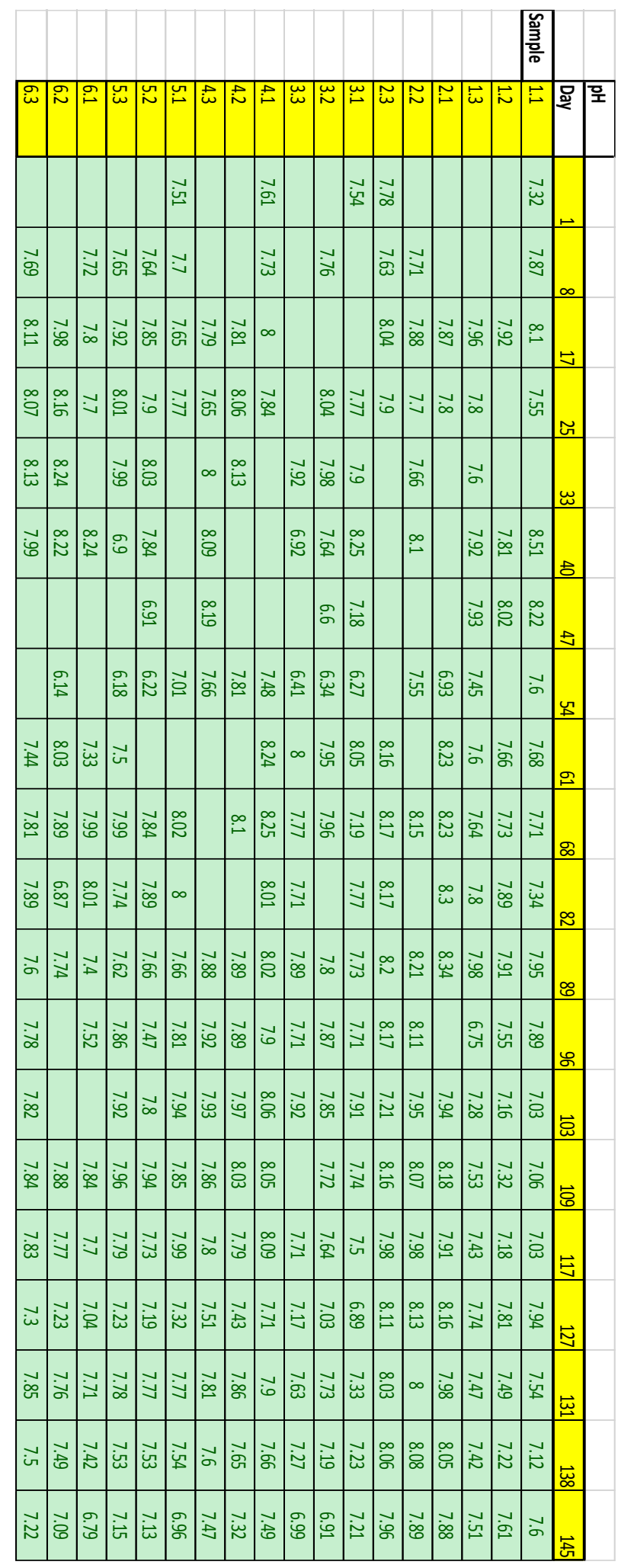


Table B. 6 Pore water conductivity, Fall 2016

\begin{tabular}{|c|c|c|c|c|c|c|c|c|c|c|c|c|c|c|c|c|}
\hline & & & & & & & & & & & & & & & 离 & \\
\hline 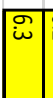 & & 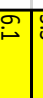 & 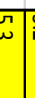 & & $\begin{array}{c}5 \\
\end{array}$ & 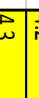 & 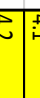 & 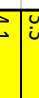 & 0 & 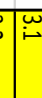 & $\tilde{\omega}$ & & $\tilde{F}$ & $\vec{\omega}$ & $\overrightarrow{\mathrm{U}} \overrightarrow{\mathrm{L}}$ & \\
\hline & & & & & 总 & & 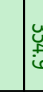 & 藍 & & & 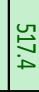 & & & & $\underset{\sim}{\stackrel{f}{*}}$ & \\
\hline E & & & & $\overrightarrow{0}$ & 㐌 & & $\mid$ & 它 & $\mid$\begin{tabular}{|l}
$u$ \\
0 \\
$\vdots$ \\
$u$
\end{tabular} & & 杰 & 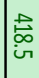 & & & $\underset{\sim}{\stackrel{d}{\mathrm{i}}}$ & \\
\hline $\begin{array}{c}\mathbf{W} \\
\infty \\
\infty\end{array}$ & 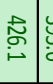 & & $E$ & : & 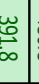 & & 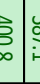 & & & & $\begin{array}{l}\text { 㥕 } \\
\infty\end{array}$ & $\mid \begin{array}{l}\text { } \\
\text { is }\end{array}$ & 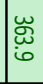 & 悹 & 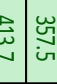 & $\Xi$ \\
\hline 惫 & 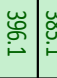 & & $\begin{array}{c}\vec{w} \\
\omega\end{array}$ & : & 岕 & 宫 & 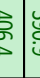 & & & $\mid$\begin{tabular}{l}
$\tilde{g}$ \\
\hdashline
\end{tabular} & 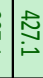 & 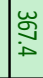 & 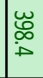 & ज़ & $\underset{\underbrace{}}{\stackrel{0}{*}}$ & \\
\hline 窎 & 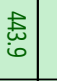 & & 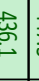 & 柰 & & $\begin{array}{l}b \\
\omega\end{array}$ & & & 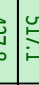 & 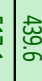 & & 岕 & & \begin{tabular}{|l}
$\vec{A}$ \\
$\infty$ \\
$\sigma$
\end{tabular} & & w \\
\hline : & 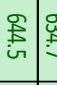 & 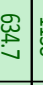 & & 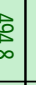 & & స్ & & & $\vec{b}$ & 志 & & 总 & & $\stackrel{\sim}{\sim}$ & 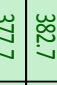 & 8 \\
\hline & & & & రా & & 용 & & & 每 & 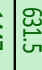 & & & & & 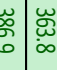 & \pm \\
\hline & 言 & & $\overrightarrow{\underline{G}}$ & 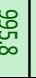 & $\vec{\infty}$ & 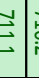 & E. & & 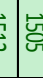 & 言 & & & 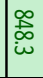 & 总 & $\begin{array}{l}\text { 亮 } \\
\text { is }\end{array}$ & sis \\
\hline 忍 & 空 & 哥 & 苫 & & & & & 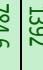 & 索瓷 & 壳 & 䓌 & & 部 & 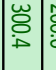 & 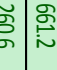 & 9 \\
\hline 忍 & 空: & 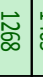 & 㥐 & 点 & 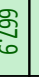 & & $E$ & $\overrightarrow{\mathrm{c}}$ & 今. & : & $\underset{\infty}{0}$ & 岕 & 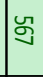 & & 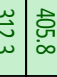 & (ळ) \\
\hline 总 & : & 富 & 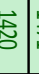 & 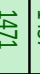 & 駕 & & & 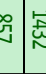 & & 憲 & 总 & & 兽 & 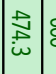 & $\begin{array}{l}8 \\
\end{array}$ & $\infty$ \\
\hline 悹 & 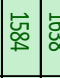 & 总 & 氙 & $\vec{a}$ & 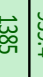 & 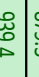 & $\begin{array}{l}0 \\
\vdots \\
\vdots\end{array}$ & $\begin{array}{l}8 \\
\\
\end{array}$ & 空 & 突 & $\underset{\substack{\mathbb{N} \\
\hdashline}}{\mathbb{N}}$ & 忍 & 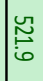 & & $\underset{\sigma}{\sigma}$ & $\infty$ \\
\hline 若 & & 悹 & 宫 & 珰 & 心 & 总 & 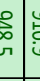 & 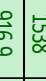 & 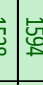 & 愎 & \& & 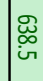 & & & 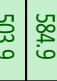 & 8 \\
\hline 㝕 & & & 突 & $\vec{~}$ & 悹 & 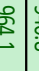 & $\begin{array}{l}\underbrace{\infty}_{\infty} \\
\end{array}$ & $\stackrel{s}{s}$ & 岁策 & 鸽 & $\mathcal{N}$ & 嵓 & $\overrightarrow{0}$ & $\underset{⿱ 士 心}{\mathbb{W}}$ & 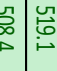 & 总 \\
\hline 怘 & 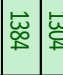 & $\overrightarrow{\breve{Q}}$ & $\overrightarrow{\mathrm{U}}$ & $\overrightarrow{\mathrm{G}}$ & 总 & 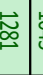 & 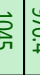 & & & 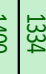 & & $\mid \begin{array}{l}\mathscr{Q} \\
\text { in }\end{array}$ & \& & 客 & 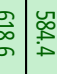 & 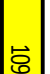 \\
\hline 怘 & 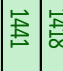 & 点 & $\vec{\omega}$ & $\vec{్}$ & $\overrightarrow{\mathrm{c}}$ & $\vec{\square}$ & 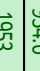 & 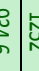 & 5 & 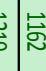 & 定 & & ખু & $\begin{array}{l}n \\
\dot{A} \\
i\end{array}$ & 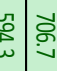 & $\Xi$ \\
\hline $\mid$ & 窎 & 怘 & $\overrightarrow{\mathrm{U}}$ & $\overrightarrow{\vec{\infty}_{\infty}}$ & $\overrightarrow{\breve{g}}$ & 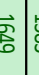 & $\stackrel{c}{c}$ & $\overrightarrow{\mathrm{c}}$ & $\vec{s}$ & $\vec{t}$ & $\underset{\infty}{\stackrel{8}{\infty}}$ & $\mid \begin{array}{l}\mathcal{P} \\
\sigma\end{array}$ & 岕 & 䜣 & 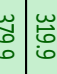 & 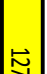 \\
\hline & & & & & & & & & $\vec{u}$ & & & 议 & ") & & $\begin{array}{l}0 \\
0 \\
0 \\
0\end{array}$ & $\stackrel{\vec{\omega}}{\underline{\omega}}$ \\
\hline$\underset{\mathbb{G}}{\mathbb{E}}$ & $\vec{\Xi}$ & 点 & $\overrightarrow{\mathrm{L}}$ & & 志 & 袬 & s. & $\vec{\Xi}$ & 它 & $\overrightarrow{\mathrm{u}}$ & 岁 & $\mid$\begin{tabular}{l}
$\mathscr{D}$ \\
\hdashline \\
\hdashline
\end{tabular} & 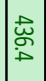 & 岕 & 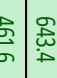 & $\overleftrightarrow{\omega_{\tilde{\omega}}}$ \\
\hline $\mid \begin{array}{l}\vec{w} \\
\tilde{c}\end{array}$ & & & & & & $\begin{array}{l}0 \\
\end{array}$ & 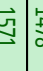 & 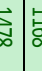 & 8 & 18 & 弇 & 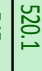 & 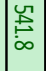 & $\ddot{g}$ & \begin{tabular}{l|l}
$\mathbb{S}$ & \multirow{心}{心}{} \\
$\infty$
\end{tabular} & \\
\hline
\end{tabular}

